\title{
Building and HVAC Characterization for Commercial Building Indoor Air Quality Investigations
}

\author{
Prepared for: \\ U.S. Environmental Protection Agency \\ Office of Air and Radiation \\ Office of Radiation and Indoor Air \\ Indoor Air Division \\ Washington, DC 20460 \\ U.S. Department of Energy \\ Office of Energy Efficiency and \\ Renewable Energy \\ Building Systems and Materials Division \\ Washington, DC 20585
}

100

.056

\#4979

1993

U. S. Department of Commerce

National Institute of Standards and Technology

Building and Fire Research Laboratory

Gaithersburg, MD 20899 


\section{Building and HVAC Characterization for Commercial Building Indoor Air Quality Investigations}

Andrew K. Persily

May 1993

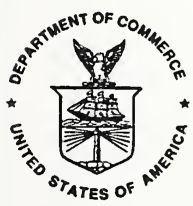

U. S. Department of Commerce Ronald H. Brown, Secretary

National Institute of Standards and Technology Raymond G. Kammer, Acting Director Building and Fire Research Laboratory Gaithersburg, MD 20899
Prepared for:

U.S. Environmental Protection Agency Carol M. Browner, Administrator

Office of Air and Radiation Office of Radiation and Indoor Air Indoor Air Division Washington, DC 20460

U.S. Department of Energy Hazel R. O'Leary, Secretary Office of Energy Efficiency and Renewable Energy

Building Systems and Materials Division Washington, DC 20585 



\section{ABSTRACT}

A series of parameters has been developed for describing building and HVAC characteristics of commercial buildings in conjunction with indoor air quality investigations. These parameters were developed in association with the activities of the Building/HVAC Team and the Steering Committee of the U.S.

Environmental Protection Agency (EPA) Building Assessment Survey and Evaluation (BASE) Program. The building and HVAC characterization includes those features considered essential to an investigation intended to obtain baseline information on a test space within a building as opposed to a detailed research study or an effort to diagnose a specific problem. The parameters include both general information on the building as well as more specific information on the space being investigated. This report consists of checklists for recording information on the building and HVAC parameters in the field, along with instructions for completing the checklists. The checklists cover four areas: A) Whole Building Description, B) Test Space Description, C) HVAC System Description, and D) HVAC System Performance. The Whole Building Description checklists provide a description of the basic features of the building being studied. The Test Space Description checklists are used to obtain more detailed information on the space within the building that is being studied, although the test space could be a whole building. The HVAC System Description checklists are used to describe the HVAC system serving the test space, and the HVAC System Performance checklists cover selected performance measurements on that HVAC system.

Key words: building diagnostics, building performance, commercial buildings, HVAC, indoor air quality, office buildings, ventilation 


\section{ACKNOWLEDGMENTS}

The development of this report was sponsored by the Indoor Air Division of the Office of Air and Radiation of the U.S. Environmental Protection Agency under Contact No. DW13935313-01-0, the Building Systems and Materials Division of the Office of Energy Efficiency and Renewable Energy of the U.S. Department of Energy under Contact No. DE-AI01-91CE21042 A001, and the Building and Fire Research Laboratory at NIST. The author expresses his appreciation to the BASE Program Steering Committee and the individual members of the Building/HVAC Team: Jack Buckley, David Grimsrud, Hal Levin, Ken Wallingford and James Woods. Jack Buckley's contributions on the classification of HVAC system types were particularly helpful. The support and assistance of John Girman, Bob Thompson, Kevin Teichman and Susan Womble of EPA and John Talbott of DOE are also acknowledged. 


\section{TABLE OF CONTENTS}

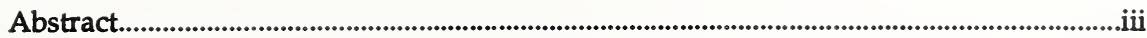

Acknowledgments........................................................................................................................... v

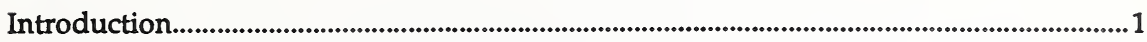

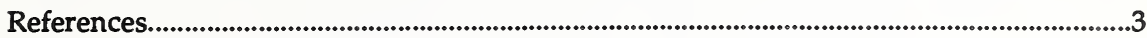

A Whole Building Description

Checklist Instructions...................................................................................................................5

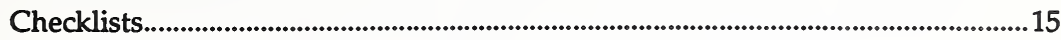

B Test Space Description

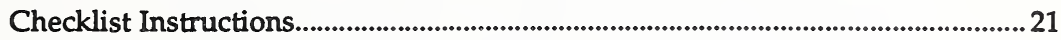

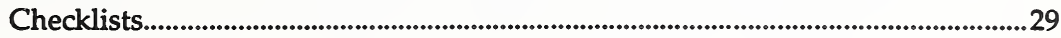

C Test Space HVAC Description

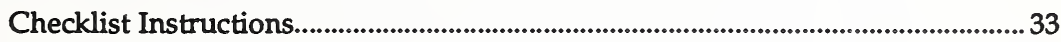

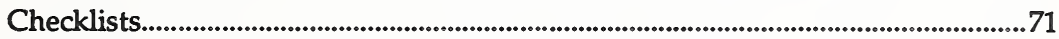

D Test Space HVAC Performance

Checklist Instructions.......................................................................................................91

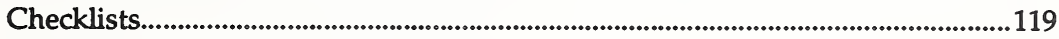




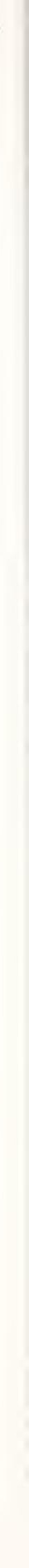




\section{INTRODUCTION}

Despite the impacts of building and ventilation system characteristics on indoor air quality, many air quality investigations have given inadequate attention to the assessment of important building features including ventilation. The assessment of building and ventilation characteristics in some investigations has been very limited, while other investigations have involved no consideration of these factors at all. Ventilation system design values are sometimes evaluated, but there are no actual performance measurements. In other cases, performance measurements are conducted using unreliable and inappropriate measurement procedures. These circumstances exist due in part to an inadequate understanding of building characteristics and ventilation systems by some indoor air quality investigators, along with a lack of standardized approaches to the assessment of building and HVAC characteristics. Indoor air quality investigations that characterize the building and its HVAC systems generally employ different approaches, which complicates a comparison of their results. In order to address the need for the characterization of building and HVAC systems, a list of parameters was identified for assessing building and HVAC characteristics for indoor air quality investigations in commercial buildings. In addition, procedures were also developed to determine the values of these parameters. These procedures enable the assessment of those features considered essential to an investigation intended to obtain baseline information as opposed to a detailed research study or an effort to diagnose a specific indoor air quality problem. This report consists of checklists to record these building and HVAC parameters in the field, along with instructions for completing these checklists. The checklists are divided into four groups: A) Whole Building Description, B) Test Space Description, C) Test Space HVAC System Description and D) Test Space HVAC System Performance.

Whole Building Description covers basic information on the building including age, size, space use, occupancy, climate and site, building equipment and information on potential sources within and outside of the building. Test Space Description provides more detailed information on the space being studied, in general only a portion of the building. These checklists include information on space use, occupancy, interior furnishings and potential contaminant sources in the test space. Test Space HVAC Description is used to record design information on the HVAC equipment serving the test space. Test Space HVAC Performance is used to record selected information on the performance of the HVAC equipment serving the test space. The ventilation performance measurements contained in this evaluation are intended to require 2 to 4 person-days and are appropriate to personnel familiar with standardized airflow measurement techniques.

The checklists were developed for use in the EPA Building Assessment Survey and Evaluation Program (BASE). The BASE Program is a multi-year research effort to collect baseline information on indoor environmental performance of commercial 
buildings throughout the U.S. Building investigations conducted under the BASE Program will include a characterization of the building and HVAC system, selected environmental measurements including pollutant levels and thermal comfort parameters, and the application of an occupant questionnaire to record occupant perceptions of the indoor environment. Each building investigation will be completed in less than one week, employing three to four people. Although the building and HVAC checklists in this report were developed as part of the BASE Program, they will be useful in other indoor air quality investigations.

The fact that the building and HVAC checklists were developed for the BASE Program affected their content and approach. The BASE Program studies will not involve the diagnosis of indoor air quality problems in specific buildings, and therefore the checklists are focused on gathering general information about the building and HVAC system as opposed to the specific information required in diagnostic efforts. In addition, while it is hoped that the information obtained in the BASE program may generate hypotheses regarding the impact of building features on the indoor environment and occupant perceptions, no specific hypotheses drove the formulation of these checklists.

The BASE program studies will involve test spaces within buildings, occupied by fifty to one-hundred people, as opposed to entire buildings. In some cases the test space will be a whole building, but generally not. Therefore, only general information is obtained on the whole building in section A. More specific information on the test space and its systems are obtained with the checklists in sections $B, C$ and $D$. In section D on HVAC performance, only established measurement procedures are employed that are accessible to personnel with a reasonable level of engineering expertise. Although recent research efforts have demonstrated measurement techniques that may sometime be more widely used, no research-grade procedures are employed in the HVAC performance assessment. In addition, the measurement procedures are consistent with the level of effort associated with the BASE studies, i.e., two to four person-days for the HVAC performance measurements. The restriction to well-established procedures that can be completed in a relatively short period of time necessarily limits the nature of the information that can be obtained, but was necessary given the nature of the BASE Program. Other research efforts and building investigations are expected to build upon the BASE Program studies by using more advanced and complete evaluation procedures. 


\section{REFERENCES}

The development of the Building and HVAC checklists were based on the input of members of the BASE Program Steering Committee as well as material from the following documents.

ASHRAE, HVAC Systems and Equipment Handbook, American Society of Heating, Refrigerating, and Air-Conditioning Engineers, Inc., Atlanta, 1992.

ASHRAE, HVAC Applications Handbook American Society of Heating, Refrigerating and Air-Conditioning Engineers, Inc., Atlanta, 1991.

ASHRAE Standard 52-76, "Method of Testing Air-Cleaning Devices Used in General Ventilation for Removing Particulate Matter," American Society of Heating, Refrigerating, and Air-Conditioning Engineers, Inc., Atlanta, 1976.

DOE, Commercial Building Characteristics 1989, DOE/EIA-0246(89), Energy Information Administration, U.S. Department of Energy, Washington, DC, 1991.

McQuiston, F.C., J.D. Parker, Heating, Ventilating, and Air Conditioning Analysis and Design, John Wiley \& Sons, New York, 1977. 



\section{CHECKLIST INSTRUCTIONS: WHOLE BUILDING DESCRIPTION}

The whole building description employs the following two forms:

\section{A-1 BUILDING DESCRIPTION}

\section{A-2 SOURCE INFORMATION}

One copy of each form must be filled out for each building.

\section{FORM A-1 BUILDING DESCRIPTION}

This form is used to obtain information on the whole building, including space use, occupancy, climate and site, building equipment and the building envelope. This information is acquired by examining the building plans, conducting a building walk-through and speaking with the building owner, manager and operator. The entries on the form are to be completed as follows:

1 Building Age: Enter the year that the building construction was completed. If there is a question as to when construction was complete, enter the year that the building was first occupied. This value should be obtained from the building owner or manager.

2 Floor Area: Enter the total floor area of the building, including the space on all floors enclosed by the exterior walls. Do not correct for the building core, interior walls or columns. This value can be estimated from the building plans or obtained from the building owner or manager. Be sure that the value they have given you is a gross floor area, as opposed to a rentable or occupied area.

Designate the units, either $\mathrm{m}^{2}$ or $\mathrm{ft}^{2}$.

Number of Floors

3 Below Grade: Enter the number of building floors that are below grade.

4 Above Grade: Enter the number of building floors that are above grade 


\section{Space Use}

For each of the following categories of space use, enter the building floors on which these spaces are located and the approximate floor area associated with each space use in percent. These floor area percentages should be selected from the following categories:

$$
<1 \% \quad 1-10 \% \quad 10-25 \% \quad 25-50 \% \quad>50 \%
$$

5 Office: This category includes open and private office space and other spaces associated with general office activities, including conference rooms.

6 Retail: This category includes commercial establishments such as retail stores and restaurants.

7 Public Assembly: This category includes large meeting rooms and auditoriums.

8 Laboratory

9 Storage

10 Food Services: This category includes kitchens and cafeterias, excluding food preparation areas used by employees.

11 Employee-Use Kitchens: Food preparation areas used by employees containing stoves and microwave ovens, excluding areas containing only coffee makers.

12 Parking: This category includes indoor parking areas.

\section{Occupancy}

13 Number of Occupants: Enter the number of people, including visitors, that normally occupy the building. This value need only be an approximation obtained from the building owner or manager, as opposed to a detailed count,.

14 Days of Week: Enter the number of days per week that the building is substantially occupied. This value should not include days that the building has only minimal (less than $25 \%$ ) occupancy and should be obtained from the building owner or manager.

Hours per Day

15 Weekdays: Enter the number of hours that the building is at $25 \%$ of more of full occupancy on weekdays. This value should be obtained from the building owner or manager.

16 Weekends: Enter the number of hours that the building is at $25 \%$ of more of full occupancy on weekends. This value should be obtained from the building owner or manager. 


\section{Climate and Site}

17 Building Location: Enter the city and state in which the building is located.

18 Heating Degree Days: Enter the average number of heating degree days for the building location. This value can obtained from the nearest station of the National Weather Service and a variety of references including meteorological manuals.

Designate the units, either ${ }^{\circ} \mathrm{C}$-Days or ${ }^{\circ} \mathrm{F}$-Days.

19 Cooling Degree Days: Enter the average number of cooling degree days for the building location. This value can obtained from the nearest station of the National Weather Service and a variety of references including meteorological manuals. Designate the units, either ${ }^{\circ} \mathrm{C}$-Days or ${ }^{\circ} \mathrm{F}$-Days.

20 Winter Design Drybulb Temperature: Enter the 99\% value of the winter design drybulb temperature for the building location. This value can obtained from the ASHRAE Handbook of Fundamentals (Chapter on Weather Data).

Designate the units, either ${ }^{\circ} \mathrm{C}$ or ${ }^{\circ} \mathrm{F}$.

21 Summer Design Drybulb Temperature: Enter the 1\% value of the summer design drybulb temperature for the building location. This value can obtained from the ASHRAE Handbook of Fundamentals (Chapter on Weather Data).

Designate the units, either ${ }^{\circ} \mathrm{C}$ or ${ }^{\circ} \mathrm{F}$.

22 Summer Design Wetbulb Temperature: Enter the 1\% value of the summer design wetbulb temperature for the building location. This value can obtained from the ASHRAE Handbook of Fundamentals (Chapter on Weather Data). Designate the units, either ${ }^{\circ} \mathrm{C}$ or ${ }^{\circ} \mathrm{F}$.

23 Site Characterization: Check the category which best characterizes the building site. The distinction between urban, suburban and rural is straightforward, with urban referring to the core of the city not simply to the incorporated area.

Within the categories of urban and suburban, the three subcategories describe the dominant influence within a $1 \mathrm{~km}$ radius of the site and are defined as follows:

Industrial: Product-oriented establishments such as manufacturing and utilities.

Commercial: Service-oriented establishments such as retail establishments, restaurants and shopping centers.

Residential: Because most areas include some residential use, this category is used in the absence of a dominating industrial or commercial influence. 
Within the category of rural, the four subcategories describe the dominant influence within a $1 \mathrm{~km}$ radius of the site and are defined as follows:

Near Urban: Essentially a rural area that is close enough to a major urban center as to be affected by the urban area.

Agricultural: Including orchards, crop raising and livestock grazing.

Industrial: Product-oriented establishments such as manufacturing and utilities.

Commercial: Service-oriented establishments such as retail establishments, restaurants and shopping centers.

\section{Building Equipment}

24 Ventilation: Enter whether the building is ventilated naturally or mechanically. Natural ventilation includes any unpowered ventilation system including operable windows, ventilation shafts, intentional ventilation openings in walls and envelope leakage. The existence of isolated mechanical exhaust fans does not disqualify such a building from the natural ventilation category. A mechanically ventilated building employs a powered system to bring outdoor air into the building, even if it also contains some natural ventilation elements as well.

25 Cooling System

Air Conditioned: Enter yes if the building is air conditioned and no if it is not.

Equipment: Enter yes for each type of cooling equipment that is employed in the building. More than one of the equipment categories may exist in the building.

26 Heating System

Heated: Enter yes if the building is heated and no if it is not.

Equipment: Enter yes for each type of heating equipment that is employed in the building. More than one of the equipment categories may exist in the building. 
Operating Schedule

Space Conditioning

27 Days per Week: Enter the number of days per week that the building space-

conditioning equipment is operated. This value should be obtained from the building owner, manager or operator.

Hours per Day

28 Weekdays: Enter the number of hours that the building space-conditioning equipment is operated during weekdays. Ask the building owner, manager or operator for a typical value that applies to normal circumstances.

29 Weekends: Enter the number of hours that the building space-conditioning equipment is operated during weekends. Ask the building owner, manager or operator for a typical value that applies to normal circumstances.

\section{Ventilation}

30 Days per Week: Enter the number of days per week that the building ventilation equipment is operated. This value should be obtained from the building owner, manager or operator.

\section{Hours per Day}

31 Weekdays: Enter the number of hours that the building ventilation equipment is operated during weekdays. Ask the building owner, manager or operator for a typical value that applies to normal circumstances.

32 Weekends: Enter the number of hours that the building ventilation equipment is operated during weekends. Ask the building owner, manager or operator for a typical value that applies to normal circumstances.

\section{Building Envelope}

33 Wall Construction: Enter the dominant construction of the exterior walls of the building, selecting from the following options:
Glass and Metal Curtain Wall Masonry
Precast Concrete Panels
Stone Panels

Exterior Insulation Finish System Siding on Frame Construction Metal Building System Other

More than one of the wall construction categories may apply in the building. In the case of Other, describe the wall construction in as few words as possible. 
34 Roof Construction: Enter the dominant construction of the roof of the building, selecting from the following options:

$\begin{array}{ll}\text { Built-Up Roof } & \text { Shingles } \\ \text { Single Ply Membrane } & \text { Metal } \\ \text { Inverted Membrane } & \text { Other }\end{array}$

In the case of Other, describe the roof construction in as few words as possible.

\section{Glazing}

35 Glazing Elements: Enter whether the windows are single, double or triple pane.

36 Operable Windows: Enter yes if the windows are operable and no if they are not.

37 Shading Elements: Enter yes if the windows incorporate shading elements such overhangs, window treatments or shades.

\section{EORM A-2 SOURCEINFORMATION}

This form is used to obtain information related to sources of indoor pollutants that may impact the building. This information is acquired through a combination of a building walk-through and discussions with the building owner, manager and operator. The entries on the form are to be completed as follows:

\section{Outdoor Sources}

Note whether each of the following sources exist in the immediate vicinity of the building.

The source need not be proximate to the outdoor air intake.

1 Garbage Dumpsters

2 Heavy Motor Vehicle Traffic: A positive response indicates the existence of heavy traffic during at least part of the day, it need not be heavy all day long.

3 Emergency Generators: A positive response indicates the existence of emergency electricity generators, even if they are generally inactive.

4 Power Plants: A positive response indicates the existence of a power plant including electricity or steam generation.

5 Construction Activities: A positive response indicates the existence of building construction on nearby building sites, including new construction, renovation and demolition.

6 Industrial Stacks: A positive response indicates the existence of stacks from industrial facilities. 
Smoking Policy: This information can be obtained from the building owner or manager.

7 Smoking Permitted: Enter yes if smoking is permitted anywhere in the building and no if smoking is not allowed.

8 Entire Building: Enter yes if smoking is permitted throughout the entire building and no if smoking is permitted only in specific locations.

9 Restricted to Smoking Lounges: Enter yes if smoking is restricted within the building except for designated smoking lounges (including designated restrooms) and no if such smoking areas do not exist.

10 Restricted to Private Offices: Enter yes if smoking is restricted within the building except for private offices and no if smoking is not allowed in private offices.

Water Damage: This information can be obtained from the building owner or manager.

11 Past Occurrences: Enter yes if there has been water damage in the building in the past.

12 Location: Note where in the building this past water damage has occurred.

13 Current Leaks: Enter yes if there is currently water leakage within the building.

14 Location: Note where in the building this water leakage is occurring.

Fire Damage: This information can be obtained from the building owner or manager.

15 Past Occurrences: Enter yes if there has been fire damage within the building.

16 When: If the fire damage occurred within the last year, enter the month. If the fire damage occurred more than one year ago, enter the year.

17 Building Wide: Enter yes if the fire damage occurred throughout the building.

18 Limited Spaces: Enter yes if the fire damage occurred only in limited areas within the building. 
Renovation: The questions on recent renovations concern only areas within the building that are adjacent to the test space (including on the floors immediately above and below the test space) and areas served by the same air handler as the test space. These areas are referred to below as "related areas." The questions on current renovations apply to the whole building. This information can be obtained from a building walk-through and from the building owner or manager.

Painting

19 Enter yes if their has been painting within related areas in the building within the last year. Enter where (the building floor) this painting has occurred and the month in which it occurred.

20 Enter yes if their is currently painting going on within the building. Enter where (the building floor) this painting is occurring.

New Carpet

21 Enter yes if new carpet has been installed within related areas in the building within the last year. Enter where (the building floor) this installation has occurred and the month in which it occurred.

22 Enter yes if new carpet is currently being installed within the building. Enter where (the building floor) this installation is occurring.

Reroofing

23 Enter yes if the roof has been replaced within the last year. Enter the month in which it occurred.

24 Enter yes if the roof is currently being replaced.

New Furniture

25 Enter yes if new furniture has been installed within related areas in the building within the last year. Enter where (the building floor) this installation has occurred and the month in which it occurred.

26 Enter yes if new furniture is currently being installed within the building. Enter where (the building floor) this installation is occurring.

Partition Replacement or Interior Wall Movement

27 Enter yes if interior partitions have been replaced or interior walls have been moved within related areas in the building within the last year. Enter where (the building floor) this work has occurred and the month in which it occurred.

28 Enter yes if interior partitions are being replaced or interior walls are being moved within the building. Enter where (the building floor) this installation is occurring. 
Cleaning: This information can be obtained from the building owner, manager or engineer.

Schedule: For each of the three following categories, enter the frequency at which the cleaning is done. The frequency should be the times per week or per month as appropriate. Note whether this cleaning is done during occupied hours, evenings or weekends.

29 Office Cleaning: This includes general cleaning of offices such as dusting.

30 Floor Cleaning: Separate entries should be provided for each of three types of floor cleaning: dry mopping, wet mopping and spray buffing.

31 Vacuuming

32 Trash Storage: Enter the locations within the building where trash is stored, other than temporarily during collection. Appropriate information includes the building floor and where on the building floor such as occupied space, stairwell, freight elevator lobby or loading dock.

Cleaning Materials

33 What: Describe the materials used in cleaning the building using generic descriptors such as window cleaner, furniture cleaner, floor wax, bathroom cleaners, ...

34 Storage Location: Enter the locations within the building where cleaning materials are stored. Appropriate information includes the building floor and where on the building floor such as janitors closet or storage room.

Pest Control: This information can be obtained from the building owner, manager or engineer.

35 Exterior Application: Enter yes if pesticides are used on the exterior of the building.

36 Frequency: Enter the frequency at which pesticides are used on the exterior of the building. The frequency should be the times per month or per year as appropriate.

37 Interior Application: Enter yes if pesticides are used on the interior of the building.

38 Frequency: Enter the frequency at which pesticides are used on the interior of the building. The frequency should be the times per month or per year as appropriate.

39 Where: Enter the locations within the building where interior pesticides are applied. Appropriate information includes the building floor and where on the building floor such as occupied space, storage areas or mechanical rooms. 


\section{Pesticides}

40 What: Describe the pesticides used outside or inside the building. This information can be obtained from Material Safety Data Sheets if available. The pesticide applicator may need to be contacted to obtain this information.

41 MSDS: Enter yes if the Material Safety Data Sheets for the pesticides are available in the building and no if they are not.

42 Storage Location: Enter the locations within the building, if any, where pesticides are stored. Appropriate information includes the building floor and where on the building floor such as janitors closet or storage room. If pesticides are not stored in the building, enter no.

43-63: Special-Use Spaces: This information can be obtained from the building owner, manager or engineer. For each of the categories (smoking lounges through parking garages), provide the following information:

Existence: Enter yes if the space use category exists in the building.

Location: Enter the location within the building where this space exists. The building floor is sufficient.

Communications with Building: Check the entries that describe the pathways for communication between the special-use space and the rest of the building. It is anticipated that more than one entry will be checked.

Dedicated ventilation system: The space has its own ventilation system, including both supply and return/exhaust, specifically designed for the space.

Dedicated exhaust fan: The space has its own exhaust fan.

Doorway: There is a doorway between the special-use space and the rest of the building.

Elevator: There is an elevator serving the special-use space that also serves the rest of the building.

Stairway: There is a stairway serving the special-use space that also serves the rest of the building. 


\section{FORM A-1: BUILDING DESCRIPTION}

Only one copy of Form A-1 is required for each building.

1 Building Age:

Number of Floors

3 Below Grade:

\section{Space Use}

5 Office

6 Retail

7 Public Assembly

8 Laboratory

9 Storage

10 Food Services

11 Employee-Use Kitchen

12 Parking

\section{Occupancy}

13 Number of Occupants:

14 Days per Weeks:

Hours per Day

15 Weekdays:

16 Weekends:
2 Floor Area: $\mathrm{m}^{2}$ or $\mathrm{ft}^{2}$

\section{Climate and Site}

17 Building Location:

18 Heating Degree Days:

19 Cooling Degree Days:

Floors

Floor Area (\%)

20 Winter Design Drybulb Temperature (99\%):

21 Summer Design Drybulb Temperature (1\%):

22 Summer Design Wetbulb Temperature (1\%):

${ }^{\circ} \mathrm{C}$-Day or ${ }^{\circ} \mathrm{F}-\mathrm{Day}$ ${ }^{\circ} \mathrm{C}$-Day or ${ }^{\circ} \mathrm{F}-\mathrm{Day}$ ${ }^{\circ} \mathrm{C}$ or ${ }^{\circ} \mathrm{F}$ ${ }^{\circ} \mathrm{C}$ or ${ }^{\circ} \mathrm{F}$ ${ }^{\circ} \mathrm{C}$ or ${ }^{\circ} \mathrm{F}$

23 Site Characterization

Urban/Industrial:

Urban/Residential:

Urban/Commercial:

Rural/Near Urban:

Rural/ Agricultural:
Suburban/Industrial:

Suburban/ Residential:

Suburban/ Commercial:

Rural/ Commercial:

Rural/ Industrial: 


\section{Building Equipment}

24 Ventilation: Natural or mechanical

25 Cooling System

Air Conditioned: $\mathrm{Y} / \mathrm{N}$

Equipment

Central Chillers: $\mathrm{Y} / \mathrm{N}$

Packaged Air Conditioning Units: _ $Y / N$

Heat Pump: $Y$ Y $/ N$

Ducted Air Distribution: _ $Y / N$

Fan Coil Units: _ $Y / N$

Individual Room Air Conditioners: __ $\mathrm{Y} / \mathrm{N}$

26 Heating System

Heated: $\mathrm{Y} / \mathrm{N}$

Equipment

Steam or Hot Water Boiler: $\mathrm{Y} / \mathrm{N}$

Central System with Heating Coils: ___ Y/N

Reheat Coils in Air Distribution System: __ $\mathrm{Y} / \mathrm{N}$

Packaged Units: __ $Y / N$

Forced Air Furnace: __ $\mathrm{Y} / \mathrm{N}$

Heat Pump: $Y / N$

Ducted Air Distribution: _ $\mathrm{Y} / \mathrm{N}$

Fan Coil Units: __ $Y / N$

Individual Space Heaters: __ $\mathrm{Y} / \mathrm{N}$

Operating Schedule

Space Conditioning

27 Days per Weeks:

Hours per Day

28 Weekdays:

29 Weekends:
Ventilation System

30 Days per Weeks:

Hours per Day

31 Weekdays:

32 Weekends:

Building Envelope

33 Wall Construction:

34 Roof Construction:

Glazing

35 Glazing Elements: Single, Double or Triple

36 Operable Windows: Y/N 37 Shading Elements: $\mathrm{Y} / \mathrm{N}$ 


\section{FORM A-2: SOURCE INFORMATION}

Only one copy of Form A-2 is required for each building.

Outdoor Sources

1 Garbage dumpsters: _ $\mathrm{Y} / \mathrm{N} 4$ Power plants:

2 Heavy motor vehicle traffic: ___ Y $/ \mathrm{N} 5$ Construction activities: __

3 Emergency generators: __ $\mathrm{Y} / \mathrm{N} 6$ Industrial stacks: $\_$Y $/ \mathrm{N}$

Smoking Policy

7 Smoking permitted:

Y/N 9 Restricted to smoking lounges: $\ldots$ Y/N

8 Entire building:

Y/N 10 Restricted to private offices:

$\mathrm{Y} / \mathrm{N}$

Water Damage

11 Past occurrences:

Y/N 13 Current leaks:

$\mathrm{Y} / \mathrm{N}$

12 Location

14 Location

Basement: —Y/N

Roof:

Basement:

$\mathrm{Y} / \mathrm{N}$

Mechanical rooms:

$\mathrm{Y} / \mathrm{N}$

Occupied space:

$\mathrm{Y} / \mathrm{N}$

$Y / N$

Roof:

$Y / N$

Mechanical rooms: _ Y Y $/ N$

Occupied space:

$\mathrm{Y} / \mathrm{N}$

Fire Damage

15 Past occurrences:

$\mathrm{Y} / \mathrm{N}$

17 Building wide:

$\mathrm{Y} / \mathrm{N}$

16 When:

18 Limited spaces: $\mathrm{Y} / \mathrm{N}$

Renovation

Painting

19

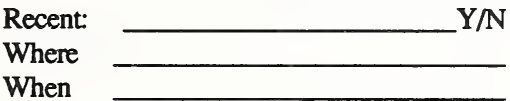

20 Current:

$\mathrm{Y} / \mathrm{N}$

When

Where

New Carpet

21 Recent:

$\mathrm{Y} / \mathrm{N}$

Where

When

Reroofing

23 Recent:

$\mathrm{Y} / \mathrm{N}$

24 Current:

$\mathrm{Y} / \mathrm{N}$

When

22 Current:

$\mathrm{Y} / \mathrm{N}$

Where

New Furniture

25 Recent:

$\mathrm{Y} / \mathrm{N}$

26

Current:

$\mathrm{Y} / \mathrm{N}$

Where

Where

When 
Partition Replacement or Interior Wall Movement

27

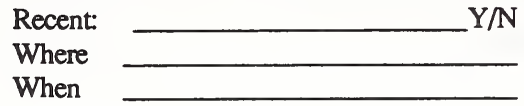

28

Current: $\mathrm{Y} / \mathrm{N}$ Where

\section{Cleaning}

Schedule

29 Office cleaning

Frequency Occupied Hours Evenings

Weekends

30 Floor cleaning

Dry mopping

Wet mopping

31 Vacuuming

Spray buffing

Trash Storage

32 Where:

Cleaning Materials

33 What:

34 Storage Location:

\section{Pest Control}

35 Exterior application:

36 Frequency:

39 Where:

Pesticides

40 What:

41 MSDS: $\mathrm{Y} / \mathrm{N}$

Special -Use Spaces

Smoking Lounges

43 Existence:

Y/N 44 Location:

45 Communication with Building

Dedicated ventilation system:

Dedicated exhaust fan:

$\mathrm{Y} / \mathrm{N}$

Doorway:

$\mathrm{Y} / \mathrm{N}$

$\mathrm{Y} / \mathrm{N}$

Laboratories

46 Existence:

$\mathrm{Y} / \mathrm{N}$

47 Location:

Floors

48 Communication with Building

Dedicated ventilation system:

$\mathrm{Y} / \mathrm{N}$

Dedicated exhaust fan:

$Y / N$

Doorway:
42 Storage Location: 
Print Shops

49 Existence:

$\mathrm{Y} / \mathrm{N}$

50

Location:

Floors

51 Communication with Building

Dedicated ventilation system:

$\mathrm{Y} / \mathrm{N}$

Dedicated exhaust fan:

$\mathrm{Y} / \mathrm{N}$

Doorway: $\mathrm{Y} / \mathrm{N}$

Graphic Arts Facilities

52 Existence:

$\mathrm{Y} / \mathrm{N}$

533 Location:

Floors

54 Communication with Building

Dedicated ventilation system: $\mathrm{Y} / \mathrm{N}$

Dedicated exhaust fan: $\mathrm{Y} / \mathrm{N}$

Doorway: Y/N

Kitchen

55 Existence:

Y/N 56 Location:

57 Communication with Building

Dedicated ventilation system:

Dedicated exhaust fan: $\mathrm{Y} / \mathrm{N}$

Doorway: $\mathrm{Y} / \mathrm{N}$ $\mathrm{Y} / \mathrm{N}$

Loading Dock

58 Existence:

$\mathrm{Y} / \mathrm{N}$

60 Communication with Building

Dedicated ventilation system:

Dedicated exhaust fan:

$\mathrm{Y} / \mathrm{N}$

Doorway: $Y / N$ $\mathrm{Y} / \mathrm{N}$

Parking Garage

61 Existence:

$\mathrm{Y} / \mathrm{N}$

63 Communication with Building

Dedicated ventilation system:

$\mathrm{Y} / \mathrm{N}$

Dedicated exhaust fan:

$Y / N$

Doorway: $\mathrm{Y} / \mathrm{N}$
Floors

Elevator:

Stairway: $\mathrm{Y} / \mathrm{N}$ Y/N

Elevator:

Stairway: $Y / N$ $\mathrm{Y} / \mathbb{N}$

59 Location: Floors

Elevator:

Stairway: $\mathrm{Y} / \mathrm{N}$ $\mathrm{Y} / \mathrm{N}$

62 Location: Floors

Elevator:

Stairway: $\mathrm{Y} / \mathrm{N}$ $\mathrm{Y} / \mathrm{N}$ 



\section{CHECKLIST INSTRUCTIONS: TEST SPACE DESCRIPTION}

The test space description employs the following two forms:

\section{B-1 TEST SPACE DESCRIPTION}

\section{B-2 SOURCE INFORMATION}

One copy of each form must be filled out for the test space.

In addition to completing forms B-1 and B-2, a floor plan of the test space should be developed as these two forms are completed. This floor plan should be drawn approximately to scale and include all exterior and interior walls, windows, work stations, supply air vents and return air vents. The supply air vents should be individually numbered on the floor plan, starting at \#1.

\section{FORM B-1 TEST SPACE DESCRIPTION}

This form is used to obtain information on the test space including occupancy and space use. This information is acquired by examining the building plans, conducting a building walk-through, an examination of the building plans and speaking with the building owner, manager and operator. The entries on the form are to be completed as follows:

1 Floor Area: Enter the total floor area enclosed by the boundaries of the test space. Do not correct for walls, partitions or columns. This value should be measured on site. Designate the units, either $\mathrm{m}^{2}$ or $\mathrm{ft}^{2}$.

2 Ceiling Height: Enter the distance from the floor to the ceiling. If the space has a suspended ceiling, the distance to the suspended ceiling should be entered.

Designate the units, either $\mathrm{m}$ or $\mathrm{ft}$.

3 Plenum Height: Enter the distance from the suspended ceiling to the floor above. If the space does not have a suspended ceiling, leave this entry blank.

Designate the units, either $\mathrm{m}$ or $\mathrm{ft}$.

4 Space Use Change: Enter yes if the space use has changed since the original design of the building, such as from storage to office use. Enter no if the space is still being used for the purpose for which it was originally designed.

5 Redesign: Enter yes if the test space ventilation system was redesigned based on the space use change, including modifications of the air handler, the ductwork and the diffusers. Enter no if not. Leave blank if there was no space use change.

6 Number of Work Stations: Enter the number of work stations in the test space.

7 Number of Occupants: Enter the number of occupants in the space, two times a day on every day of the test period. Obtain this value by counting the number of people, including visitors, at approximately 10 am and $3 \mathrm{pm}$. 
8 Average Number of Occupants: Calculate the average of the values recorded in entry $\# 7$.

9 Average Floor Area per Work Station: Divide the floor area of the test space (entry \#1) by the number of work stations (entry \#6).

Designate the correct units, either $\mathrm{m}^{2}$ or $\mathrm{ft}^{2}$.

10 Average Floor Area per Occupant: Divide the floor area of the test space (entry \#1) by the average number of occupants (entry \#8).

Designate the units, either $\mathrm{m}^{2}$ or $\mathrm{ft}^{2}$.

11 Design Floor Area per Occupant: Enter the design value for the floor area per occupant if available. This value may be in the building plans or may be known by the building owner or manager. If this value is not available, then leave this entry blank.

Designate the units, either $\mathbf{m}^{2}$ or $\mathrm{ft}^{2}$.

Space Description: This information is obtained during a walk-through of the test space.

Private Offices: These are offices that contain no more than three work stations, are enclosed by permanent walls and have a door.

12 Number of Work Stations: Enter the number of work stations that are within private offices.

13 Number with Visual Access to Windows: Enter the number of works stations within private offices from which the occupant can see a window when seated.

Partitioned Office Space: These are offices in which the work stations are enclosed by partitions that do not extend to the ceiling.

14 Number of Work Stations: Enter the number of work stations that are within partitioned office space.

15 Number with Visual Access to Windows: Enter the number of works stations within partitioned office space from which the occupant can see a window when seated.

16 Partition Height: Enter the height of the top of the partitions from the floor. Designate the units, either $\mathrm{m}$ or $\mathrm{ft}$.

Open Office Space: These are offices in which the work stations are not separated by any partitions.

17 Number of Work Stations: Enter the number of work stations that are within open office space.

18 Number with Visual Access to Windows: Enter the number of works stations within open office space from which the occupant can see a window when seated. 


\section{Boundaries}

19 Exterior Walls: Enter yes if the test space boundaries include exterior walls.

20 Interior Walls: Enter yes if the test space boundaries include interior walls.

21 Open to Other Areas: Enter yes if the test space is open to other areas in the building, e.g., the test space is contained within a larger area of open office space.

Interior Finishes

22 Wall Finish: Enter the wall finishes that exist in the test space, selecting from the following options. If more than one finish is used, include them all.

$\begin{array}{ll}\text { Painted wallboard } & \text { Wall paper } \\ \text { Fabric wall covering } & \text { Wood Paneling } \\ \text { Metal } & \text { Other }\end{array}$

In the case of Other, describe the wall finish in as few words as possible.

23 Partition Finish: Enter the surface finish of the partitions in the test space, selecting from the following options. If more than one finish is used, include them all.

$\begin{array}{ll}\text { Cloth } & \text { Plastic } \\ \text { Wood Veneer } & \text { Wood } \\ \text { Metal } & \text { Other }\end{array}$

In the case of Other, describe the partition finish in as few words as possible. If there are no partitions, leave the entry blank.

24 Ceiling Finish: Enter the ceiling finishes that exist in the test space, selecting from the following options. If more than one finish is used, include them all.

$\begin{array}{ll}\text { Suspended Ceiling Panels } & \text { Painted wallboard } \\ \text { Metal } & \text { Wood Paneling }\end{array}$

Other

In the case of Other, describe the ceiling finish in as few words as possible.

25 Floor Finish: Enter the floor finishes that exist in the test space, selecting from the following options. If more than one finish is used, include them all.

$\begin{array}{ll}\text { Carpet } & \text { Tile or sheet } \\ \text { Wood } & \text { Concrete } \\ \text { Other } & \end{array}$

In the case of Other, describe the floor finish in as few words as possible.

Furniture

26 Number of Work Stations with Systems Furniture: Enter the number of work stations with systems furniture, i.e., furniture that is fixed to the floor and can not be moved without detaching installation hardware. 
27 Systems Furniture Material: Enter the surface finish of the systems furniture, selecting from the following options. If more than one finish is used, include them all.

Wood Veneer Metal
Other

In the case of Other, describe the finish in as few words as possible.

28 Number of Work Stations with Movable Furniture: Enter the number of work stations with movable furniture, i.e., furniture that is not fixed to the floor and can be moved without detaching the furniture from any hardware.

29 Movable Furniture Material: Enter the surface finish of the movable furniture, selecting from the following options. If more than one finish is used, include them all.

$\begin{array}{ll}\text { Wood Veneer } & \text { Metal } \\ \text { Wood } & \text { Other }\end{array}$

In the case of Other, describe the finish in as few words as possible.

\section{Lighting}

30 Lamp Type: Enter whether the test space has fluorescent, incandescent or high intensity discharge light fixtures. If the space has more than one type of lamp, enter all types used.

31 Incandescent: If the space has incandescent lamps, enter the number of lamps and the typical wattage of the lamps.

32 Fluorescent: If the space has fluorescent lamps, enter the number of lamps and the lamp type indicated on the lamp itself. Also, select the luminaire type from the schematics depicted below:

LOUVERED PARABOLIC

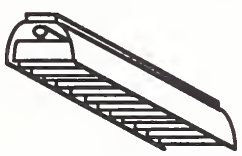

INDIRECT/DIRECT

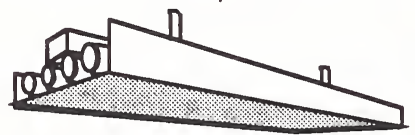

PARABOLIC OPEN REFLECTOR

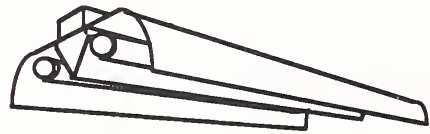

LENSED

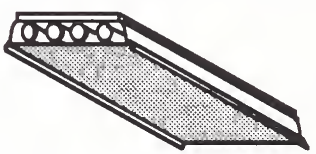

TROFFER

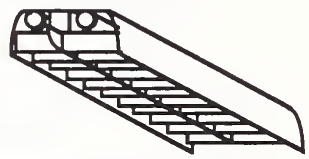

INDIRECT

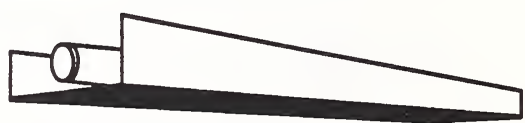

BARE LAMP

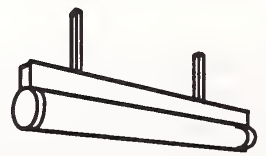


33 High Intensity Discharge: If the space has high intensity discharge lamps, enter whether the lamp is metal halide, mercury vapor or low pressure sodium, the number of lamps and the lamp type indicated on the lamp itself.

34 Work Stations with Task Lighting: Enter the number of work stations with task lighting built into the systems furniture.

35 Work Stations with Desk Lamps: Enter the number of work stations with desk lamps.

Ventilation Fixtures

36 Supply Vent Type: Enter the type of supply vent used in the test space, including the discharge direction, horizontal or vertical. Select from the following options. If more than one type is used, include them all.

Linear ceiling diffusers

Sidewall diffusers

High sidewall grilles

Floor registers

Perforated ceiling panels
Square or round ceiling diffusers

Floor or near-floor diffusers

Low sidewall grilles

Fan coil units or unit ventilators

Other

In the case of Other, describe the vent in as few words as possible.

37 Number of Supply Vents: Enter the total number of all types of supply vents in the test space.

38 Return Vent Type: Enter the type of return vent used in the test space. Select from the following options. If more than one type is used, include them all.

Ceiling grilles

Ceiling slots

Low sidewall or floor grilles
Slots around ceiling luminaires

High sidewall grilles

Other

In the case of Other, describe the vent in as few words as possible.

39 Number of Return Vents: Enter the total number of all types of return vents in the test space.

Auxiliary Environmental Equipment: For each of the following, enter yes if such equipment exists in the test space and no if not. If the equipment does exist, enter the number of devices in the test space.

40 Air Cleaners

41 Space Heaters

42 Humidifiers

43 Dehumidifiers

44 Fans 


\section{FORM B-2 SOURCE INFORMATION}

This form is used to obtain information related to the contaminant sources within the test space. This information is acquired through a combination of a test space walk-through and discussions with the building owner, manager and operator. The entries on the form are to be completed as follows:

Smoking Policy: This information can be obtained from the building owner or manager.

1 Smoking Permitted: Enter yes if smoking is permitted in the test space and no if smoking is not allowed.

2 Entire Test Space: Enter yes if smoking is permitted throughout the entire test space and no if smoking is permitted only in specific locations.

3 Restricted to Smoking Lounges: Enter yes if smoking is restricted within the test space except for designated smoking lounges (including designated restrooms) and no if such smoking areas do not exist.

4 Restricted to Private Offices: Enter yes if smoking is restricted within the test space except for private offices and no if smoking is not allowed in private offices.

Water Damage: This information can be obtained from the building owner or manager and from the test space walk-through.

5 Past Occurrences: Enter yes if there has been water damage in the test space in the past.

6 Location: Note where in the test space this water damage occurred.

7 Current Leaks: Enter yes if there is currently water leakage within the test space.

8 Location: Note where in the test space this water leakage is occurring.

Fire Damage: This information can be obtained from the building owner or manager.

9 Past Occurrences: Enter yes if there has been fire damage within the test space.

10 When: If the fire damage occurred within the last year, enter the month. If the fire damage occurred more than one year ago, enter the year.

Renovation: This information can be obtained from a test space walk-through and from the building owner or manager.

Painting

11 Enter yes if their has been painting within the test space within the last year.

12 When: If the painting occurred within the last year, enter the month. If the painting occurred more than one year ago, enter the year. 


\section{New Carpet}

13 Enter yes if new carpet has been installed within the test space within the last year.

14 When: If the carpet was installed within the last year, enter the month. If the installation occurred more than one year ago, enter the year.

New Furniture

15 Enter yes if new furniture has been installed within the test space within the last year.

16 When: If the furniture was installed within the last year, enter the month. If the installation occurred more than one year ago, enter the year.

Partition Replacement or Interior Wall Movement

17 Enter yes if interior partitions have been replaced or interior walls have been moved within the test space within the last year.

18 When: If the partitions or walls were installed within the last year, enter the month. If the installation occurred more than one year ago, enter the year.

Cleaning: This information can be obtained from the building owner, manager or engineer.

19 Differences from the Whole Building: Enter any differences in the test space cleaning from the whole building cleaning information entered on Form A-2. Such differences would include frequency of cleaning, when the cleaning is done and cleaning materials.

20 Trash Storage in Test Space: Enter yes if trash is stored within the test space and no if it is not.

Pest Control: This information can be obtained from the building owner, manager or engineer.

21 Differences from the Whole Building: Enter any differences in the test space pest control activities from the whole building information entered on Form A-2. Such differences would include frequency of application and pesticides employed.

22 Application in Test Space: Enter yes if pesticides are applied within the test space and no if they are not.

23 Frequency: Enter the frequency at which pesticides are used in the test space. The frequency should be entered in times per month or per year as appropriate. 
24-31: Special-Use Spaces: This information can be obtained from a test space walk through. For each of the categories (smoking lounge through graphics art facility), provide the following information:

Existence: Enter yes if the space use category exists in the test space.

Communications with Test Space: Check the entries that describe the pathways for communication between the special-use space and the rest of the test space. More than one entry may be checked.

Dedicated ventilation system: The special-use space has its own ventilation system, including both supply and return/exhaust, specifically designed for the special-use space.

Dedicated exhaust fan: The special-use space has its own exhaust fan.

Doorway: There is a doorway between the special-use space and the rest of the test space. 


\section{FORM B-1: TEST SPACE DESCRIPTION}

Only one copy of Form B-1 is required for the test space.

1 Floor Area: $\mathrm{m}^{2}$ or $\mathrm{ft}^{2}$

2 Ceiling Height: $\mathrm{m}$ or $\mathrm{ft} 3$ Plenum Height: $\mathrm{m}$ or $\mathrm{ft}$

4 Space Use Change: Y/N 5 Redesign: $\mathrm{Y} / \mathrm{N}$

\section{Occupancy}

6 Number of Work Stations:

7 Number of Occupants

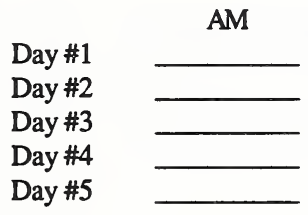

PM

8 Average Number of Occupants:

9 Average Floor Area per Work Station, \#1 divided by \#6: $\mathrm{m}^{2}$ or $\mathrm{ft}^{2}$

10 Average Floor Area per Occupant, \#1 divided by \#8: $\mathrm{m}^{2}$ or $\mathrm{ft}^{2}$

11 Design Floor Area per Work Station: $\mathrm{m}^{2}$ or $\mathrm{ft}^{2}$

\section{Space Description}

Private Offices

12 Number of Work Stations:

13 Number with Visual Access to Windows:

Partitioned Office Space

14 Number of Work Stations:

15 Number with Visual Access to Windows:

16 Partition Height: $\mathrm{m}$ or $\mathrm{ft}$

Open Office Space

17 Number of Work Stations:

18 Number with Visual Access to Windows: 
Boundaries

19 Exterior Walls: $\mathrm{Y} / \mathrm{N}$

20 Interior Walls: $\mathrm{Y} / \mathrm{N}$

21 Open to Other Areas: $\mathrm{Y} / \mathrm{N}$

\section{Interior Finishes}

22 Wall Finish:

23 Partition Finish:

24 Ceiling Finish:

25 Floor Finish:

Furniture

26 Number of Work Stations with Systems Furniture:

27 Systems Furniture Material:

28 Number of Work Stations with Movable Furniture:

29 Movable Furniture Material:

Lighting

30 Lamp Type:

31 Incandescent

Number:

32 Fluorescent

Number:

Luminaire:

33 High Intensity Discharge

Type:

Lamp:

34 Work Stations with Task Lighting:

35 Work Stations with Desk Lamps:

Wattage:

Lamp:

Number:

Ventilation Fixtures

36 Supply Vent Type:

37 Number of Supply Vents:

38 Return Vent Type:

39 Number of Return Vents:

Equipment

40 Air Cleaners:

41 Space Heaters:

42 Humidifiers:

43 Dehumidifiers:

44 Fans:

$\mathrm{Y} / \mathrm{N}$
$\mathrm{Y} / \mathrm{N}$
$\mathrm{Y} / \mathrm{N}$
$\mathrm{Y} / \mathrm{N}$
$\mathrm{Y} / \mathrm{N}$

$\mathrm{Y} / \mathrm{N}$

$\mathrm{Y} / \mathrm{N}$ 


\section{FORM B-2: SOURCE INFORMATION}

Only one copy of Form B-2 is required for the test space.

Smoking Policy

1 Smoking permitted:

Y/N 3 Restricted to smoking lounges:

$\mathrm{Y} / \mathrm{N}$

2 Entire test space:

Y/N 4 Restricted to private offices:

$\mathrm{Y} / \mathrm{N}$

Water Damage

5 Past occurrences:

Y/N 7 Current leaks:

$\mathrm{Y} / \mathrm{N}$

6 Location:

8 Location:

Fire Damage

9 Past occurrences:

Y/N 10 When:

Renovation

Painting

11 Recent:

Y/N 12 When:

New Carpet

13 Recent:

Y/N 14 When:

New Furniture

15 Recent:

Y/N 16 When:

Partition Replacement or Interior Wall Movement

17 Recent:

Y/N 18 When:

\section{Cleaning}

19 Differences from Whole Building:

20 Trash Storage in Test Space:

$\mathrm{Y} / \mathrm{N}$

\section{Pest Control}

21 Differences from Whole Building:

22 Application in Test Space: Y/N 23 Frequency: 
Special-Use Spaces

Smoking Lounge

24 Existence:

25 Communication with Test Space

Dedicated ventilation system:

Dedicated exhaust fan:

Doorway:

Photo Lab

28 Existence:

29 Communication with Test Space

Dedicated ventilation system:

Dedicated exhaust fan:

Doorway:

\section{Copy Room}

Y/N 26 Existence:

27 Communication with Test Space

Dedicated ventilation system:

Dedicated exhaust fan::

Doorway:

$\mathrm{Y} / \mathrm{N}$

$\mathrm{Y} / \mathrm{N}$

$\mathrm{Y} / \mathrm{N}$

$\mathrm{Y} / \mathrm{N}$

Graphic Arts Facility

Y/N 30 Existence:

31 Communication with Test Space

Dedicated ventilation system:

Dedicated exhaust fan::

Doorway:

$\mathrm{Y} / \mathrm{N}$

$Y / N$

$\mathrm{Y} / \mathrm{N}$

$\mathrm{Y} / \mathrm{N}$ $\mathrm{Y} / \mathrm{N}$

$\mathrm{Y} / \mathrm{N}$

$\mathrm{Y} / \mathrm{N}$ $\mathrm{Y} / \mathrm{N}$ $\mathrm{Y} / \mathrm{N}$ $\mathrm{Y} / \mathrm{N}$ 


\section{CHECKLIST INSTRUCTIONS: TEST SPACE HVAC SYSTEM DESCRIPTION}

The description of the HVAC system serving the test space employs a series of forms, with the specific forms used and their number depending on the system. The use of forms C-1 through C10 depends on the components of the HVAC system. Forms C-11 and C-12 will be used in all buildings. The forms for HVAC performance are as follows:
C-1 CENTRAL AIR HANDLING AND DISTRIBUTION SYSTEM
C-2 PERIMETER ZONE UNITS
C-3 UNTTARY SYSTEMS
C-4 EVAPORATIVE COOLING SYSTEMS
C-5 OUTDOOR AIR INTAKE CONTROL
C-6 NATURAL VENTILATION SYSTEMS
C-7A AIR HANDLER SPECIFICATIONS
C-7B EXHAUST FAN SPECIFICATIONS
C-8 FILTRATION AND AIR CLEANING SYSTEMS
C-9 AIR WASHERS
C-10 HUMIDIFICATION SYSTEMS
C-11 MAINTENANCE
C-12 INSPECTION 


\section{FORM C-1 CENTRAL AIR HANDLING AND DISTRIBUTION SYSTEM}

This form is used to describe the central air handling and distribution systems serving the test space, if such a system exists. One form is required for each central system serving the test space. Central systems, sometimes also referred to as "all-air," provide space conditioning to the space by supplying conditioned air. No additional cooling is provided in the space, although supplementary heating is sometimes provided in particular zones. The term "central" does not refer to the equipment location, since such a system can be located in a basement, penthouse or mechanical room on an occupied floor. Rather, central refers to the fact that such a unit generally serves several zones and employs a distribution system of ductwork to transport the supply air from the central equipment to the zones.

1 Air Handler Number: Enter the air handler number used in the building mechanical plans or on the air handler itself.

2 Air Handler Location: Enter the location of the air handler, using a room number from the building plans if available. If no room number is available, enter the floor and location on the floor.

3 System Type: Select the system type from one of the following options. The system type can sometimes be determined from the mechanical equipment specifications, but must be verified by inspection and discussion with the building operator.

\section{A Single Duct, Constant Volume, Single Zone}

The air handler supplies a constant volume of supply air to a single zone with minimum heating and cooling load variations. The load within the space is controlled by varying the temperature of the supply air. The supply air temperature is controlled by varying the quantity and/or temperature of the heating or cooling source, by varying the relative proportions of outdoor air intake and recirculation air, by modulating the position of face and bypass dampers within the air handler, or a combination of these approaches.

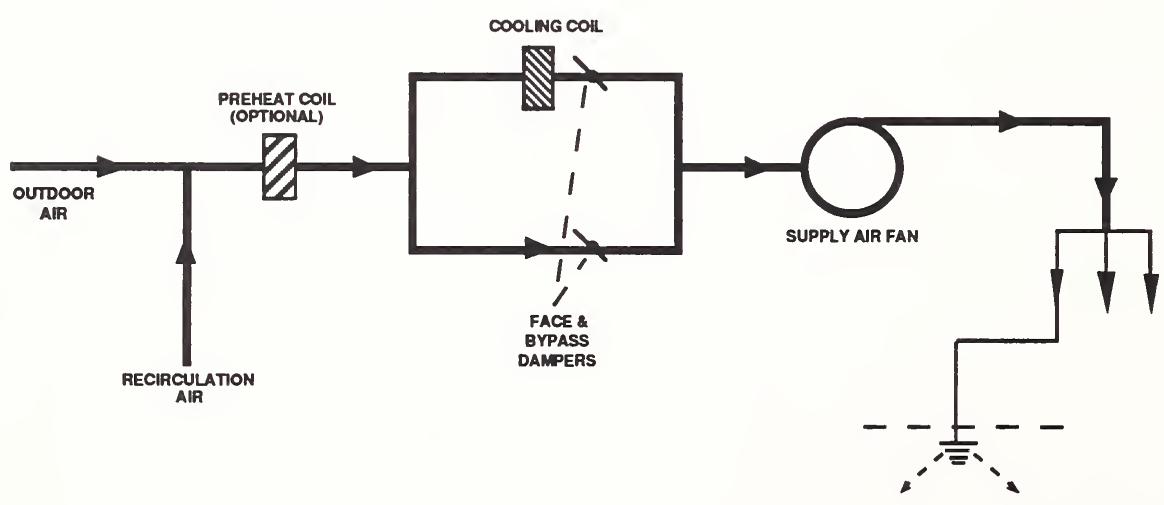


B Single Duct, Constant Volume, Multiple Zone Reheat

The air handler supplies a constant volume of supply air to multiple zones with unequal loads. The load within each zone is controlled by varying the temperature of the supply air delivered to the zone. The supply air temperature is controlled by varying the amount of heating or cooling at the air handler, the relative proportions of outdoor air intake and recirculation, the position of face and bypass dampers within the air handler, or a combination of these approaches. Further temperature control in individual zones is provided by reheat coils in the ducts in each individual zone.

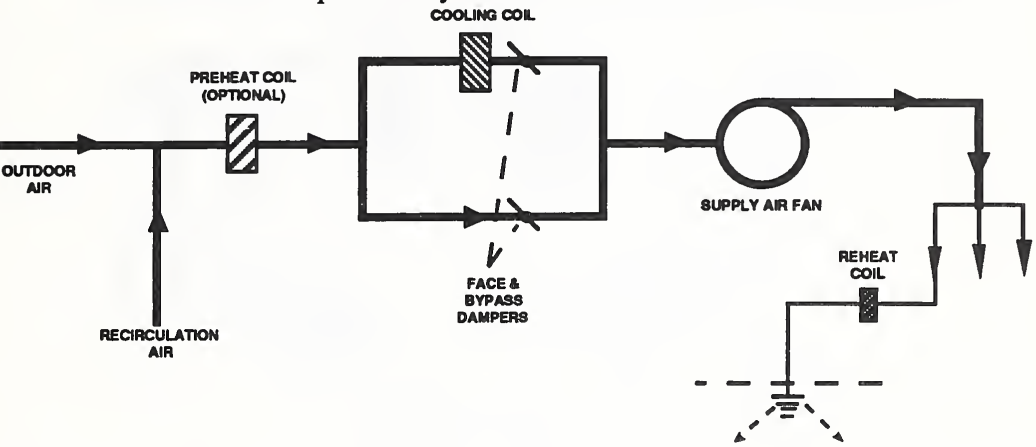

C Single Duct, Constant Volume, Multiple Zone Bypass

The air handler supplies a constant volume of supply air to multiple zones with unequal loads. The load within each zone is controlled by varying the temperature of the supply air delivered to the zone and the amount of supply air that is actually delivered to the zone. The supply air temperature is controlled by varying the amount of heating or cooling at the air handler, the relative proportions of outdoor air intake and recirculation, the position of face and bypass dampers within the air handler, or a combination of these approaches. Further temperature control in individual zones is provided through the use of a bypass box in the zone which dumps some of the supply air into the return air plenum or duct.

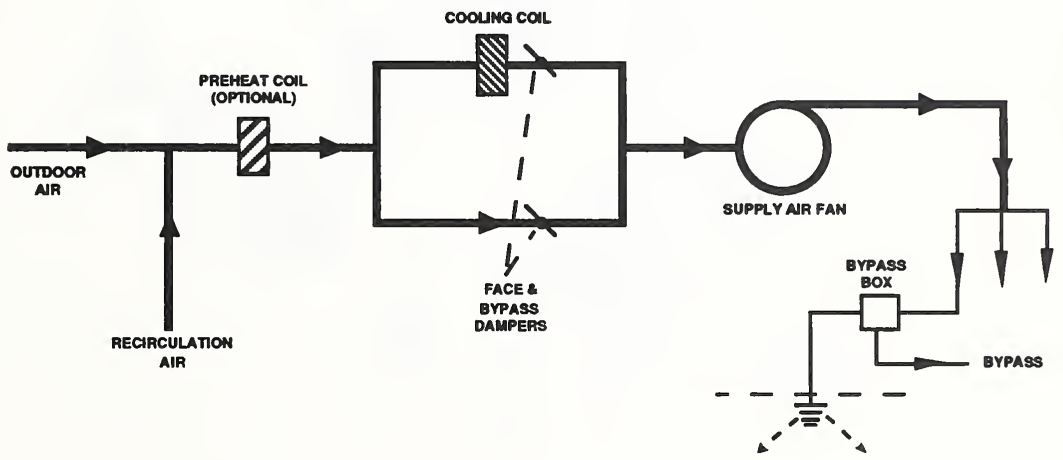


D Single Duct, Variable Air Volume

The air handler supplies air at a constant temperature of approximately $13^{\circ} \mathrm{C}$ $\left(55^{\circ} \mathrm{F}\right)$ through a duct system to VAV units located in the ceiling plenum. In each zone, the VAV unit controls the quantity of supply air delivered to meet the cooling load requirements within that zone. The total quantity of supply air delivered by the air handler therefore varies in response to variations in the space load within the building. A true VAV system provides cooling only, with perimeter zones heated by some other system.

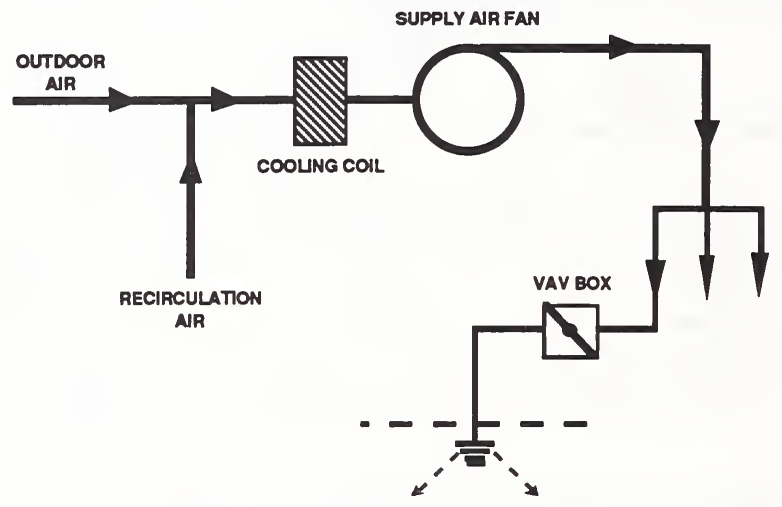

E Single Duct, Variable Air Volume, Reheat

This system is a modification of a true VAV system capable of providing both heating and cooling. Heat is provided in or near the terminal units after the supply airflow rate has been reduced to a predetermined minimum.

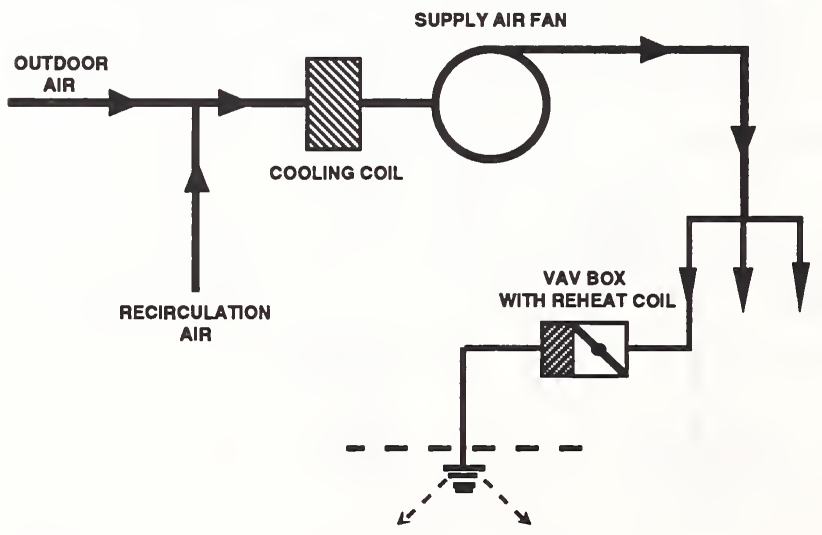


F Single Duct, Variable Air Volume, Induction

A VAV air handler provides primary air to unpowered VAV terminal units that induce plenum or room air into the supply airstream. The combination of primary and induced air provide a constant airflow. Variations in space load are met by varying the relative proportions of the primary and induced air. Reheat coils or some other form of auxiliary heat are required when heat gain in the room and ceiling is less than the sum of the transmission losses and the cooling loads associated with the primary air.

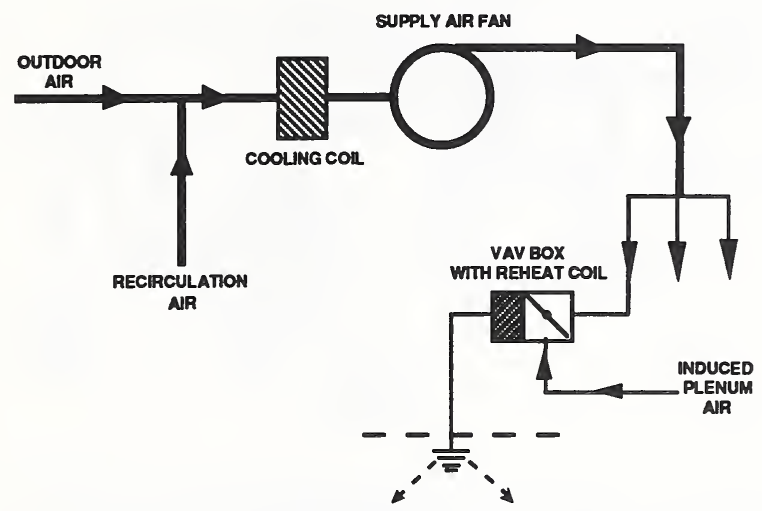

G Single Duct, Variable Air Volume, Fan Powered, Constant Fan

A VAV air handler supplies primary air to fan-powered VAV induction units that are installed in series with the primary supply airflow. The fan-powered units run continuously and operate at a relatively constant volume. In each zone, the unit mixes primary supply air with induced return air from the plenum to meet the space loads. Terminal units in exterior zones have heating coils for winter heating requirements. The heating coil is not activated until the primary air volume is reduced to a minimum value.

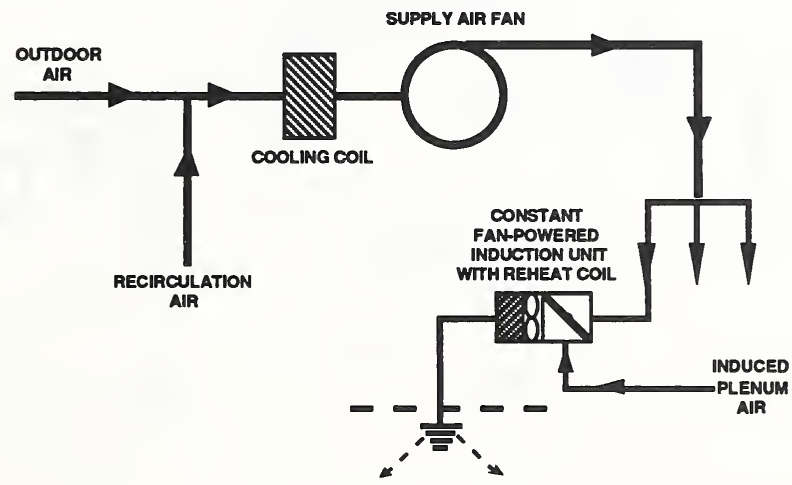


H Single Duct, Variable Air Volume, Fan Powered, Intermittent Fan

A VAV air handler supplies primary air to fan-powered VAV induction units that are installed in parallel with the primary supply airflow. The unit modulates the primary supply air in response to the cooling loads of the zone and operates the fan-powered unit when induced air is needed to meet the heating requirements. The primary air and the induced air mix within a common plenum within the fanpowered unit.

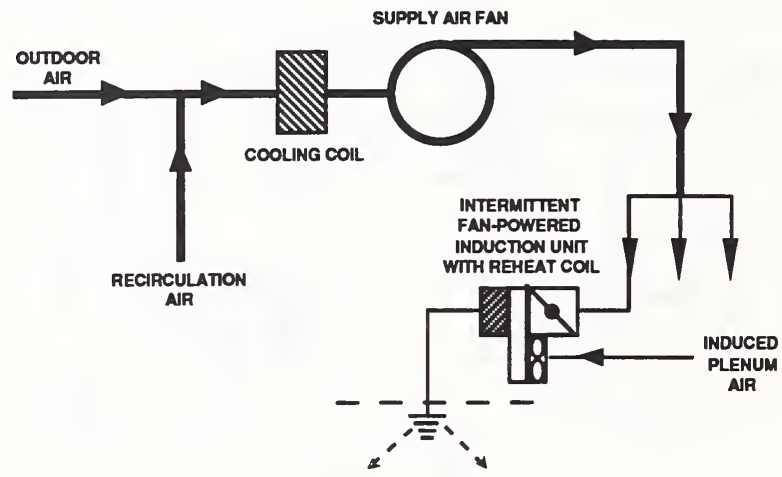

I Single Duct, Variable Air Volume, Dual Conduit

This system has two airstreams, one system used to meet year round cooling loads and a second system to offset transmission losses. The first system is a conventional central VAV system that provides year round cooling to meet space cooling loads. The second system operates at constant volume, with the air temperature varied to meet transmission losses, and conditions return air from the ceiling plenum or the room. In some systems, this second system operates only during peak loads.

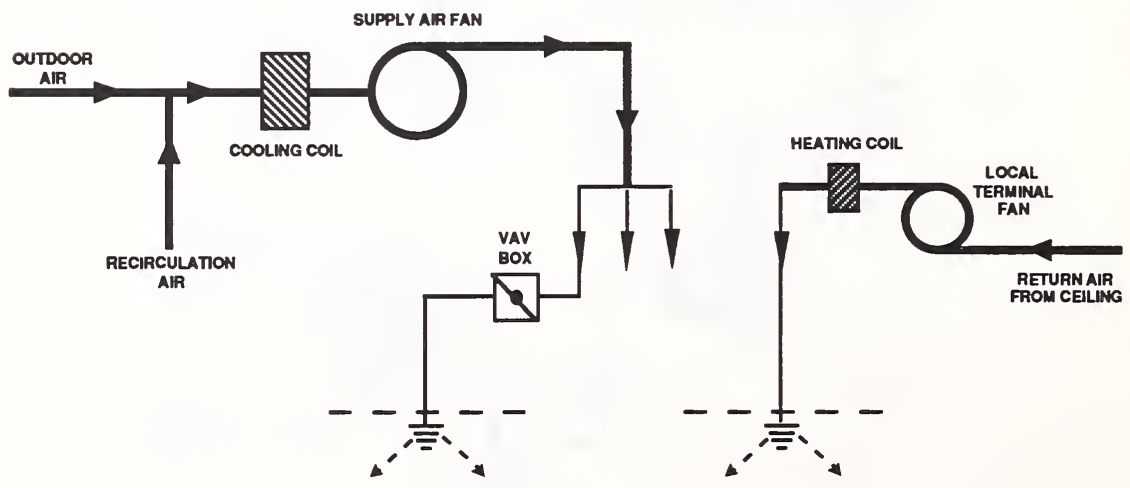




\section{J Dual Duct, Constant Volume}

The air handler supplies a constant volume of supply air to multiple zones, with the supply fan blowing through cooling coil and bypass sections connected to cold and hot decks respectively. These two decks run through the building to unpowered mixing boxes in the ceiling plenum, which mix the warm and cold air to meet the loads in the zone.

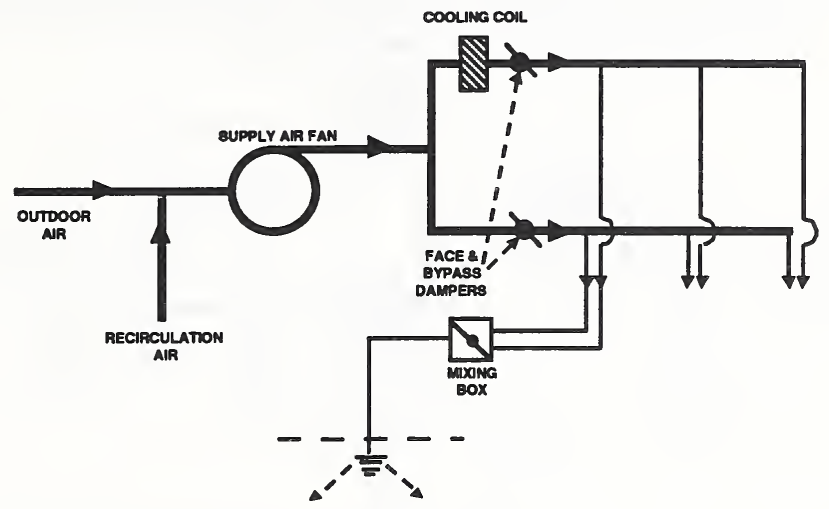

K Dual Duct, Constant Volume, Reheat

The air handler supplies a constant volume of supply air to multiple zones, with the supply airstream being split into two flows, one blowing through cooling coils and the other blowing through heating coils. The hot and cold air decks run through the building to unpowered mixing boxes in the ceiling plenum, which mix the hot and cold air to meet the loads in the zone. Interior zones mixing boxes may only be connected to the cold deck.

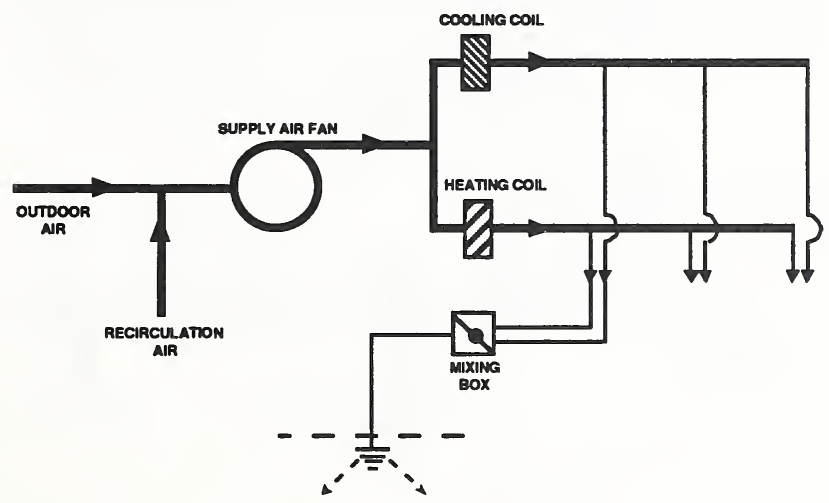


L Dual Duct, Variable Air Volume, Single Fan

A single VAV air handler supplies air to multiple zones, with the supply fan blowing through cooling and heating coil sections connected to cold and hot decks respectively. These two decks run through the building to VAV mixing boxes in the ceiling plenum, which mix the hot and cold air to meet the loads in the zone. The dampers in the mixing boxes are controlled by zone thermostats. Interior zone boxes may be connected to only the cold duct, while exterior zones will be connected to both the hot and cold decks.

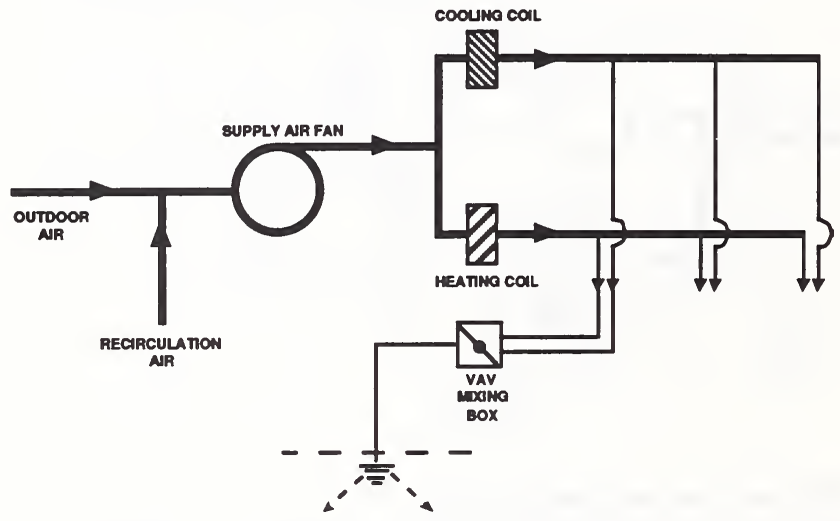

M Dual Duct, Variable Air Volume, Dual Fan

In this system, separate supply fans serve the cold and hot decks. The two decks run through the building to VAV mixing boxes in the ceiling plenum, which mix the hot and cold air to meet the loads in the zone. Interior zone boxes may be connected to only the cold duct; while exterior zones will be connected to both the hot and cold ducts.

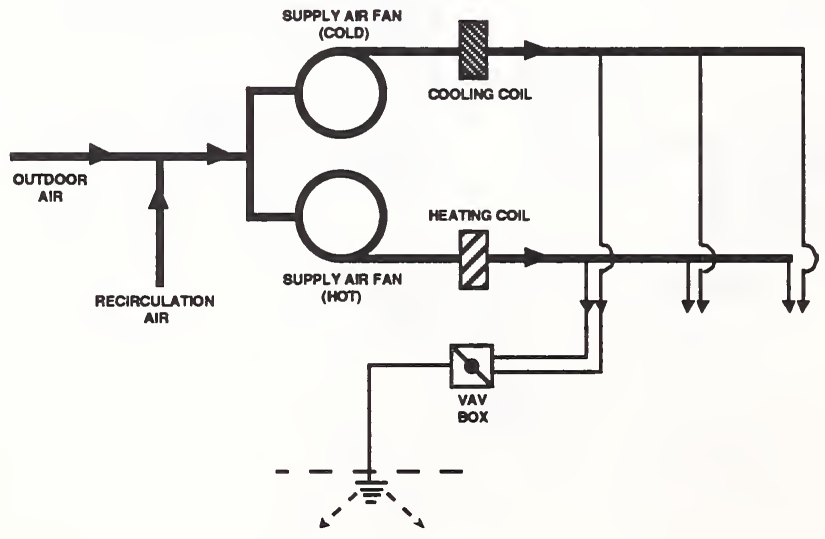


N Multizone, Constant Volume

A constant volume air handler serves multiple zones, with the supply fan blowing through a cooling or heating coil, or both. Each zone's space load is met with a mixture of the hot and cold airstreams carried by a single duct to the zone. The mixing of the two airstreams for each zone takes place at the unit, with dampers in the hot and cold decks. The airflow rate to each zone is fairly constant depending on the pressure drop through each coil and the position of the mixing dampers.

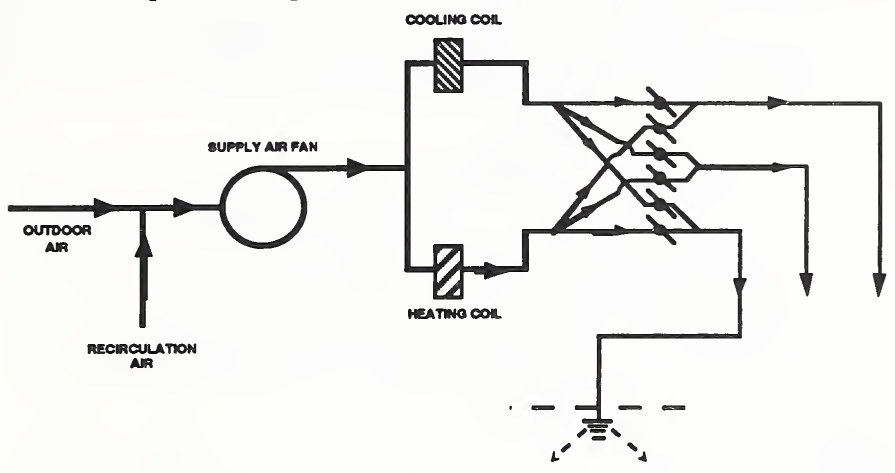

O Constant Volume, Blow-Through Bypass

A constant volume air handler serves multiple zones, with the supply fan blowing air through the cooling coil section or through a bypass section around the cooling coil. The two supply ducts, cold and bypass, split off such that there is a cold duct and bypass air duct for each zone. These two supply airflows are brought together within the mechanical room, with a damper in the bypass air duct and a heating coil downstream of where the two flows merge. A constant quantity of air is supplied to each zone through this single duct, and the supply air temperature to each zone is varied to meet space load by modulating the bypass damper and the use of the heating coil. The heating coil is activated only when all of the zone's supply air is bypass air. Interior zones may not have the heating coil in their ducts.

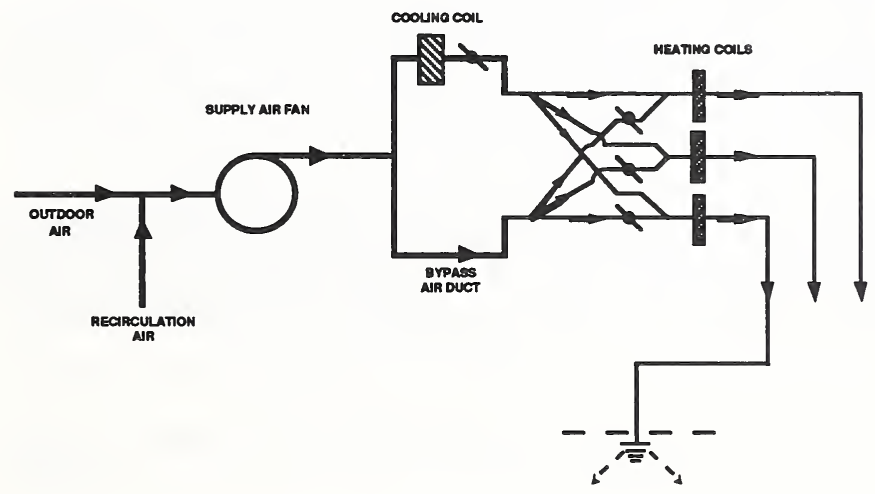


P Texas Multizone, or Three-Deck Multizone

The air handler supplies a constant volume of supply air to multiple zones, with the supply fan blowing through a cooling coil, a bypass section or a heating coil. The space load of each zone is met through a mixture of the cold, bypass and hot airstreams that is carried by single duct to the zone. The mixing of the three airstreams for each zone takes place at the unit, employing dampers in the three decks. Interior zones are generally not connected to the hot deck. The heating coils are activated only if the bypass air can not meet the loads. The total air quantity to each zone is more or less constant depending on the pressure drop through each coil and the position of the mixing dampers.

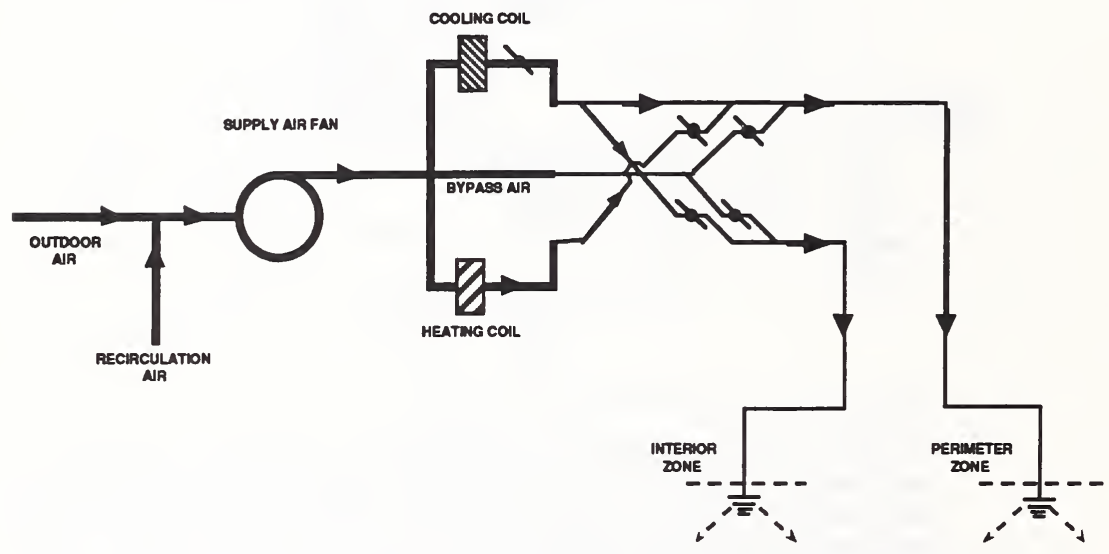

Other System Information: The following information can sometimes be determined from the mechanical equipment specifications but must be verified by inspection and discussion with the building operator.

4 Number of zones served by the air handler: Enter the number of thermostaticallycontrolled zones served by the air handler. Include the total number of zones, both within and outside the test space.

5 Return air fan: Enter yes if the system has a return fan and no if not.

6 Variable supply air temperature setpoint: Enter yes if the system is variable air volume and the supply air temperature is varied by the control system in response to conditions. Enter no if the system is VAV and does not have a variable supply air temperature setpoint. Leave blank if the system is not VAV. 


\section{FORM C-2 Perimeter Zone Units}

This form is used to describe systems that provide space conditioning to perimeter zones. In many cases, the systems within the section on central systems will also serve perimeter zones, but the systems described on this form are intended solely for perimeter applications. Only one form is required for the test space. If the test space is not served by a separate perimeter system, then this form is not required.

System Type: Select the system type from one of the following options. The system type can sometimes be determined from the mechanical equipment specifications, but must be verified by inspection and may require discussion with the building operator.

1 Air-Water Induction Units: Enter yes if the perimeter is conditioned by air-water induction units. Air handling units, usually constant volume and at a central location, supply high velocity conditioned air to induction type terminal units along the perimeter of a building. The high pressure air flows through induction nozzles within the unit, inducing secondary airflow from the room. The units have chilled or hot water coils in the face of the unit to cool or heat the room air induced by the primary supply air. Each unit has an automatic or manual valve to control the temperature in the space. These units are usually located under a window, although overhead installations also exist.

2 Condensate drain pan: Enter yes if the unit has a condensate drain pan and no if not.

3 Filters for secondary airflow: Enter yes if the units have filters for the secondary airflow induced from the room and no if not.

4 Fan-Coil Units: Enter yes if the perimeter is conditioned by fan-coil units. These units consist of a finned-tube coil supplied with hot or chilled water from a central source and a fan that circulates room air over the coil. In other cases, the units are sometimes provided with an outdoor air connection through the exterior wall. Temperature controllers in the unit meter the chilled or hot water to the coil. Air volume is adjusted by a manual speed controller. These units may have an auxiliary heating coil. Ventilation air from a central system may be introduced directly into to the unit.

5 Ventilation air: Enter yes if the fan-coil unit is connected to a source of ventilation air and no if not.

6 Source of ventilation air: If the answer to the above question is yes, enter the source of this ventilation air, i.e., a central system or openings in the exterior wall. The latter systems are sometimes referred to as unit or "through-the-wall" ventilators.

7 Condensate drain pan: Enter yes if the unit has a condensate drain pan and no if not.

8 Filters for secondary airflow: Enter yes if the units have filters for the secondary airflow induced from the room and no if not.

9 Fin-Tubed Radiators: Enter yes if the perimeter is conditioned by fin-tubed radiators.

10 Electric Baseboard: Enter yes if the perimeter is conditioned by electric baseboard heaters. 


\section{FORM C-3 Unitary Systems}

This form is used to describe unitary air conditioning equipment, which includes a range of systems consisting of factory-assembled components providing heating, cooling and outdoor air. Generally, each zone is served by a separate unit, unless the zone is very large.

System Type: Select the system type from one of the following options. The system type can sometimes be determined from the mechanical equipment specifications, but must be verified by inspection and may require discussion with the building operator.

1 Roof Top Units: Enter yes if the test space is conditioned by roof top units. These units are single package units consisting of unitary equipment, a ducted air distribution system and a temperature control system. They may serve single or multiple zones, and may be constant and variable air volume.

2 Number of Systems: Enter the number of roof top units that serve the test space.

3 Zoning: Enter single if the roof top units serve only a single thermostatically-controlled zone and multi if they serve multiple zones.

4 Constant or Variable Volume: Enter constant if the roof top units are constant air volume systems and variable if they are variable air volume.

5 Through-the-Wall Conditioner System: Enter yes if the test space is conditioned by through-the-wall conditioner systems. These self-contained systems are designed to heat and cool individual rooms and are mounted through the wall. Each unit contains an air-cooled refrigeration system, a heating coil (optional), a fan and the necessary controls. Ventilation air may be supplied by a central system to the individual units within the building through a system of ductwork, or the individual units may provide ventilation air. A window air conditioner would fall under this category.

6 Ventilation air: Enter yes if the through-the-wall system is connected to a source of ventilation air and no if not.

7 Ducted: Enter yes if the supply air is distributed through a system of ductwork and no if not.

8 Number of Systems: Enter the number of through-the-wall systems that serve the test space.

9 Heat Pump Systems: Enter yes if the test space is conditioned by heat pump systems. Unitary heat pump systems are factory assembled units with the capacity to heat and cool. A single system can be used to condition an entire building or several smaller units can be used for individual zones. Heat pumps types include air-to-air, water-toair, air-to-water and water-to-water. Ventilation air may be supplied by a central system to the individual units within the building through a system of ductwork, or the individual units may provide ventilation air.

10 Number of Systems: Enter the number of heat pump systems that serve the test space.

11 Ventilation air: Enter yes if the heat pump system is connected to a source of ventilation air and no if not.

12 Source of ventilation air: If the answer to the above question is yes, enter the source of this ventilation air, i.e., a central system or the unit itself. 


\section{EORM C-4 Evaporative Cooling Systems}

This form is used to describe evaporative cooling systems, if such a system is used to condition the test space. Evaporative cooling systems are non-refrigerant systems that cool air by exchanging sensible heat for latent heat, thereby reducing temperatures but raising humidity levels. The units operate with $100 \%$ outside air and constant air volume.

System Type: Select the system type from one of the following options. The system type can sometimes be determined from the mechanical equipment specifications, but must be verified by inspection and may require discussion with the building operator.

1 Direct evaporative air coolers: Enter yes if the system is a direct type in which heat in the incoming airstream evaporates water from a wetted element or an air spray.

2 Direct System Type: Enter the type of direct system, selecting from the following options.

Wetted-media air coolers: In these systems a fan pulls air through wetted pads and delivers the cooled air to the space. A pump lifts water from a reservoir, and the water flows down through the pads back to the sump.

Rigid-media air coolers: In these systems a fan moves air horizontally through wetted sheets of rigid, corrugated material. A pump lifts water from a reservoir, and the water flows down the media back to the sump.

Slinger packaged air coolers: In these systems a fan draws outdoor air through a water spray, an evaporative filter pad and an entrained-moisture eliminator pad. The spray is created by a motor-driven disk that is partially immersed in a water reservoir.

Packaged rotary air coolers: In these systems a fan pulls air through a pad that rotates through a water reservoir.

3 Indirect evaporative air coolers: Enter yes if the system is an indirect type in which a so-called secondary air stream of outdoor air or exhaust air is cooled through evaporation by direct wetting of the heat exchanger surface or a direct evaporative system. A fan forces this secondary air stream across one side of a heat exchanger. On the other side of the heat exchanger, the primary airstream (conditioned air being supplied to the space) is sensibly cooled by contact with the heat exchanger surfaces. The primary air may be recirculated room air, outdoor air, or a mixture. An indirect evaporative air cooler may either by self-contained with its own primary air supply fan assembly, or it may be part of a more complete packaged air-handling system perhaps providing precooling to a conventional refrigeration system. 


\section{EORM C-5 Outdoor Air Intake Control}

This form is used to describe the means of outdoor air intake control employed in the mechanical ventilation system serving the test space. The information on this form can sometimes be determined from the mechanical equipment specifications, but must be verified by inspection and discussion with the building operator. Only one copy of form C-5 is required for the test space.

Intake Strategy: Select one of the following options.

1 Conditioned positive: A separate fan is used to bring in the required amount of outdoor air. This air is filtered and possibly dehumidified and heated or cooled prior to being delivered to the air handler.

2 Unconditioned positive: A separate fan is used to bring in the required amount of outdoor air, but this air is not treated prior to being delivered to the air handler.

3 Unconditioned suction: Outdoor air is brought into the building through a separate duct by the suction induced by the supply fan. This air is not treated prior to being delivered to the air handler.

4 Unconditioned suction with no duct: Untreated outdoor air intake is induced by the supply fan suction, directly into the air handling unit.

Intake Control Strategy: For the air handler serving the test space, determine the control scheme used to determine the rate of outdoor air intake. Select one of the following options.

$5100 \%$ outdoor air intake: The air handler provides $100 \%$ outdoor air at all times, with no recirculation of return air.

6 Fixed minimum outdoor air intake: The rate of outdoor air intake is constant whenever the air handler is operating. The supply air consists of constant proportions of outdoor air and recirculated return air.

7 Economizer cycle: If the outdoor air temperature is above a low temperature setpoint, the return, relief and outdoor air intake dampers modulate to maintain the mixed air temperature at its setpoint. When the outdoor air temperature is below this setpoint, the outdoor air intake is at a minimum. When the outdoor air temperature is above a high temperature limit, the outdoor air intake is reduced to a minimum level.

8 Enthalpy economizer cycle: If the outdoor air enthalpy is above a low enthalpy setpoint, the return, relief and outdoor air intake dampers modulate to maintain the mixed air temperature at its setpoint. When the outdoor air enthalpy is below this setpoint, the outdoor air intake is at a minimum. When the outdoor air enthalpy is above a high enthalpy limit, the outdoor air intake is reduced to a minimum level. 
Means of maintaining minimum outdoor air intake: Select one of the following means for maintaining the outdoor air intake under minimum conditions.

9 Fixed damper positions: The intake and recirculation dampers are fixed, and the pressure in the mixed air plenum determines the outdoor air intake rate.

10 Supply/return fan tracking: Based on the difference between the supply and return fan airflow rates, the outdoor air intake dampers position is modulated to provide constant outdoor air intake rate.

11 Intake airflow monitoring: The outdoor air intake rate is monitored with an airflow station, and the control system modulates the outdoor air intake dampers based on the measured airflow rate as compared to a setpoint.

There are three additional outdoor air intake control cycles of interest. Note whether the control system has provisions for the following cycles:

12 Morning warm-up cycle: During unoccupied hours, the system operates with no outdoor air intake to warm-up the building prior to occupancy.

13 Morning purge cycle: Prior to occupancy, the system operates at a high level of outdoor air intake to purge the building of any contaminants that may have built up over the night.

14 Night cool-down cycle: Under appropriate outdoor air temperature and humidity conditions, the system is run at $100 \%$ outdoor air intake in order to cool the building prior to occupancy.

\section{FORM C-6 Natural Ventilation Systems}

This form is used to describe the ventilation strategy employed in naturally ventilated buildings. Natural ventilation systems operate without external power, employing pressure differences caused by wind and temperature differences to induce airflow through the building. A building with a natural ventilation system may still have powered exhaust systems serving toilets and other areas. Information on the natural ventilation system can sometimes be determined from the mechanical equipment specifications, but must be verified by inspection and may require discussion with the building operator. Only one copy of form C-6 is required for the building, and only if it is naturally ventilated.

Select which of the following natural ventilation systems exist in the building and answer the system specific questions.

1 Operable Windows: Enter yes if the building is ventilated by airflow through operable windows and no if it is not.

2 Through-the-Wall Vents: Enter yes if the building is ventilated by airflow through openings in the exterior wall and no if it is not. 
3 Number of openings: Enter the number of ventilation openings in the exterior walls of the test space.

4 Size of openings: Enter the size of the ventilation openings in the exterior walls of the test space.

Designate the units, either $\mathrm{cm}^{2}$ or in 2 .

5 Central Shaft: Enter yes if the the building is ventilated through a central shaft that connects to the floors and carries air to the roof of the building.

6 Exhaust System: Enter yes if the building also has mechanical exhaust systems and no if it does not.

7 Area Served by Exhaust System: If the building has mechanical exhaust systems, describe the areas which they serve. Entering the building floors and the areas on the floor (e.g., toilets) is sufficient.

\section{FORM C-7A Air Handler Specifications}

This form is used to record the design specifications of the air handler(s) serving the test space. Information on the air handler is generally found in the mechanical equipment specifications, if they are available. The current accuracy of these specifications must be verified by discussions with the building operator, in which the existence of updated information is specifically investigated. One copy of form C-7A is required for each air handler serving the test space.

1 Air Handler Number: Enter the air handler number used in the building mechanical plans.

2 Location of Air Handler: Enter the location of the air handler, using a room number from the building plans if available. If no room number is available, enter the floor and location on the floor.

3 Design Supply Airflow Rate Capacity: Enter the design supply airflow rate capacity for the air handler.

Designate the units, either $\mathrm{m}^{3 / \mathrm{s}}$ or $\mathrm{cfm}$.

4 Source of Value: Enter the source of the value in entry \#3. If it is obtained from the building plans, enter the drawing number and the date on the drawing. If it is obtained from the building operator, enter the name and title of the individual.

5 Design Minimum Outdoor Air Intake Rate: Enter the minimum outdoor air intake rate for the air handler.

Designate the units, either $\mathrm{m}^{3 / \mathrm{s}}$ or $\mathrm{cfm}$.

6 Source of Value: Enter the source of the value in entry \#5. If it is obtained from the building plans, enter the drawing number and the date on the drawing. If it is obtained from the building operator, enter the name and title of the individual. 
7 Space Served by Air Handler: Describe the portion of the building that is served by the air handler. Enter the floors, and for each floor, describe the side of the floor served or use column numbers.

8 Source of Value: Enter the source of the value in entry \#7. If it is obtained from the building plans, enter the drawing number and the date on the drawing. If it is obtained from the building operator, enter the name and title of the individual.

9 Floor Area Served by the Air Handler: Enter the floor area served by the air handler. Designate the units, either $\mathrm{m}^{2}$ or $\mathrm{ft}^{2}$.

10 Source of Value: Enter the source of the value in entry \#9. If it is obtained from the building plans, enter the drawing number and the date on the drawing. If it is obtained from the building operator, enter the name and title of the individual.

11 Number of Occupants Served by the Air Handler: Enter the number of occupants in the space served by the air handler. This value will rarely be found in the building plans, and should be obtained from the building manager.

12 Source of Value: Enter the source of the value in entry \#11. If it is obtained from the building plans, enter the drawing number and the date on the drawing. If it is obtained from the building manager or operator, enter the name and title of the individual.

13 Design Cooling Load: Enter the design cooling load for the space served by the air handler, if available.

Designate the units, either $W / \mathrm{m}^{2}$ or $W / \mathrm{ft}^{2}$.

14 Source of Value: Enter the source of the value in entry \#13. If it is obtained from the building plans, enter the drawing number and the date on the drawing. If it is obtained from the building operator, enter the name and title of the individual.

15 Existence of Return Fan: Enter yes if the air handler has a return fan and no if not. This can generally be determined by the building plans and should be verified by inspection.

16 Return Fan Capacity: If the air handler has a return fan, enter the design return fan airflow rate.

Designate the units, either $\mathrm{m} 3 / \mathrm{s}$ or $\mathrm{cfm}$.

17 Source of Value: Enter the source of the value in entry \#16. If it is obtained from the building plans, enter the drawing number and the date on the drawing. If it is obtained from the building operator, enter the name and title of the individual.

18 Space Served by Return System: Describe the portion of the building that is served by the return side of the air handler, even if there is no return fan. Enter the floors, and for each floor, describe the side of the floor served or use column numbers.

19 Source of Value: Enter the source of the value in entry \#18. If it is obtained from the building plans, enter the drawing number and the date on the drawing. If it is obtained from the building operator, enter the name and title of the individual. 
20 Floor Area Served by the Return System: Enter the floor area served by the return side of the air handler, even if there is no return fan.

Designate the units, either $\mathbf{m}^{2}$ or $\mathrm{ft}^{2}$.

21 Source of Value: Enter the source of the value in entry \#20. If it is obtained from the building plans, enter the drawing number and the date on the drawing. If it is obtained from the building operator, enter the name and title of the individual.

\section{EORM C-7B Exhaust Fan Specifications}

This form is used to record the design specifications of the exhaust fan(s) serving the test space. Information on the exhaust fans is generally found in the mechanical equipment specifications, if they are available. The current accuracy of these specifications must be verified by discussions with the building operator, in which the existence of updated information is specifically investigated. One copy of form $\mathrm{C}-7 \mathrm{~B}$ is required for each exhaust fan serving the test space.

1 Exhaust Fan Number: Enter the exhaust fan number used in the building mechanical plans.

2 Location of Exhaust Fan: Enter the location of the exhaust fan, using a room number from the building plans if available. If no room number is available, enter the floor and location on the floor.

3 Design Exhaust Airflow Rate: Enter the design airflow rate for the exhaust fan. Designate the units, either $\mathrm{m}^{3} / \mathrm{s}$ or $\mathrm{cfm}$.

4 Source of Value: Enter the source of the value in entry \#3. If it is obtained from the building plans, enter the drawing number and the date on the drawing. If it is obtained from the building operator, enter the name and title of the individual.

5 Space Served by Exhaust Fan: Describe the portion of the building that is served by the exhaust fan. Enter the floors, and for each floor, describe the side of the floor served or use column numbers.

6 Source of Value: Enter the source of the value in entry \#5. If it is obtained from the building plans, enter the drawing number and the date on the drawing. If it is obtained from the building operator, enter the name and title of the individual.

7 Floor Area Served by the Exhaust Fan: Enter the floor area served by the exhaust fan. Designate the units, either $\mathrm{m}^{2}$ or $\mathrm{ft}^{2}$.

8 Source of Value: Enter the source of the value in entry \#7. If it is obtained from the building plans, enter the drawing number and the date on the drawing. If it is obtained from the building operator, enter the name and title of the individual. 
Controls: Check the entry which describes the manner in which the operation of the exhaust fan is controlled.

9 Manual: Enter yes if the exhaust fan operation is controlled manually with an on/off switch.

10 Time of Day: Enter yes if the exhaust fan operation is controlled automatically based on the time of day.

11 Temperature: Enter yes if the exhaust fan operation is controlled automatically based on temperature.

12 Equipment Operation: Enter yes if the exhaust fan operation is controlled automatically based on the operation of a piece of equipment.

\section{FORM C-8 Filtration and Air Cleaning Systems}

This form is used to record information regarding filtration and air cleaning systems used in the air handlers serving the test space. Information on these systems is generally found in the mechanical equipment specifications, if they are available. The current accuracy of these specifications must be verified by inspection of the systems and discussion with the building operator. One copy of form C-8 is required for each filtration and air cleaning system. Therefore, more than one copy of the form may be needed for a given air handler, for example if the air handler has a prefilter and a HEPA filter.

1 Air Handler Number: Enter the air handler number used in the building mechanical plans in which the filtration or air cleaning system is installed.

2 Location within Air Handler: Enter the location of the filtration or air cleaning system within the air handler. Appropriate entries include recirculation air, outdoor air, mixed air upstream of coils, mixed air downstream of coils, and supply air downstream of fan.

3 Filter, Electronic Air Cleaner or Gaseous Air Cleaner: Enter the type of system being described in the form.

Air Filtration Systems: If the form is being used to describe an air filtration system, complete entries \#4 through \#11.

4 Manufacturer: Enter the manufacturer of the filter.

5 Model Number: Enter the manufacturer's model number for the filter. 
System Type: Provide information on the type of air filtration system as indicated. This information may be in the mechanical system plans, but it must be verified by an inspection of the air handler.

6 Panel or Roll Filter: Enter panel if the system employs a fibrous media unit or panel filter consisting of replaceable filter units. Enter roll if the system employs a renewable media or roll filter in which fresh media is introduced into the airstream as needed.

7 Panel Filter Type: Enter whether the filter is a viscous impingement filter or a dry filter. Viscous filters consist of a coarse media of high porosity that is treated with a viscous substance such as an oil to which particles adhere when they impinge on the filter. Dry filters are made of random filter mats or blankets. If the system employs a dry filter, enter the dry filter type: flat panel, pleated, bag or HEPA.

8 Roll Filter Type: Enter whether the roll filter is a viscous impingement filter or a dry filter. Also enter whether the mechanism to introduce new media into the airstream is manual or automated.

9 Size: Enter the dimensions of the filter bank. Designate the units, either $\mathrm{m}$ or $\mathrm{ft}$.

10 Filter Media: Enter the type of media employed in the filter.

11 Rating: Enter the rating of the filter as determined from the manufacturer's specifications. Specify the rating as the synthetic dust weight arrestance, the atmospheric dust spot efficiency or the dust holding capacity as determined according to ASHRAE Standard 52-76, or the DOP efficiency of HEPA filters as determined according to U.S. Military Standard, MIL-STD-282.

Electronic Air Cleaners: If the form is being used to describe an electronic air cleaner, complete entries \#12 through \#15.

12 Manufacturer: Enter the manufacturer of the electronic air cleaner.

13 Model Number: Enter the manufacturer's model number for the air cleaner.

14 Size: Enter the dimensions of the air cleaner.

Designate the units, either $\mathrm{m}$ or $\mathrm{ft}$.

15 Automatic Wash System: Enter yes if the air cleaner has an automatic wash system and no if not.

Gaseous Air Cleaners: If the form is being used to describe a gaseous air cleaner, complete entries \#16 through \#20.

16 Manufacturer: Enter the manufacturer of the gaseous air cleaner.

17 Model Number: Enter the manufacturer's model number for the air cleaner. 
18 Size: Enter the dimensions of the air cleaner.

Designate the units, either $\mathrm{m}$ or $\mathrm{ft}$.

19 Depth: Enter the depth of the media bed.

Designate the units, either $\mathrm{m}$ or $\mathrm{ft}$.

20 Absorbent Media: Enter the media utilized in the air cleaner.

\section{EORM C-9 Air Washers}

This form is used to record information on air washer systems used in the air handlers serving the test space, if such systems exist. Information on these systems is generally found in the mechanical equipment specifications, if they are available. The current accuracy of these specifications must be verified by inspection of the systems and discussion with the building operator. One copy of form C-9 is required for each air handler serving the test space which contains an air washer.

1 Air Handler Number: Enter the air handler number in which the air washer is installed.

2 System Type: Enter whether the air washer is a high-velocity spray type or a cell type system. In a high-velocity spray, water is pumped to a series of spray nozzles that discharge a finely atomized spray of water into the airstream. In cell type systems, air is passed through a tiered arrangement of cells packed with glass, metal or fiber screens. Water is pumped to the top of this tier and flows down over the cells, providing contact between the water and air.

\section{FORM C-10 Humidification Systems}

This form is used to record information on humidification systems used in the air handlers serving the test space, if such systems exist. Information on these systems is generally found in the mechanical equipment specifications, if they are available. The current accuracy of these specifications must be verified by inspection of the systems and discussion with the building operator. One copy of form C-10 is required for each air handler serving the test space which contains a humidification system.

1 Air Handler Number. Enter the air handler number in which the humidification system is installed.

2 System Type: Enter the type of humidification system, selecting from the following options.

Heated Pan: A heated pan of water is exposed to the air duct, and water evaporates directly into the airstream.

Steam Type, Enclosed Steam Grid: A steam pipe passes through an enclosure within the air duct and releases steam into this enclosure. Condensate is drained from the enclosure, and dry steam is released into the airstream. 
Steam Type, Cup or Pot-Type: Steam is fed into a cup attached under an air duct. Condensate drains from the cup, and steam is released into the airstream.

Steam Type, Jacketed Dry-steam: Steam is supplied to a perforated tube after passing through a condensate separator. This perforated discharge tube is located within a jacket fed by the steam before it passes through the separator. The perforations face into the airstream.

Steam Type, Self-contained: Tap water is converted into steam by electrical energy, and the steam is injected directly into the airstream.

Atomizing: A high speed disk slings water through a fine comb to create a mist that is introduced directly into the airstream, where it evaporates.

Wetted element: Air is circulated over or through a wetted element, and water evaporates into the airstream.

3 Water Softening System: Enter yes if a water softening system is used to reduce scaling of system components and no if not.

4 Demineralizer: Enter yes if a water demineralizing system is used to reduce hardness and remove dissolved solids from the makeup water and no if not.

\section{EORM C-11 Maintenance}

This form is used to record information regarding HVAC system maintenance procedures and schedules. This information should be obtained through discussion with the building manager and operator. One copy of form C-11 is required for the building.

Air Handler Inspections

1 Regularly Scheduled: Enter yes if there are regularly scheduled inspections of the air handling systems, including the air intakes, dampers, damper controls, filters, fans, fan belts, and fan housings. Enter no if this equipment is not regularly inspected.

2 Recorded in Logbook: Enter yes if the air handler inspections are recorded in a logbook, whether or not they are scheduled. Enter no if these inspections are not recorded in a logbook.

3 Frequency: Enter the frequency of these inspections. The frequency should be entered in times per year or months between inspections. If there are no regularly scheduled inspections, leave this entry blank. 
Particulate Filtration Systems

Panel Filter Replacement

4 Regularly Scheduled: Enter yes if there is a regular schedule for filter replacement, and enter no if not.

5 Recorded in Logbook: Enter yes if filter replacement is recorded in a logbook, whether or not it is scheduled. Enter no if the replacement is not recorded in a logbook.

6 Frequency: Enter the frequency of panel filter replacement. The frequency should be entered in times per year or months between replacement. If there is no regular schedule for filter replacement, leave this entry blank.

Manual Roll Filter Advancement

7 Regularly Scheduled: Enter yes if there is a regular schedule for roll filter advancement, and enter no if not.

8 Recorded in Logbook: Enter yes if filter advancement is recorded in a logbook, whether or not it is scheduled. Enter no if the advancement is not recorded in a logbook.

9 Frequency: Enter the frequency of filter advancement. The frequency should be entered in times per year or months between advancements. If there is no regular schedule for filter advancement, leave this entry blank.

Automatic Roll Filter Inspection

10 Regularly Scheduled: Enter yes if there is a regular schedule for inspection of the advancement mechanism for automatic roll filters, and enter no if not.

11 Recorded in Logbook: Enter yes if inspection is recorded in a logbook, whether or not it is scheduled. Enter no if the inspection is not recorded in a logbook.

12 Frequency: Enter the frequency of advancement mechanism inspection. The frequency should be entered in times per year or months between inspections. If there is no regular schedule for inspection, leave this entry blank.

Electronic air cleaners

Inspection

13 Regularly Scheduled: Enter yes if there is a regular schedule for inspection of the electronic air cleaners, and enter no if not.

14 Recorded in Logbook: Enter yes if the inspection is recorded in a logbook, whether or not it is scheduled. Enter no if the inspection is not recorded in a logbook.

15 Frequency: Enter the frequency of air cleaner inspection. The frequency should be entered in times per year or months between inspections. If there is no regular schedule for inspection, leave this entry blank. 


\section{Cleaning}

16 Regularly Scheduled: Enter yes if there is a regular schedule for cleaning the electronic air cleaners, and enter no if not.

17 Recorded in Logbook: Enter yes if cleaning is recorded in a logbook, whether or not it is scheduled. Enter no if the cleaning is not recorded in a logbook.

18 Frequency: Enter the frequency of air cleaner cleaning. The frequency should be entered in times per year or months between cleanings. If there is no regular schedule for cleaning, leave this entry blank.

Heating and Cooling Coils

Inspection

19 Regularly Scheduled: Enter yes if there is a regular schedule for inspection of the heating and cooling coils, and enter no if not.

20 Recorded in Logbook: Enter yes if the inspection is recorded in a logbook, whether or not it is scheduled. Enter no if the inspection is not recorded in a logbook.

21 Frequency: Enter the frequency of coil inspection. The frequency should be entered in times per year or months between inspections. If there is no regular schedule for inspection, leave this entry blank.

Cleaning

22 Regularly Scheduled: Enter yes if there is a regular schedule for cleaning the heating and cooling coils, and enter no if not.

23 Recorded in Logbook: Enter yes if cleaning is recorded in a logbook, whether or not it is scheduled. Enter no if the cleaning is not recorded in a logbook.

24 Frequency: Enter the frequency of coil cleaning. The frequency should be entered in times per year or months between cleanings. If there is no regular schedule for cleaning, leave this entry blank.

\section{Drain Pans}

Inspection

25 Regularly Scheduled: Enter yes if there is a regular schedule for inspection of the drain pans in the air handlers, and enter no if not.

26 Recorded in Logbook: Enter yes if the inspection is recorded in a logbook, whether or not it is scheduled. Enter no if the inspection is not recorded in a logbook.

27 Frequency: Enter the frequency of drain pan inspection. The frequency should be entered in times per year or months between inspections. If there is no regular schedule for inspection, leave this entry blank. 


\section{Cleaning}

28 Regularly Scheduled: Enter yes if there is a regular schedule for cleaning the drain pans in the air handlers, and enter no if not.

29 Recorded in Logbook: Enter yes if cleaning is recorded in a logbook, whether or not it is scheduled. Enter no if the cleaning is not recorded in a logbook.

30 Frequency: Enter the frequency of drain pan cleaning. The frequency should be entered in times per year or months between cleanings. If there is no regular schedule for cleaning, leave this entry blank.

Air Distribution Ductwork

Inspection

31 Regularly Scheduled: Enter yes if there is a regular schedule for inspection of the air distribution ductwork, and enter no if not.

32 Recorded in Logbook: Enter yes if the inspection is recorded in a logbook, whether or not it is scheduled. Enter no if the inspection is not recorded in a logbook.

33 Frequency: Enter the frequency of ductwork inspection. The frequency should be entered in times per year or months between inspections. If there is no regular schedule for inspection, leave this entry blank.

Cleaning

34 Regularly Scheduled: Enter yes if there is a regular schedule for cleaning the air distribution ductwork, and enter no if not.

35 Frequency: Enter the frequency of ductwork cleaning. The frequency should be entered in times per year or months between cleanings. If there is no regular schedule for cleaning, leave this entry blank.

\section{Humidifiers}

Inspection

36 Regularly Scheduled: Enter yes if there is a regular schedule for inspection of humidifiers in the air handlers, and enter no if not.

37 Recorded in Logbook: Enter yes if the inspection is recorded in a logbook, whether or not it is scheduled. Enter no if the inspection is not recorded in a logbook.

38 Frequency: Enter the frequency of humidifier inspection. The frequency should be entered in times per year or months between inspections. If there is no regular schedule for inspection, leave this entry blank. 


\section{Cleaning}

39 Regularly Scheduled: Enter yes if there is a regular schedule for cleaning the humidifiers in the air handlers, and enter no if not.

40 Recorded in Logbook: Enter yes if cleaning is recorded in a logbook, whether or not it is scheduled. Enter no if the cleaning is not recorded in a logbook.

41 Frequency: Enter the frequency of humidifier cleaning. The frequency should be entered in times per year or months between cleanings. If there is no regular schedule for cleaning, leave this entry blank.

42 Purge or Blowdown: Enter yes if there is a regular schedule for purging or blowing down the humidifiers. Enter no if not.

43 Purge Frequency: Enter the frequency of purging the humidifiers. The frequency should be entered in times per year or months between purgings. If there is no regularly scheduled purging, leave this entry blank.

44 Purge Duration: Enter the length of time of the purge cycle in hours.

45 Purge Control: Enter automatic if the purge cycle is done automatically or manual if it is initiated manually.

Evaporative coolers

Inspection

46 Regularly Scheduled: Enter yes if there is a regular schedule for inspection of evaporative coolers, and enter no if not.

47 Recorded in Logbook: Enter yes if the inspection is recorded in a logbook, whether or not it is scheduled. Enter no if the inspection is not recorded in a logbook.

48 Frequency: Enter the frequency of evaporative cooler inspection. The frequency should be entered in times per year or months between inspections. If there is no regular schedule for inspection, leave this entry blank.

Cleaning

49 Regularly Scheduled: Enter yes if there is a regular schedule for cleaning the evaporative coolers, and enter no if not.

50 Recorded in Logbook: Enter yes if cleaning is recorded in a logbook, whether or not it is scheduled. Enter no if the cleaning is not recorded in a logbook.

51 Frequency: Enter the frequency of evaporative cooler cleaning. The frequency should be entered in times per year or months between cleanings. If there is no regular schedule for cleaning, leave this entry blank.

52 System Bleeding Frequency: Enter the frequency of bleeding of the system to minimize scale accumulation. The frequency should be entered in times per year or months between bleedings. If there are no regularly system bleeding, leave this entry blank. 
53 Water Treatment: Enter yes if the water in the system is treated to keep dissolved solids in suspension. Enter no if not.

54 Water Treatment Frequency: Enter the frequency of application of water treatment to the system. The frequency should be entered in times per year or months between treatments. If there is no regular water treatment, leave this entry blank.

55 Water Treatment Compound: Enter the compound used in the water treatment.

56 Biocide Treatment: Enter yes if the water in the system is treated to control biological growth. Enter no if not.

57 Biocide Treatment Frequency: Enter the frequency of application of biocide to the system. The frequency should be entered in times per year or months between treatments. If there is no biocide treatment, leave this entry blank.

58 Biocide Treatment Compound: Enter the compound used in the biocide treatment.

Air washers

Inspection

59 Regularly Scheduled: Enter yes if there is a regular schedule for inspection of air washers, and enter no if not.

60 Recorded in Logbook: Enter yes if the inspection is recorded in a logbook, whether or not it is scheduled. Enter no if the inspection is not recorded in a logbook.

61 Frequency: Enter the frequency of air washer inspection. The frequency should be entered in times per year or months between inspections. If there is no regular schedule for inspection, leave this entry blank.

Cleaning

62 Regularly Scheduled: Enter yes if there is a regular schedule for cleaning the air washers, and enter no if not.

63 Recorded in Logbook: Enter yes if cleaning is recorded in a logbook, whether or not it is scheduled. Enter no if the cleaning is not recorded in a logbook.

64 Frequency: Enter the frequency of air washer cleaning. The frequency should be entered in times per year or months between cleanings. If there is no regular schedule for cleaning, leave this entry blank.

65 Tank Maintenance Frequency: Enter the frequency of draining and cleaning the air washer tanks. The frequency should be entered in times per year or months between drainings and cleanings. If there are no regularly scheduled cleaning, leave this entry blank.

66 Eliminator Repainting Frequency: Enter the frequency of repainting of the eliminators and baffles to prevent corrosion. The frequency should be entered in times per year or months between painting. If there is no regularly scheduled repainting, leave this entry blank. 
67 Glass Media Cleaning Frequency: Enter the frequency of cleaning of the glass media. The frequency should be entered in times per year or months between cleanings. If there is no regularly scheduled cleaning, leave this entry blank.

68 System Bleeding Frequency: Enter the frequency of bleeding of the system to minimize scale accumulation. The frequency should be entered in times per year or months between bleedings. If there is no regularly scheduled system bleeding, leave this entry blank.

69 Water Treatment: Enter yes if the water in the air washer system is treated to keep dissolved solids in suspension. Enter no if not.

70 Water Treatment Frequency: Enter the frequency of application of water treatment to the system. The frequency should be entered in times per year or months between treatments. If there is no regular water treatment, leave this entry blank.

71 Water Treatment Compound: Enter the compound used in the water treatment.

72 Biocide Treatment: Enter yes if the water in the air washer system is treated to control biological growth. Enter no if not.

73 Biocide Treatment Frequency: Enter the frequency of application of biocide to the system. The frequency should be entered in times per year or months between treatments. If there is no biocide treatment, leave this entry blank.

74 Biocide Treatment Compound: Enter the compound used in the biocide treatment.

\section{Control system}

Inspection

75 Regularly Scheduled: Enter yes if there is a regular schedule for inspection of the control system components, and enter no if not.

76 Recorded in Logbook: Enter yes if the inspection is recorded in a logbook, whether or not it is scheduled. Enter no if the inspection is not recorded in a logbook.

77 Frequency: Enter the frequency of control system inspection. The frequency should be entered in times per year or months between inspections. If there is no regular schedule for inspection, leave this entry blank.

Sensor Recalibration

78 Regularly Scheduled: Enter yes if there is a regular schedule for recalibrating the control system sensors, and enter no if not.

79 Recorded in Logbook: Enter yes if recalibration is recorded in a logbook, whether or not it is scheduled. Enter no if the recalibration is not recorded in a logbook.

80 Frequency: Enter the frequency of recalibration. The frequency should be entered in times per year or months between cleanings. If there is no regular schedule for recalibration, leave this entry blank. 
Testing and balancing

81 Regularly Scheduled: Enter yes if there is a regular schedule for testing and balancing the HVAC system, and enter no if not.

82 Frequency: Enter the frequency of testing and balancing. The frequency should be entered in times per year or months between testing and balancing efforts. If there is no regular schedule, leave this entry blank.

Cooling towers

Inspection

83 Regularly Scheduled: Enter yes if there is a regular schedule for inspection of the cooling towers, and enter no if not.

84 Recorded in Logbook: Enter yes if the inspection is recorded in a logbook, whether or not it is scheduled. Enter no if the inspection is not recorded in a logbook.

85 Frequency: Enter the frequency of cooling tower inspection. The frequency should be entered in times per year or months between inspections. If there is no regular schedule for inspection, leave this entry blank.

86 Surface Cleaning Frequency: Enter the frequency at which the system is drained and the wetted surface cleaned. The frequency should be entered in times per year or months between cleanings. If there is no regularly scheduled cleaning, leave this entry blank.

87 Scale Control Treatment: Enter yes if the scale control treatment is used in the cooling tower system, either blowdown or chemical treatment. Enter no if not.

88 Blowdown or Chemical Treatment: Enter blowdown if blowdown is used to control scaling or chemical if a chemical treatment is used.

89 Blowdown Frequency: Enter the frequency of system blowdown or chemical treatment. The frequency should be entered in times per year or months between blowdowns. If there is no regular schedule, leave this entry blank.

90 Scale Control Treatment Compound: Enter the compound used in the scale control treatment.

91 Corrosion Treatment: Enter yes if the water in the cooling tower system is treated to control corrosion. Enter no if not.

92 Corrosion Treatment Frequency: Enter the frequency of application of the corrosion treatment to the system. The frequency should be entered in times per year or months between treatments. If there is no corrosion treatment, leave this entry blank.

93 Corrosion Treatment Compound: Enter the compound used in the corrosion treatment.

94 Biocide Treatment: Enter yes if the water in the cooling tower system is treated to control biological growth. Enter no if not.

95 Biocide Treatment Frequency: Enter the frequency of application of biocide to the system. The frequency should be entered in times per year or months between treatments. If there is no biocide treatment, leave this entry blank. 
96 Biocide Treatment Compound: Enter the compound used in the biocide treatment.

97 Silt Treatment: Enter yes if the water in the cooling tower system is treated to control silt. Enter no if not.

98 Silt Treatment Frequency: Enter the frequency of application of biocide to the system. The frequency should be entered in times per year or months between treatments. If there is no silt treatment, leave this entry blank.

99 Silt Treatment Compound: Enter the compound used in the silt treatment.

Fan coil units

Inspection

100 Regularly Scheduled: Enter yes if there is a regular schedule for inspection of the fan coil units in the building, including the condensate drainage, valves, fans and coils. Enter no if not.

101 Recorded in Logbook: Enter yes if the inspection is recorded in a logbook, whether or not it is scheduled. Enter no if the inspection is not recorded in a logbook.

102 Frequency: Enter the frequency of fan coil unit inspection. The frequency should be entered in times per year or months between inspections. If there is no regular schedule for inspection, leave this entry blank.

Filter Replacement

103 Regularly Scheduled: Enter yes if there is a regular schedule for replacing the filters in the fan coil units, and enter no if not.

104 Recorded in Logbook: Enter yes if filter replacement is recorded in a logbook, whether or not it is scheduled. Enter no if the replacement is not recorded in a logbook.

105 Frequency: Enter the frequency of filter replacement. The frequency should be entered in times per year or months between replacement. If there is no regular schedule for replacement, leave this entry blank.

Terminal units

Inspection

106 Regularly Scheduled: Enter yes if there is a regular schedule for inspection of the terminal units in the building, and enter no if not.

107 Recorded in Logbook: Enter yes if the inspection is recorded in a logbook, whether or not it is scheduled. Enter no if the inspection is not recorded in a logbook.

108 Frequency: Enter the frequency of terminal unit inspection. The frequency should be entered in times per year or months between inspections. If there is no regular schedule for inspection, leave this entry blank. 


\section{FORM C-12 Inspection}

This form is used to record information obtained during the inspection of the HVAC system and its major components. Some of this information will be dependent on when the inspection is conducted and how the system is being operated at this time. One copy of form C-12 is required for the building.

Mechanical Room: These entries are intended to provide information on the state of the mechanical room containing the air handling equipment.

1 General condition: Enter 1, 2 or 3 based on the following descriptions.

1 Clean, no sign of water leakage

2 Fairly dusty, some evidence of water on floor

3 Very dirty, standing water on floor

2 Part of Return System: Enter yes if unducted return air flows through the mechanical room before being recirculated through the air handler. Enter no if not.

3 Used for Storage: Enter yes if the mechanical room is used for storage of chemicals or refuse. Enter no if not.

System Check-Out: These entries are intended to provide information on the operation of the air handling system.

Supply Fans

4 Operating: Enter yes if the supply fans serving the test space were operating at the time of the inspection. Enter no if not, and identify the fans that were not operating.

5 Correct Direction of Fan Rotation: Enter yes if the supply fans were rotating in the correct direction at the time of the inspection. Enter no if not, and identify the fans that were not rotating in the correct direction.

6 Correct Airflow Direction: Enter yes if air was flowing through the supply fans in the correct direction at the time of the inspection. Enter no if not, and identify the fans through which air was flowing in the wrong direction.

\section{Return Fans}

7 Operating: Enter yes if the return fans serving the test space were operating at the time of the inspection. Enter no if not, and identify the fans that were not operating.

8 Correct Direction of Fan Rotation: Enter yes if the return fan was rotating in the correct direction at the time of the inspection. Enter no if not, and identify the fans that were not rotating in the correct direction.

9 Correct Airflow Direction: Enter yes if air was flowing through the return fans in the correct direction at the time of the inspection. Enter no if not, and identify the fans through which air was flowing in the wrong direction. 


\section{Exhaust Fans}

10 Operating: Enter yes if the exhaust fans serving the test space were operating at the time of the inspection. Enter no if not, and identify the fans that were not operating.

11 Correct Direction of Fan Rotation: Enter yes if the exhaust fans were rotating in the correct direction at the time of the inspection. Enter no if not, and identify the fans that were not rotating in the correct direction.

12 Correct Airflow Direction: Enter yes if air was flowing through the exhaust fans in the correct direction at the time of the inspection. Enter no if not, and identify the fans through which air was flowing in the wrong direction.

Outdoor Air Intake

13 Correct Airflow Direction: Enter yes if outdoor air was flowing into the building through the air intake at the time of the inspection. Enter no if air was flowing out of the building through the intake.

14 Height: Enter the height above the ground of the outdoor air intake serving the test space. If the intake is on the roof, enter the height of the intake above the roof.

Designate the units, either $m$ or $\mathrm{ft}$.

Proximity to Pollutant Sources: For the following entries, enter yes if the source is located within $7.5 \mathrm{~m}(25 \mathrm{ft})$ of the outdoor air intake serving the test space.

15 Standing Water

16 Exhaust Vents

17 Sanitary Vents

18 Cooling Tower

19 Loading Dock

20 Parking Garage

21 Vehicle Traffic

22 Trash Dumpster 


\section{Air Handler Housing}

23 General condition: Enter 1, 2 or 3 based on the following descriptions.

1 Clean, metal panels securely in place

2 Fairly dusty, some gaps at seams

3 Very dirty, many gaps at seams, metal panels loose

24 Sound liner: Enter 1, 2 or 3 based on the following descriptions.

1 Clean, dry, securely in place

2 Moist in places, loose in some spots

3 Very dirty, moist and separating from panels at many locations

Air Handler Components

25 General condition: Enter 1, 2 or 3 based on the following descriptions.

1 Clean and dry, components in place and operational

2 Some dust and moisture, some components not securely in place

3 Very dirty, significant moisture, some components out of position or not operational

26 Intakes: Enter 1, 2 or 3 based on the following descriptions.

1 Clean insect screen, no debris inside plenum, linkages in good condition, minimum dampers open

2 Insect screen needs cleaning, some debris inside plenum, linkages need maintenance

3 Insect screen partially blocked, much debris inside plenum, linkages broken or in very bad condition, minimum dampers closed

27 Dampers: Enter 1, 2 or 3 based on the following descriptions.

1 Linkages in good condition, dampers in correct positions, closed dampers fully closed and not excessively leaky, open dampers properly positioned

2 Linkages need maintenance, small deviations from correct positions, closed dampers leaking

3 Linkages broken or in very bad condition, dampers not in correct positions

28 Coils: Enter 1, 2 or 3 based on the following descriptions.

1 Coils clean

2 Coils somewhat dirty

3 Coils very dirty

29 Drain pans: Enter 1, 2 or 3 based on the following descriptions.

1 Drain pans clean and draining well

2 Some residue in pans but still draining

3 Drain pans very dirty, poor drainage from pans 
30 Fan belts: Enter 1, 2 or 3 based on the following descriptions.

1 Belts in good condition

2 Belts somewhat worn, will need replacement soon

3 Belts fraying or broken, need immediate replacement

Air Distribution Ductwork: The inspection should include examination of the exterior of the ductwork within the mechanical room as well as of the interior ductwork that is accessible from all access panels.

31 General condition: Enter 1, 2 or 3 based on the following descriptions.

1 Clean and dry, securely in place, well labeled

2 Some dust and moisture, some ducts not securely in place

3 Very dirty, significant moisture, some ducts poorly secured

32 Leakage at seams: Enter 1, 2 or 3 based on the following descriptions.

1 No or only minimal leakage

2 Small leaks at only some of the locations

3 Large leaks at many locations

33 Liners: Enter 1,2 or 3 based on the following descriptions.

1 Clean, dry, securely in place

2 Moist in places, loose in some spots

3 Very dirty, moist and very loose at many locations

Exhaust Fans: The following items concern the condition of all the exhaust fans serving the test space. These fans may be located in the mechanical room and elsewhere.

34 General condition: Enter 1, 2 or 3 based on the following descriptions.

1 Clean and dry, operational

2 Some dust and moisture, some ducts not securely in place

3 Very dirty, significant moisture, some ducts poorly secured

35 Fan belts: Enter 1, 2 or 3 based on the following descriptions.

1 Belts in good condition

2 Belts somewhat worn, will need replacement soon

3 Belts fraying or broken, need immediate replacement

Particulate Filtration Systems: The following items concern the particulate filtration systems within the air handler, as opposed to desktop air cleaners within the occupied space.

36 General condition: Enter 1, 2 or 3 based on the following descriptions.

1 Filters and frames in good physical condition, securely in position

2 Filters somewhat old, some filters not securely in place

3 Filters very old and deteriorating, some filters out of position, frames in very bad shape 
37 Accessibility: Enter 1, 2 or 3 based on the following descriptions.

1 Large access doors providing access to both sides of filters, adequate space for inspecting and changing filters

2 Small access doors, very limited space for inspecting and changing filters

3 No access doors, no means of inspecting or changing filters

38 Filter Fit into Frames: Enter 1, 2 or 3 based on the following descriptions.

1 Filters fit very well into frames, minimal leakage around filters

2 Filters fit marginally well into frames, some bypass around filters

3 Filters fit poorly into frames, large amounts of bypass around filters

39 Condition: Enter 1, 2 or 3 based on the following descriptions.

1 Filters in very good physical condition, recently changed or no need to change anytime soon

2 Filters somewhat old, will need to be changed soon

3 Filters very dirty, need to be changed immediately

40 Evenness of Loading: Enter 1, 2 or 3 based on the following descriptions.

1 Filter loading very even across the face

2 Some unevenness in loading

3 Filter loading very uneven, some areas heavily loaded while others are like new

41 Indicator of Resistance: Enter yes if the system contains an indicator for the resistance across the filter bank, generally a differential pressure gauge.

42 Time to Change Label: Enter yes if the resistance indicator shows when the filter should be changed.

43 Pressure Indicator Reading: If the system contains a differential pressure indicator across the filter bank, enter the reading of the pressure gauge.

Designate the units, either $\mathbf{P a}$ or in. wg.

Humidifiers: The following items concern any humidification systems within the air handler, as opposed to any local devices within the occupied space.

44 General Condition: Enter 1, 2 or 3 based on the following descriptions. Inspect water lines and any pumps, pump filters and fans.

1 Components clean and in good physical condition, no corrosion

2 Components somewhat dirty, some corrosion, some water leakage

3 Components very dirty, heavily corrosion, large water leaks, some components not held securely in position

45 Drain Pans: Enter 1, 2 or 3 based on the following descriptions.

1 Drain pans clean and draining well

2 Some residue in pans but still draining

3 Drain pans very dirty, poor drainage from pans 


\section{Evaporative Coolers}

46 General Condition: Enter 1, 2 or 3 based on the following descriptions. Inspect water lines, pumps, pump filters and fans.

1 Components clean and in good physical condition

2 Components somewhat dirty, some water leakage

3 Components very dirty, large water leaks, some components not held securely in position

47 Water Pans: Enter 1, 2 or 3 based on the following descriptions.

1 Pans very clean

2 Some residue in pans

3 Drain pans very dirty, no evidence of ever having been cleaned

48 Water Clarity: Enter 1, 2 or 3 based on the following descriptions.

1 Water very clear

2 Water somewhat dirty, can see bottom of pan

3 Water very dirty, can't see bottom of pan

Air Washers

49 General Condition: Enter 1, 2 or 3 based on the following descriptions. Inspect water lines, pumps, nozzles, pump filters and fans.

1 Components clean and in good physical condition, all nozzles working, uniform coil coverage

2 Components somewhat dirty, some water leakage, moderately uniform coil coverage

3 Components very dirty, large water leaks, some components not held securely in position, many nozzles clogged, coil coverage very nonuniform

50 Water Pans: Enter 1, 2 or 3 based on the following descriptions.

1 Pans very clean

2 Some residue in pans

3 Drain pans very dirty, no evidence of ever having been cleaned

51 Water Clarity: Enter 1, 2 or 3 based on the following descriptions.

1 Water very clear

2 Water somewhat dirty, can see bottom of pan

3 Water very dirty, can't see bottom of pan

52 Eliminators and Baffles: Enter 1, 2 or 3 based on the following descriptions.

1 Very clean, no corrosion

2 Somewhat dirty, some corrosion

3 Very dirty, heavily corroded, some out of position or loose 
Control System

53 General Condition: Enter 1, 2 or 3 based on the following descriptions.

1 Components clean and in good physical condition

2 Components somewhat dirty, some electrical and/or pneumatic connections loose

3 Components very dirty, some electrical and/or pneumatic connections disconnected.

54 Sensors: Enter 1, 2 or 3 based on the following descriptions.

1 Sensors clean and securely in place

2 Sensors somewhat dirty, some sensor connections loose

3 Sensors very dirty, some sensors out of position

Cooling Tower

55 General condition: Enter 1, 2 or 3 based on the following descriptions. or 3

1 Components clean and in good physical condition

2 Components somewhat dirty, some deterioration evident

3 Components very dirty, some components seriously deteriorated

56 Surfaces: Enter 1, 2 or 3 based on the following descriptions.

1 Surfaces clean and in good physical condition, free of scaling

2 Surfaces somewhat dirty, some deterioration evident

3 Surfaces very dirty, heavy scaling, serious deterioration evident

57 Water Condition: Enter 1, 2 or 3 based on the following descriptions.

1 Water very clear

2 Water somewhat dirty

3 Water very dirty

Fan Coil Units: The following items concern fan coil units located within the occupied space. All of the fan coil units within the test space should be inspected.

58 General condition: Enter 1, 2 or 3 based on the following descriptions.

1 Components clean and in good physical condition

2 Components somewhat dirty, some deterioration evident

3 Components very dirty, some components seriously deteriorated

59 Valves: Enter 1, 2 or 3 based on the following descriptions.

1 Valves clean and in good working order

2 Valves somewhat dirty, some deterioration evident

3 Valves very dirty, seriously deterioration evident

60 Fans: Enter 1, 2 or 3 based on the following descriptions.

1 Fans clean and in good working order

2 Fans somewhat dirty, some rust or other deterioration evident

3 Fans very dirty, rust and other serious deterioration evident 
61 Coils: Enter 1, 2 or 3 based on the following descriptions.

1 Coils clean and in good physical condition

2 Coils somewhat dirty, some deterioration evident

3 Coils very dirty, serious deterioration evident

62 Drain Pans: Enter 1, 2 or 3 based on the following descriptions.

1 Drain pans clean and draining well

2 Some residue in pans but still draining

3 Drain pans very dirty, poor or no drainage from pans

63 Air Filters: Enter 1, 2 or 3 based on the following descriptions.

1 Filters clean or recently changed, securely in position

2 Filters somewhat dirty, will need changing soon

3 Filters very dirty, need to be changed immediately, some filters out of position

Terminal Units: The following items concern terminal boxes located within the occupied space. All of the terminal boxes within the test space should be inspected.

64 General Condition: Enter 1, 2 or 3 based on the following descriptions.

1 Components clean and in good physical condition

2 Components somewhat dirty, some deterioration evident

3 Components very dirty, some components seriously deteriorated

65 Dampers: Enter 1, 2 or 3 based on the following descriptions.

1 Dampers clean, linkages in good condition

2 Dampers somewhat dirty, some deterioration of linkages evident

3 Dampers very dirty, linkages seriously deteriorated, dampers unable to modulate 


\section{FORM C-1: CENTRAL AIR HANDLING AND DISTRIBUTION SYSTEM}

One form is required for each central air handling system serving the test space.

1 Air Handler Number:

2 Air Handler Location:

3 System Type:

Qther System Information

4 Number of zones served by the air handler:

5 Return air Fan: $\mathrm{Y} / \mathrm{N}$

6 Variable supply air temperature setpoint: $\mathrm{Y} / \mathrm{N}$ 


\section{FORM C-2: PERIMETER ZONE UNITS}

This form is used to describe the systems that provide space conditioning to perimeter zones. These systems are intended solely for perimeter applications, as opposed to central systems that also serve exterior zones. Only one copy of Form C-2 is required for the test space.

System Type: Select one of the following systems and answer the system specific questions.

1 Air-Water Induction Units: $\mathrm{Y} / \mathrm{N}$

2 Condensate Drain Pan: $\mathrm{Y} / \mathrm{N}$

3 Filters for Secondary Airflow: $\mathrm{Y} / \mathrm{N}$

4 Fan-Coil Units: $\mathrm{Y} / \mathrm{N}$

5 Ventilation Air: $\mathrm{Y} / \mathrm{N}$ Source of Ventilation Air:

7 Condensate Drain Pan: $\mathrm{Y} / \mathrm{N}$

8 Filters for Secondary Airflow: $\mathrm{Y} / \mathrm{N}$

9 Fin-Tubed Radiator: $\mathrm{Y} / \mathrm{N}$

10 Electric Baseboard: $\mathrm{Y} / \mathrm{N}$ 


\section{FORM C-3: UNITARY SYSTEMS}

This form is used to describe any unitary air conditioning equipment that serves the test space. Only one copy of Form C-3 is required for the test space. If the test space is not served by a unitary system, this form is not required.

System Type: Select one of the following systems and answer the system specific questions.

1 Roof-Top Units: $\mathrm{Y} / \mathrm{N}$

2

Number of Systems:

3

Zoning:

4

Constant or Variable:

5 Through-the-Wall Conditioner Systems: $\mathrm{Y} / \mathrm{N}$

6

7

Ventilation Air. $\mathrm{Y} / \mathrm{N}$

Ducted: $\mathrm{Y} / \mathrm{N}$

Number of Systems:

9 Heat Pump Systems: $\mathrm{Y} / \mathrm{N}$

10 Number of Systems:

11

Ventilation Air. $\mathrm{Y} / \mathrm{N}$

12 Source of Ventilation Air: 


\section{FORM C-4: EVAPORATIVE COOLING SYSTEMS}

This form is used to describe evaporative cooling systems used to condition the test space. If the test space has such a system, only one copy of Form C-4 is required.

System Type: Select one of the following systems and answer the system specific questions.

1 Direct Evaporative Air Cooler: $\mathrm{Y} / \mathrm{N}$

2 Direct System Type:

3 Indirect Evaporative Air Cooler: $\mathrm{Y} / \mathrm{N}$ 


\section{FORM C-5: OUTDOOR AIR INTAKE}

This form is used to describe the outdoor air intake strategy employed by the mechanical ventilation system serving the test space. Only one copy of Form C-5 is required for the test space.

Intake Strategy: Select one of the following options.

1 Conditioned Positive:

2 Unconditioned Positive:

3 Unconditioned Suction:

4 Unconditioned Suction, No Duct:

Intake Control Strategy: Select one of the following options.

$5 \quad 100 \%$ Outdoor Air Intake:

6 Fixed Minimum Outdoor Air Intake:

7 Economizer Cycle:

8 Enthalpy Economizer Cycle:

Means of maintaining minimum outdoor air intake: Select one of the following options.

9 Fixed Damper Positions:

10 Supply/Return Fan Tracking:

11 Intake Airflow Monitoring:

Additional Intake Control Information

12 Morning Warm-Up Cycle: $\mathrm{Y} / \mathrm{N}$

13 Morning Purge Cycle: $\mathrm{Y} / \mathrm{N}$

14 Night Cool-Down Cycle: $\mathrm{Y} / \mathrm{N}$ 


\section{FORM C-6: NATURAL VENTILATION SYSTEM}

This form is used to describe the ventilation strategy employed in naturally ventilated buildings. Only one copy of Form C-6 is required for the building, and only if it is naturally ventilated.

Select which of the following natural ventilation systems exist in the building and answer the system specific questions.

1 Operable Windows: $\mathrm{Y} / \mathrm{N}$

2 Through-the-Wall Vents: $\mathrm{Y} / \mathrm{N}$

3 Number of Vents:

4 Size of Vents: $\mathrm{cm}^{2}$ or in ${ }^{2}$

5 Central Shaft: $\mathrm{Y} / \mathrm{N}$

6 Exhaust system: $\mathrm{Y} / \mathrm{N}$

7 Area served by exhaust system: 


\section{FORM C-7A: AIR HANDLER SPECIFICATIONS}

This form is used to describe the specifications of the air handlers serving the test space. One copy of Form C-7A is required for each air handler serving the test space.

1 Air Handler Number:

2 Location of Air Handler:

3 Design Supply Airflow Rate Capacity: $\mathrm{m} 3 / \mathrm{s}$ or $\mathrm{cfm}$

4 Source of Value:

5 Design Minimum Outdoor Air Intake Rate: $\mathrm{m} 3 / \mathrm{s}$ or $\mathrm{cfm}$

6 Source of Value:

7 Space Served by Air Handler:

8 Source of Value:

9 Floor Area Served by Air Handler: $\mathrm{m}^{2}$ or $\mathrm{ft}^{2}$

10 Source of Value:

11 Number of Occupants Served by Air Handler:

12 Source of Value:

13 Design Cooling Load: $\mathrm{W} / \mathrm{m}^{2}$ or $\mathrm{W} / \mathrm{ft}^{2}$

14 Source of Value:

15 Existence of Return Fan: $\mathrm{Y} / \mathrm{N}$

16 Return Fan Capacity: $\mathrm{m}^{3} / \mathrm{s}$ or cfm

17 Source of Value:

18 Space Served by Return System:

19 Source of Value:

20 Floor Area Served by Return System: $\mathrm{m}^{2}$ or $\mathrm{ft}^{2}$

21 Source of Value: 


\section{FORM C-7B： EXHAUST FAN SPECIFICATIONS}

This form is used to describe the specifications of the exhaust fans serving the test space. One copy of Form C-7B is required for each exhaust fan serving the test space.

1 Exhaust Fan Number:

2 Location of Exhaust Fan:

3 Design Exhaust Airflow Rate:

$\mathrm{m}^{3} / \mathrm{s}$ or $\mathrm{cfm}$

4 Source of Value:

5 Space Served by Exhaust Fan:

6 Source of Value:

7 Floor Area Served by Exhaust Fan:

$\mathrm{m}^{2}$ or $\mathrm{ft}^{2}$

8 Source of Value:

\section{Controls}

9 Manual:

$\mathrm{Y} / \mathrm{N}$

10 Time of Day:

$\mathrm{Y} / \mathrm{N}$

11 Temperature:

$\mathrm{Y} / \mathrm{N}$

12 Equipment Operation:

$\mathrm{Y} / \mathrm{N}$ 


\section{FORM C-8: FILTRATION AND AIR CLEANING SYSTEMS}

This form is used to describe the filtration and air cleaning systems used in the air handlers serving the test space. One copy of Form C-8 is required for each air filter or air cleaning system within the air handler.

1 Air Handler Number:

2 Location within Air Handler:

3 Filter, Electronic Air Cleaner or Gaseous Air Cleaner:

\section{Air Filtration System}

4 Manufacturer:

5 Model Number:

System Type

6 Panel or Roll Filter:

7 Panel Filter Type:

8 Roll Filter Type:

9 Size:

$\mathrm{mx}$ m or ft $\mathrm{x} \mathrm{ft}$

10 Filter Media:

11 Rating:

\section{Electronic Air Cleaner}

12 Manufacturer:

13 Model Number:

14 Size: $\mathrm{mx}$ m or ft $\mathrm{x} \mathrm{ft}$

15 Automatic Wash System: $\mathrm{Y} / \mathrm{N}$

\section{Gaseous Air Cleaner}

16 Manufacturer:

17 Model Number:

18 Size: $\mathrm{mx}$ m or $\mathrm{ft} x \mathrm{ft}$

19 Depth: $\mathrm{m}$ or $\mathrm{ft}$

20 Absorbent Media: 


\section{FORM C-9: AIR WASHERS}

This form is used to describe air washer systems within the air handlers serving the test space, if such systems exist. One copy of Form C-9 is required for each air handler serving the test space which contains an air washer.

1 Air Handler Number:

2 System Type: 


\section{FORM C-10: HUMIDIFICATION SYSTEMS}

This form is used to describe humidification systems used in the air handlers serving the test space, if such systems exist. One copy of Form C-10 is required for each air handler serving the test space which contains a humidification system.

1 Air Handler Number:

2 System Type:

3 Water Softening System: $\mathrm{Y} / \mathrm{N}$

4 Demineralizer: $\mathrm{Y} / \mathrm{N}$ 


\section{FORM C-11: MAINTENANCE}

This form is used to describe the HVAC system maintenance procedures and schedules. One copy of Form C-11 is required for the building.

Air Handler Inspections

1 Regularly Scheduled:

$\mathrm{Y} / \mathrm{N}$

2 Recorded in Logbook: $\mathrm{Y} / \mathrm{N}$

3 Frequency:

Particulate Filtration Systems

Panel Filter Replacement

4 Regularly Scheduled: — Y $/ \mathrm{N}$

5 Recorded in Logbook: $\mathrm{Y} / \mathrm{N}$

6 Frequency:

Manual Roll Filter Advancement

7 Regularly Scheduled: — $\mathrm{Y} / \mathrm{N}$

8 Recorded in Logbook: _ $\mathrm{Y} / \mathrm{N}$

9 Frequency:

Automatic Roll Filter Inspection

10 Regularly Scheduled: — $\mathrm{Y} / \mathrm{N}$

11 Recorded in Logbook: _ $\mathrm{Y} / \mathrm{N}$

12 Frequency:

Electronic Air Cleaners

Inspection

13 Regularly Scheduled: _ Y Y $/ \mathrm{N}$

14 Recorded in Logbook: _ $\mathrm{Y} / \mathrm{N}$

15 Frequency:

Cleaning

16 Regularly Scheduled: $\mathrm{Y} / \mathrm{N}$

17 Recorded in Logbook: $\mathrm{Y} / \mathrm{N}$

18 Frequency: 
Heating and Cooling Coils Inspection

19 Regularly Scheduled: $\mathrm{Y} / \mathrm{N}$

20 Recorded in Logbook: $\mathrm{Y} / \mathrm{N}$

21 Frequency:

Cleaning

22 Regularly Scheduled: $\mathrm{Y} / \mathrm{N}$

23 Recorded in Logbook: $\mathrm{Y} / \mathrm{N}$

24 Frequency:

Drain Pans

Inspection

25 Regularly Scheduled: $\mathrm{Y} / \mathrm{N}$

26 Recorded in Logbook: $\mathrm{Y} / \mathrm{N}$

27 Frequency:

Cleaning

28 Regularly Scheduled: $\mathrm{Y} / \mathrm{N}$

29 Recorded in Logbook: $\mathrm{Y} / \mathrm{N}$

30 Frequency:

Air Distribution Ductwork

Inspection

31 Regularly Scheduled: $\mathrm{Y} / \mathrm{N}$

32 Recorded in Logbook: $\mathrm{Y} / \mathrm{N}$

33 Frequency:

Cleaning

34 Regularly Scheduled: $\mathrm{Y} / \mathrm{N}$

35 Frequency:

Humidifiers

Inspection

36 Regularly Scheduled: $\mathrm{Y} / \mathrm{N}$

37 Recorded in Logbook: $\mathrm{Y} / \mathrm{N}$

38 Frequency: 
Cleaning

39 Regularly Scheduled: _ $\mathrm{Y} / \mathrm{N}$

40 Recorded in Logbook: _ Y Y $/ \mathrm{N}$

41 Frequency:

42 Purge or Blowdown: $\mathrm{Y} / \mathrm{N}$

43 Purge Frequency:

44 Purge Duration:

45 Purge Control:

Evaporative coolers

Inspection

46 Regularly Scheduled: _ $\mathrm{Y} / \mathrm{N}$

47 Recorded in Logbook: _ $\mathrm{Y} / \mathrm{N}$

48 Frequency:

Cleaning

49 Regularly Scheduled: _ Y $\mathrm{YN}$

50 Recorded in Logbook: _ $\mathrm{Y} / \mathrm{N}$

51 Frequency:

52 System Bleeding Frequency:

53 Water Treatment: $\mathrm{Y} / \mathrm{N}$

54 Water Treatment Frequency:

55 Water Treatment Compound:

56 Biocide Treatment: $\mathrm{Y} / \mathrm{N}$

57 Biocide Treatment Frequency:

58 Biocide Treatment Compound:

Air washers

Inspection

59 Regularly Scheduled: _ $\mathrm{Y} / \mathrm{N}$

60 Recorded in Logbook: _ $\mathrm{Y} / \mathrm{N}$

61 Frequency:

Cleaning

62 Regularly Scheduled: $\mathrm{Y} / \mathrm{N}$

63 Recorded in Logbook: $\mathrm{Y} / \mathrm{N}$

64 Frequency: 
65 Tank Maintenance Frequency:

66 Eliminator Repainting Frequency:

67 Glass Media Cleaning Frequency:

68 System Bleeding Frequency:

69 Water Treatment: $\mathrm{Y} / \mathrm{N}$

70 Water Treatment Frequency:

71 Water Treatment Compound:

72 Biocide Treatment: $\mathrm{Y} / \mathrm{N}$

73 Biocide Treatment Frequency:

74 Biocide Treatment Compound:

Control System

Inspection

75 Regularly Scheduled: $\mathrm{Y} / \mathrm{N}$

76 Recorded in Logbook: $\mathrm{Y} / \mathrm{N}$

77 Frequency:

Sensor Recalibration

78 Regularly Scheduled: $\mathrm{Y} / \mathrm{N}$

79 Recorded in Logbook: $\mathrm{Y} / \mathrm{N}$

80 Frequency:

Testing and Balancing

81 Regularly Scheduled: $\mathrm{Y} / \mathrm{N}$

82 Frequency:

Cooling Towers Inspection

83 Regularly Scheduled: $\mathrm{Y} / \mathrm{N}$

84 Recorded in Logbook: $\mathrm{Y} / \mathrm{N}$

85 Frequency:

86 Surface Cleaning Frequency:

87 Scale Control Treatment: $\mathrm{Y} / \mathrm{N}$

88 Blowdown or Chemical Treatment:

89 Blowdown or Chemical Treatment Frequency:

90 Scale Control Treatment Compounds: 
91 Corrosion Treatment: $\mathrm{Y} / \mathrm{N}$

92 Treatment Frequency:

93 Corrosion Treatment Compounds:

94 Biocide Treatment: $\mathrm{Y} / \mathrm{N}$

95 Biocide Treatment Frequency:

96 Biocide Treatment Compounds:

97 Silt Treatment: $\mathrm{Y} / \mathrm{N}$

98 Silt Treatment Frequency:

99 Silt Treatment Compounds:

Fan coil Units

Inspection

100 Regularly Scheduled:

$\mathrm{Y} / \mathrm{N}$

101 Recorded in Logbook: $\mathrm{Y} / \mathrm{N}$

102 Frequency:

Filter Replacement

103 Regularly Scheduled: $\mathrm{Y} / \mathrm{N}$

104 Recorded in Logbook: $\mathrm{Y} / \mathrm{N}$

105 Frequency:

Terminal Units

Inspection

106 Regularly Scheduled:

$\mathrm{Y} / \mathrm{N}$

107 Recorded in Logbook: $\mathrm{Y} / \mathrm{N}$

108 Frequency: 


\section{INSPECTION}

This form is used to record information obtained during the inspection of the HVAC system and its major components. One copy of Form C-12 is required for the building.

\section{Mechanical Room}

1 General Condition:

2 Part of Return System:

$\mathrm{Y} / \mathrm{N}$

3 Used for Storage: $\mathrm{Y} / \mathrm{N}$

System Check-Out

Supply Fan

4 Operating: $\mathrm{Y} / \mathrm{N}$

5 Correct Direction of Fan Rotation: _ $\mathrm{Y} / \mathrm{N}$

6 Correct Airflow Direction: $\mathrm{Y} / \mathrm{N}$

Return Fan

7 Operating: $\mathrm{Y} / \mathrm{N}$

8 Correct Direction of Fan Rotation: _ $\mathrm{Y} / \mathrm{N}$

9 Correct Airflow Direction: $\mathrm{Y} / \mathrm{N}$ Exhaust Fan

10 Operating: $\mathrm{Y} / \mathrm{N}$

11 Correct Direction of Fan Rotation: _ $\mathrm{Y} / \mathrm{N}$

12 Correct Airflow Direction: $\mathrm{Y} / \mathrm{N}$

Outdoor Air Intake

13 Correct Airflow Direction: $\mathrm{Y} / \mathrm{N}$

14 Height: $\mathrm{m}$ or $\mathrm{ft}$

Proximity to Pollutant Sources

15 Standing Water: $\mathrm{Y} / \mathrm{N}$

16 Exhaust Vents: $\mathrm{Y} / \mathrm{N}$

17 Sanitary Vents: $\mathrm{Y} / \mathrm{N}$

18 Cooling Tower: $\mathrm{Y} / \mathrm{N}$

19 Loading Dock: $\mathrm{Y} / \mathrm{N}$

20 Parking Garage: $\mathrm{Y} / \mathrm{N}$

21 Vehicle Traffic: $\mathrm{Y} / \mathrm{N}$

22 Trash Dumpster: $\mathrm{Y} / \mathrm{N}$ 
Air Handler Housing

23 General Condition:

24 Sound Liner:

Air Handler Components

25 General Condition:

26 Intakes:

27 Dampers:

28 Coils:

29 Drain Pans:

30 Fan Belts:

Air Distribution Ductwork

31 General Condition:

32 Leakage at Seams:

33 Liners:

Exhaust Fans

34 General Condition:

35 Fan Belts:

Particulate Filtration Systems

36 General Condition:

37 Accessibility:

38 Filter Fit into Frames:

39 Filter Condition:

40 Evenness of Loading:

41 Indicator of Resistance:

$\mathrm{Y} / \mathrm{N}$

42 Time to Change Label: $\mathrm{Y} / \mathrm{N}$

43

Pressure Indicator Reading:

$\mathrm{Pa}$ or in. wg.

Humidifiers

44 General Condition:

45 Drain Pans: 
Evaporative Coolers

46 General Condition:

47 Water Pans:

48 Water Clarity:

Air Washers

49 General Condition:

50 Water Pans:

51 Water Clarity:

52 Eliminators and Baffles:

Control System

53 General Condition:

54 Sensors:

Cooling Towers

55 General Condition:

56 Surfaces:

57 Water Condition:

Fan Coil Units

58 General Condition:

59 Valves:

60 Fans:

61 Coils:

62 Drain Pans:

63 Air Filters:

Terminal Units

64 General Condition:

65 Dampers: 



\section{CHECKLIST INSTRUCTIONS: TEST SPACE HVAC SYSTEM PERFORMANCE}

The evaluation of the performance of the test space HVAC system employs a series of forms, with the specific forms used and their number being dependent on the building being evaluated. The checklist forms for HVAC performance are as follows:

D-1A SUPPLY AIRFLOW RATE

D-1B PERCENT OUTDOOR AIR INTAKE

D-1C OUTDOOR AIR INTAKE RATE

D-1D SUPPLY AIR TEMPERATURE AND RELATIVE HUMIDITY

D-2A EXHAUST FAN OPERATION

D-2B EXHAUST FAN AIRFLOW RATE

D-3A LOCAL VENTILATION PERFORMANCE - AIRFLOW RATE

D-3B LOCAL VENTILATION PERFORMANCE - SUPPLY AIR TEMPERATURE

D-4A NATURAL VENTILATION - CONTINUOUS CARBON DIOXIDE

D-4B NATURAL VENTILATION - TRACER GAS DECAY

D-5A AIR INFILTRATION RATE: TEST DESCRIPTION

D-5B AIR INFILTRATION RATE: SUPPLY AIRFLOW RATE

D-5C AIR INFILTRATION RATE: PERCENT OUTDOOR AIR INTAKE

D-5D AIR INFILTRATION RATE: OUTDOOR AIR INTAKE RATE

D-5E AIR INFILTRATION RATE: TRACER GAS DECAY

D-5F AIR INFILTRATION RATE: DATA ANALYSIS

D-X1 TRAVERSE OF RECTANGULAR DUCT

D-X2 TRAVERSE OF ROUND DUCT

Evaluations of mechanically ventilated buildings require the D-1, D-3 and D-5 forms. Naturally ventilated buildings require the D-4 forms. Either type of ventilation system will require the D-2 forms if the test space has any mechanical exhaust systems. 


\section{D-1 FORMS TEST SPACE AIR HANDLERS}

Forms D-1A through D-1D are used in the evaluations of the air handlers serving the test space. Four of each of these forms are required for each air handler serving the test space. The four forms are used in the air handler evaluations to be conducted in the morning and afternoon on the two days of monitoring, at approximately 10 am and $3 \mathrm{pm}$ on each day.

\section{FORM D-1A SUPPLY AIRFLOW RATE}

This form is used to measure the supply airflow rate in each air handler serving the test space. The airflow rate measurement is performed with a pitot tube traverse according to standard procedures contained in the ACGIH Industrial Ventilation Manual, AMCA Publication 203-90 and the ASHRAE Standard 111. A traverse with a calibrated hot-wire anemometer is acceptable, using the same procedures as recommended for a pitot traverse. Each of the four measurements of the supply airflow rate will require one Form D-1A. The entries on the form are to be completed as follows:

1 Date of Test: Enter the date on which the measurement is conducted.

2 Time: Enter the time at which the measurement is conducted.

3 Air Handler Number: Enter the air handler number used in the building mechanical plans.

4 Air Handler Location: Enter the location of the air handler, using a room number from the building plans if available. If no room number is available, enter the floor and location on the floor.

5 Location of Duct Traverse: Describe the point within the supply ductwork at which the traverse is conducted. Provide the distance from the fan, designated as upstream or downstream.

6 Measurement Device Type: Describe the device used in the traverse, i.e., a pitot-static tube and differential pressure gauge or a calibrated hot-wire anemometer.

7 Manufacturer: In the case of a pitot traverse, enter the manufacturer of the pressure gauge. In the case of a hot-wire anemometer, enter the manufacturer of the anemometer.

8 Model Number: Enter the model number of the device.

9 Serial Number: Enter the serial number of the device.

10 Rectangular or Round: Note whether the duct is rectangular or round.

11 Duct Area: Enter the cross-sectional area of the duct at the point of the traverse. Designate the units, either $\mathrm{m}^{2}$ or $\mathrm{ft}^{2}$.

The traverse data is recorded on Form $\mathrm{X} 1$ for a rectangular duct and Form $\mathrm{X} 2$ for a round duct. The instructions for these forms are provided at the end of section $\mathrm{D}$. 
12 Start of Traverse: Enter the time at which the collection of traverse data began.

13 End of Traverse: Enter the time at which the collection of traverse data was completed.

14 Root Mean Square Velocity Pressure: In the case of a pitot traverse, calculate the root mean square velocity pressure using the formula contained on the form. In the case of a hot-wire traverse, leave this space blank.

Designate the units, either $(\mathrm{Pa})^{1 / 2}$ or (in.w.g.) $)^{1 / 2}$.

15 Average Air Speed: In the case of a hot-wire traverse, calculate the average value of the air speed. In the case of a pitot traverse, calculate the average air speed from the root mean square velocity pressure using the appropriate formula contained on the form.

Designate the units, either $\mathrm{m} / \mathrm{s}$ or $\mathrm{fpm}$.

16 Airflow Rate: Calculate the supply airflow rate by multiplying the duct area at entry \#11 by the average air speed at entry \#15.

Designate the units, either $\mathrm{m}^{3 / \mathrm{s}}$ or $\mathrm{cfm}$.

\section{FORM D-1B PERCENT OUTDOOR AIR INTAKE}

This form is used to measure the percent outdoor air intake in each air handler serving the test space. The percent outdoor air intake is determined using a mass balance of air and carbon dioxide based on carbon dioxide concentration measurements in the outdoor air, the return air and the supply air. Each of the four measurements of the percent outdoor air intake will require one Form D-1B. The entries on the form are to be completed as follows:

1 Date of Test: Enter the date on which the measurement is conducted.

2 Time: Enter the time at which the measurement is conducted.

3 Air Handler Number: Enter the air handler number used in the building mechanical plans.

4 Air Handler Location: Enter the location of the air handler, using a room number from the building plans if available. If no room number is available, enter the floor and location on the floor.

5 Air Sample Location, Outdoor Air Intake: Describe the location at which the outdoor air intake carbon dioxide concentration is measured. Provide the distance from the outdoor air intake grille, designated as upstream or downstream.

6 Air Sample Location, Supply Air: Describe the location at which the supply air carbon dioxide concentration is measured. Provide the distance from the supply fan, designated as upstream or downstream.

7 Air Sample Location, Return Air: Describe the location at which the return air carbon dioxide concentration is measured. Provide the distance upstream from the point at which the return and outdoor airstreams mix. 
8 Manufacturer: Enter the manufacturer of the carbon dioxide concentration measurement device.

9 Model Number: Enter the model number of the device.

10 Serial Number: Enter the serial number of the device.

The span and zero of the carbon dioxide monitor will be checked immediately before each determination of the percent outdoor air intake.

11 Span Concentration: Enter the carbon dioxide concentration of the span gas used to check the monitor.

12 Reading: Enter the response of the carbon dioxide monitor to the span gas.

13 Reading: Enter the response of the carbon dioxide monitor to the zero gas.

The concentration measurements are to consist of five successive readings at each of the three locations. At each location, record the concentration reading every 10 seconds. After the five readings, move immediately to the next location in order to complete all the measurements in the minimum amount of time.

14 Start of Measurement: Enter the time at which the concentration measurements began.

15 Outdoor Air: Enter the five concentration readings from the outdoor airstream.

16 Return Air: Enter the five concentration readings from the return airstream.

17 Supply Air: Enter the five concentration readings from the supply airstream.

18 End of Measurement: Enter the time at which the concentration measurements were completed.

19 Enter the mean of the outdoor air concentration readings.

20 Enter the standard deviation of the outdoor air concentration readings.

21 Enter the mean of the return air concentration readings.

22 Enter the standard deviation of the return air concentration readings.

23 Enter the mean of the supply air concentration readings.

24 Enter the standard deviation of the supply air concentration readings.

25 Percent Outdoor Air: Calculate the percent outdoor air intake using the formula provided on the form.

26 Error Estimate: Calculate the estimated error in the percent outdoor air intake using the formula provided on the form. 


\section{FORM D-1C OUTDOOR AIR INTAKE RATE}

This form is used to determine the outdoor air intake rate in each air handler serving the test space. Two methods are available to make this determination, the first being a pitot-tube traverse of the outdoor air intake duct according to standard procedures contained in the ACGIH Industrial Ventilation Manual, AMCA Publication 203-90 and the ASHRAE Standard 111. A traverse with a calibrated hot-wire anemometer is acceptable, using the same procedures as recommended for a hot-wire traverse. The second method involves the multiplication of the supply airflow rate (Form D-1A) by the percent outdoor air intake (Form D-1B). Method \#1 can only be used if the outdoor air intake is configured such that a traverse is possible (see the referenced documents for the ductwork configurations appropriate for conducting a traverse). Each of the four determinations of the outdoor air intake rate will require one Form D-1C. The entries on the form are to be completed as follows:

1 Date of Test: Enter the date on which the measurement is conducted.

2 Time: Enter the time at which the measurement is conducted.

3 Air Handler Number: Enter the air handler number used in the building mechanical plans.

4 Air Handler Location: Enter the location of the air handler, using a room number from the building plans if available. If no room number is available, enter the floor and location on the floor.

5 Location of Duct Traverse: Describe the point within the outdoor air intake ductwork at which the traverse is conducted. Provide the distance downstream from the outdoor air intake grille.

6 Measurement Device Type: Describe the device used in the traverse, i.e, a pitot-static tube and differential pressure gauge or a calibrated hot-wire anemometer.

7 Manufacturer: In the case of a pitot traverse, enter the manufacturer of the pressure gauge. In the case of a hot-wire anemometer, enter the manufacturer of the anemometer.

8 Model Number: Enter the model number of the device.

9 Serial Number: Enter the serial number of the device.

10 Rectangular or Round: Note whether the duct is circular or rectangular.

11 Duct Area: Enter the cross-sectional area of the duct at the point of the traverse. Designate the units, either $\mathrm{m}^{2}$ or $\mathrm{ft}^{2}$.

The traverse data is recorded on Form $\mathrm{X} 1$ for a rectangular duct and Form $\mathrm{X} 2$ for a round duct. The instructions for these forms are provided at the end of section $\mathrm{D}$.

12 Start of Traverse: Enter the time at which the collection of traverse data began.

13 End of Traverse: Enter the time at which the collection of traverse data was completed. 
14 Root Mean Square Velocity Pressure: In the case of a pitot traverse, calculate the root mean square velocity pressure using the formula contained on the form. In the case of a hot-wire traverse, leave this space blank.

Designate the correct units, either $(\mathbf{P a})^{1 / 2}$ or (in.w.g.) $)^{1 / 2}$.

15 Average Air Speed: In the case of a hot-wire traverse, calculate the average value of the air speed. In the case of a pitot traverse, calculate the average air speed from the root mean square velocity pressure using the appropriate formula contained on the form.

Designate the units, either $\mathrm{m} / \mathrm{s}$ or $\mathrm{fpm}$.

16 Airflow Rate: Calculate the outdoor air intake rate by multiplying the duct area at entry \#11 by the average air speed at entry \#15.

Designate the units, either $\mathrm{m}^{3 / \mathrm{s}}$ or $\mathrm{cfm}$.

17 Supply Airflow Rate: Enter the supply airflow rate for the air handler at the corresponding date and time from Form D-1A, entry \#16.

Designate the units, either $\mathrm{m}^{3 / \mathrm{s}}$ or $\mathrm{cfm}$.

18 Percent Outdoor Air Intake: Enter the percent outdoor air intake for the air handler at the corresponding date and time from Form D-1B, entry \#25.

19 Outdoor Air Intake Rate: Calculate the outdoor air intake rate by multiplying the supply airflow rate in entry \#17 by the percent outdoor air intake in entry \#18 and dividing the result by 100 .

Designate the units, either $\mathrm{m}^{3} / \mathrm{s}$ or $\mathrm{cfm}$.

\section{FORM D-1D SUPPLY AIR TEMPERATURE AND RELATIVE HUMIDITY}

This form is used to measure the supply air temperature and relative humidity for each air handler serving the test space. Each of the four measurements will require one Form D-1D. The entries on the form are to be completed as follows:

1 Date of Test: Enter the date on which the measurement is conducted.

2 Time: Enter the time at which the measurement is conducted.

3 Air Handler Number: Enter the air handler number used in the building mechanical plans.

4 Air Handler Location: Enter the location of the air handler, using a room number from the building plans if available. If no room number is available, enter the floor and location on the floor.

5 Location of Measurements: Describe the point within the supply ductwork at which the measurements are conducted. Provide the distance downstream from the fan. The measurement location should be as far downstream of the heating and cooling coils as possible. 
6 Measurement Device Type: Describe the air temperature sensor.

7 Manufacturer: Enter the manufacturer of the temperature sensor.

8 Model Number: Enter the model number of the temperature sensor.

9 Serial Number: Enter the serial number of the temperature sensor.

10 Measurement Device Type: Describe the relative humidity sensor.

11 Manufacturer: Enter the manufacturer of the relative humidity sensor.

12 Model Number: Enter the model number of the relative humidity sensor.

13 Serial Number: Enter the serial number of the relative humidity sensor.

The temperature and humidity measurements are to consist of five successive readings each, with each quantity recorded every 10 seconds. Allow sufficient time for the sensors readings to stabilize before recording the data.

14 Start of Measurement: Enter the time at which the measurements began.

15 Air Temperature: Enter the five air temperature readings. Designate the units, either ${ }^{\circ} \mathrm{C}$ or ${ }^{\circ} \mathrm{F}$.

16 Relative Humidity: Enter the five relative humidity readings.

17 End of Measurement: Enter the time at which the measurements were completed.

18 Enter the mean of the supply air temperature readings.

19 Enter the standard deviation of the supply air temperature readings.

20 Enter the mean of the supply air relative humidity readings.

21 Enter the standard deviation of the supply air relative humidity readings. 


\section{D-2 FORMS TEST SPACE EXHAUST FANS}

Forms D-2A and D-2B are used in the evaluations of the exhaust fans serving the test space. Both forms must be completed for each exhaust fan serving the test space.

\section{EORM D-2A EXHAUSTFAN OPERATION}

This form is used to record the operation of each exhaust fan serving the test space. The operation of the fan is to be checked twice a day, once in the morning and once in the afternoon, on five consecutive working days. One form is required for each exhaust fan serving the test space. The entries on the form are to be completed as follows:

1 Exhaust Fan Number: Enter the exhaust fan number used in the building mechanical plans.

2 Exhaust Fan Location: Enter the location of the exhaust fan, using a room number from the building plans if available. If no room number is available, enter the floor and location on the floor.

The exhaust fan is checked twice a day to determine whether it is operating or not. Both the morning and afternoon checks need not occur at any particular time, but they should be conducted when the building is fully occupied. The times on all five days should be reasonably consistent.

3 Time Operation Checked: Enter the time at which the morning operation is checked on Day \#1.

4 Operating: Enter yes if the fan is operating and no if not.

5 Time Operation Checked: Enter the time at which the afternoon operation is checked on Day \#2.

6 Operating: Enter yes if the fan is operating and no if not.

For entries \#7 through \#22, enter the time and operating status for days \#2 through \#5 as described for day \#1. 


\section{FORM D-2B EXHAUST FAN AIRFLOW RATE}

This form is used to measure the airflow rate in each exhaust fan serving the test space. The airflow rate measurement is performed with a pitot tube traverse according to standard procedures contained in the ACGIH Industrial Ventilation Manual, AMCA Publication 203-90 and the ASHRAE Standard 111. A traverse with a calibrated hot-wire anemometer is acceptable, using the same procedures as recommended for a pitot traverse. Only one airflow rate measurement is required in each exhaust fan. The entries on the form are to be completed as follows:

1 Date of Test: Enter the date on which the measurement is conducted.

2 Time: Enter the time at which the measurement is conducted.

3 Exhaust Fan Number: Enter the exhaust fan number used in the building mechanical plans.

4 Exhaust Fan Location: Enter the location of the exhaust fan, using a room number from the building plans if available. If no room number is available, enter the floor and location on the floor.

5 Location of Duct Traverse: Describe the point within the exhaust fan ductwork at which the traverse is conducted. Provide the distance from the fan, designated as upstream or downstream.

6 Measurement Device Type: Describe the device used in the traverse, i.e, a pitot-static tube and differential pressure gauge or a calibrated hot-wire anemometer.

7 Manufacturer: In the case of a pitot traverse, enter the manufacturer of the pressure gauge. In the case of a hot-wire anemometer, enter the manufacturer of the anemometer.

8 Model Number: Enter the model number of the device.

9 Serial Number: Enter the serial number of the device.

10 Rectangular or Round: Note whether the duct is rectangular or round.

11 Duct Area: Enter the cross-sectional area of the duct at the point of the traverse.

Designate the units, either $\mathrm{m}^{2}$ or $\mathrm{ft}^{2}$.

The traverse data is recorded on Form X1 for a rectangular duct and Form X2 for a round duct. The instructions for these forms are provided at the end of section $\mathrm{D}$.

12 Start of Traverse: Enter the time at which the collection of traverse data began.

13 End of Traverse: Enter the time at which the collection of traverse data was completed.

14 Root Mean Square Velocity Pressure: In the case of a pitot traverse, calculate the root mean square velocity pressure using the formula contained on the form. In the case of a hot-wire traverse, leave this space blank.

Designate the units, either $(\mathrm{Pa})^{1 / 2}$ or (in.w.g.) $)^{1 / 2}$ 
15 Average Air Speed: In the case of a hot-wire traverse, calculate the average value of the air speed. In the case of a pitot traverse, calculate the average air speed from the root mean square velocity pressure using the appropriate formula contained on the form.

Designate the units, either $\mathrm{m} / \mathrm{s}$ or fpm.

16 Airflow Rate: Calculate the exhaust airflow rate by multiplying the duct area at entry \#11 by the average air speed at entry \#15.

Designate the units, either $\mathrm{m}^{3 /} / \mathrm{s}$ or $\mathrm{cfm}$. 


\section{D-3 FORMS LOCAL VENTILATION PERFORMANCE}

Forms D-3A and D-3B are used in the evaluation of the test space ventilation system at the local level, with one of each form required.

\section{FORM D-3A LOCAL VENTILATION PERFORMANCE - AIRFLOW RATE}

This form is used to record the airflow rate out of each supply air diffuser within the test space using a flow measuring hood. Only one form is required for the test space. The entries on the form are to be completed as follows:

1 Date of Test: Enter the date on which the measurements are conducted.

2 Measurement Device Type: Describe the type of flow measuring hood employed, such as swinging vane anemometer, differential air pressure gage or manometer.

3 Manufacturer: Enter the manufacturer of the flow measuring hood.

4 Model Number: Enter the model number of the flow hood.

5 Serial Number: Enter the serial number of the flow hood.

6 Date of Last Calibration: Enter the date of the last calibration of the flow hood.

7 Start of Measurement: Enter the time at which the flow hood measurements began.

8 Units of the Airflow Rate Measurements: Enter the airflow rate units read off the flow hood, e.g. $\mathrm{cfm}, \mathrm{m}^{3} / \mathrm{s}$ or $\mathrm{L} / \mathrm{s}$.

9 Airflow Rate: Enter the airflow rate measured at each diffuser in the test space. Use the numbering scheme for the diffusers (\#1 through \#75) employed on the test space floor plan.

10 End of Measurement: Enter the time at which the flow hood measurements were completed.

\section{FORM D-3B LOCAL VENTILATION PERFORMANCE - SUPPLY AIR TEMPERATURE}

This form is used to record the supply air temperature at each supply air diffuser within the test space. Only one form is required for the test space. The entries on the form are to be completed as follows:

1 Date of Test: Enter the date on which the measurements are conducted.

2 Measurement Device Type: Describe the air temperature sensor.

3 Manufacturer: Enter the manufacturer of the temperature sensor. 
4 Model Number: Enter the model number of the temperature sensor.

5 Serial Number: Enter the serial number of the temperature sensor.

6 Start of Measurement: Enter the time at which the temperature measurements began.

7 Units of the Temperature Measurements: Enter the units of the temperature measurements, either ${ }^{\circ} \mathrm{C}$ or ${ }^{\circ} \mathrm{F}$.

8 Supply Air Temperature: Enter the supply air temperature measured at each diffuser in the test space. Use the numbering scheme for the diffusers (\#1 through \#75) employed on the test space floor plan.

9 End of Measurement: Enter the time at which the temperature measurements were completed. 


\section{D-4 FORMS NATURALLY VENTILATED BUILDINGS}

Forms D-4A and D-4B are used in the evaluations of naturally ventilated buildings. Two copies of Form D-4A and one Form D-4B are required for each building.

\section{FORM D-4A NATURAL VENTILATION - CONTINUOUS CARBON DIOXIDE}

This form is used to record the results of continuous carbon dioxide monitoring at three locations within the test space. This monitoring is to take place for two full days, and therefore two of these forms are required. The entries on the form are to be completed as follows:

1 Date of Test: Enter the date on which the measurement is conducted.

2 Manufacturer: Enter the manufacturer of the carbon dioxide concentration measurement device.

3 Model Number: Enter the model number of the device.

4 Serial Number: Enter the serial number of the device.

5 Measurement Location, Outdoor Air: Describe the location at which the outdoor air carbon dioxide concentration is measured. A sample location on the roof of the building, at least 20 meters from any exhaust vents, is preferred.

6 Measurement Location, Occupied Space \#1: Describe the first location within the occupied space at which the carbon dioxide concentration is measured. Use column numbers if available, and note the location on the test space floor plan.

For entries \#7 and \#8, describe occupied space locations \#2 and \#3 as was done for occupied space location \#1 in entry \#6.

The carbon dioxide concentrations at these four locations are to be monitored continuously, with a reading at each location taken every 15 minutes or less. After this data has been recorded, it must be analyzed and the following information extracted.

9 Outdoor Reading, 6 am: Enter the outdoor concentration recorded at 6 am.

10 Outdoor Reading, $10 \mathrm{am}$ : Enter the outdoor concentration recorded at $10 \mathrm{am}$.

11 Outdoor Reading, 2 pm: Enter the outdoor concentration recorded at 2 pm.

12 Outdoor Reading, $6 \mathrm{pm}$ : Enter the outdoor concentration recorded at $6 \mathrm{pm}$.

13 Occupied Space \#1, 6 am: Enter the concentration at occupied space location \#1 recorded at $6 \mathrm{am}$.

14 Occupied Space \#1, Morning Maximum Concentration: Enter the maximum carbon dioxide concentration recorded at occupied space location \#1 during the morning. 
15 Occupied Space \#1, Morning Maximum Time: Enter the time at which the morning maximum carbon dioxide concentration occurred at occupied space location \#1.

16 Occupied Space \#1, Morning Maximum, Outdoor Concentration: Enter the outdoor concentration recorded at the same time as the morning maximum carbon dioxide concentration at occupied space location \#1.

17 Occupied Space \#1, Afternoon Maximum Concentration: Enter the maximum carbon dioxide concentration recorded at occupied space location \#1 during the afternoon.

18 Occupied Space \#1, Afternoon Maximum Time: Enter the time at which the afternoon maximum carbon dioxide concentration occurred at occupied space location \#1.

19 Occupied Space \#1, Afternoon Maximum, Outdoor Concentration: Enter the outdoor concentration recorded at the same time as the afternoon maximum carbon dioxide concentration at occupied space location \#1.

For entries \#20 through \#33, record the information on the morning and afternoon maxima at occupied space locations \#2 and \#3 as described above for location \#1.

\section{FORM D-4B NATURAL VENTILATION - TRACER GAS DECAY}

This form is used to record the results of a tracer gas decay test in the building conducted to estimate the whole building air change rate. This test is to be conducted in accordance with ASTM E741. Based on the requirements contained in ASTM E741, this test must be conducted to determine the whole building air change rate. Tracer gas must be released into the entire building such that the concentration is uniform throughout the building. This test can not be performed by releasing tracer gas into the test space alone. Only a single tracer gas decay test is required, and therefore only one form is needed. However, one can repeat the test if the initial attempt does not provide satisfactory results. This measurement can be conducted using occupant generated carbon dioxide as the tracer gas after the occupants have left the building. The entries on the form are to be completed as follows:

1 Date of Test: Enter the date on which the measurement is conducted.

2 Tracer Gas: Enter the tracer gas employed in the test.

3 Manufacturer: Enter the manufacturer of the tracer gas concentration measurement device.

4 Model Number: Enter the model number of the device.

5 Serial Number: Enter the serial number of the device.

6 Concentration Units: Enter the tracer gas concentration units provided by the device. 
The tracer gas concentration must be monitored at one outdoor location and ten locations within the occupied space during the decay test. The ten interior locations must be distributed throughout the entire building in order to be able to verify that the tracer gas concentration is uniform throughout the building prior to and during the decay. The specific locations that are selected will depend on the layout of the building including such factors as the number of stories and the floor area per story.

7 Measurement Location, Outdoor Air: Describe the location at which the outdoor air tracer gas concentration is measured. A sample location on the roof of the building, at least 20 meters from any exhaust vents, is preferred.

8 Measurement Location, Occupied Space \#1: Describe the first location within the occupied space of the building at which the tracer gas concentration is measured. Use column numbers if available, and note the building floor.

For entries \#9 through \#17, describe the second through tenth occupied space sampling location as described in entry \#8 above.

The concentration at each location should be measured once every 30 minutes, though the exact time interval is not critical as long as the sample times are recorded accurately. If one employs occupant generated carbon dioxide as the tracer gas, then the carbon dioxide concentrations must be monitored after the occupants have left the building, while the interior carbon dioxide concentration is still significantly above the outdoor concentration. The concentration monitoring should begin very soon after the occupants have left the building, before the interior concentrations decay significantly. The tracer gas decay test requires that the interior concentration is significantly above the outdoor concentration and the interior concentration is uniform (within 10\%) throughout the building. If either of these conditions is not satisfied, the test will not provide acceptable estimates of the building air change rate.

\section{Initial Reading}

Outdoor, Time: Enter the time at which the outdoor conditions are measured.

Outdoor, Concentration: Enter the outdoor tracer gas concentration.

Outdoor, Temperature: Enter the outdoor air temperature.

Designate the units, either ${ }^{\circ} \mathrm{C}$ or ${ }^{\circ} \mathrm{F}$.

Outdoor, Wind Speed: Enter the wind speed.

Designate the units, either $\mathrm{m} / \mathrm{s}$ or $\mathrm{mph}$.

Location \#1, Time: Enter the time at which the tracer gas concentration at location \#1 is recorded.

Location \#1, Concentration: Enter the tracer gas concentration at location \#1. 
For locations \#2 through \#10, enter the time and concentration as described for location \#1.

19 Second Reading: Record the information as described above for the initial reading.

20 Third Reading: Record the information as described above for the initial reading.

21 Fourth Reading: Record the information as described above for the initial reading.

22 Fifth Reading: Record the information as described above for the initial reading.

The data analysis involves determining the tracer gas decay rate in air changes per hour at each of the 10 interior locations. This is done by performing a least squares linear regression of the natural logarithm of concentration against time. Based on the assumption of a uniform tracer gas concentration within the building, the tracer gas concentration at each location decays according to the following expression:

$\mathrm{C}(\mathrm{t})=\mathrm{C}_{\mathrm{o}} \exp (-\mathrm{It})$

where

$\mathrm{C}(\mathrm{t})=$ the tracer gas concentration at a location at time $\mathrm{t}$ minus the outdoor concentration recorded at the same time

$\mathrm{C}_{\mathrm{o}}=$ the tracer gas concentration at a location time $\mathrm{t}=0$ minus the outdoor concentration recorded at the same time

I = the tracer gas decay rate at that location

In order to determine $\mathrm{I}$, one rewrites the above equation in log form:

$\ln \mathrm{C}=\ln \mathrm{C}_{\mathrm{o}}-\mathrm{It}$

This equation can be used to solve for I at each location by regressing the log of the difference between the tracer gas concentration at the location and the outdoor concentration against time. Linear regression techniques are described in many handbooks and are contained in many computer spreadsheet programs, as are procedures for determining the error associated with the estimate of the slope I.

23 Decay Rates: Enter the calculated decay rate in air changes per hour for each of the ten locations and the standard error of this decay rate.

24 Building Average Decay Rate: Enter the average of the decay rates at the ten locations.

25 Standard Deviation: Enter the standard deviation of the decay rates at the ten locations.

26 Average Exterior Temperature: Enter the average exterior temperature during the decay. Designate the units, either ${ }^{\circ} \mathrm{C}$ or ${ }^{\circ} \mathrm{F}$.

27 Average Wind Speed: Enter the average of the wind speeds during the decay. Designate the units, either $\mathrm{m} / \mathrm{s}$ or $\mathrm{mph}$. 


\section{D-5 FORMS AIR INFILTRATION RATE IN MECHANICALLY VENTILATED BUILDINGS}

Forms D-5A through D-5F are used to estimate the envelope infiltration rate in mechanically ventilated buildings. This is done by conducting a tracer gas decay test with the air handlers operating to determine the whole building air change rate. The outdoor air intake rate is then measured at the air handlers and subtracted from the whole building air change rate to determine the building infiltration rate. Only one such test is required in each building.

\section{EORMD-5A AIRINEILTRATIONRATE: TEST DESCRIPTION}

This form is used to describe the sample locations used in the tracer gas decay test. Only one form is required.

1 Date of Test: Enter the date on which the measurement is conducted.

The tracer gas concentration must be monitored during the decay test at one outdoor location, ten locations within the occupied space, and locations within the air handlers. The outdoor air concentration is monitored at an outdoor air intake. The ten interior locations must be distributed throughout the building in order to verify that the tracer gas concentration is uniform throughout the building prior to and during the decay. The specific locations that are selected will depend on the layout of the building including such factors as number of stories and floor area per story. The tracer gas concentration must also be monitored within the return airstreams of the building air handlers. The forms allow for ten return air locations, although a smaller number may be used depending on the number of air handlers in the building. If there are more than ten major air handlers, additional copies of Form D-5A will be required.

2 Tracer Gas: Enter the tracer gas employed in the test.

3 Measurement Location, Outdoor Air: Describe the location at which the outdoor air tracer gas concentration is measured. Providing the distance from the outdoor air intake grille, designated as upstream or downstream, is preferred.

4 Measurement Location, Occupied Space \#1: Describe the first location within the occupied space of the building at which the tracer gas concentration is measured. Use column numbers if available, and note the building floor.

For entries \#5 through \#13, describe the second through tenth interior sampling location as described in entry \#4 above.

14 Measurement Location, \#1 Air Handler: Describe the first air handler sampling location at which the tracer gas concentration is measured. Enter the air handler number used in the building mechanical plans. Enter the location of the air handler, using a room number from the building plans if available. If no room number is available, enter the floor and location on the floor.

For entries \#15 through \#23, describe the second through tenth air handler sampling location as described in entry \#14 above. 


\section{FORM D-5B AIR INFILTRATION RATE: SUPPLY AIRFLOW RATE}

This form is used to measure the supply airflow rate in each air handler serving the entire building. The airflow rate measurement is performed with a pitot tube traverse according to standard procedures contained in the ACGIH Industrial Ventilation Manual, AMCA Publication 203-90 and the ASHRAE Standard 111. A traverse with a calibrated hot-wire anemometer is acceptable, using the same procedures as recommended for a pitot traverse. One form is required for each air handler serving the building. The entries on the form are to be completed as follows:

1 Date of Test: Enter the date on which the measurement is conducted.

2 Time: Enter the time at which the measurement is conducted.

3 Air Handler Number: Enter the air handler number used in the building mechanical plans.

4 Air Handler Location: Enter the location of the air handler, using a room number from the building plans if available. If no room number is available, enter the floor and location on the floor.

5 Location of Duct Traverse: Describe the point within the supply ductwork at which the traverse is conducted. Provide the distance from the fan, designated as upstream or downstream.

6 Measurement Device Type: Describe the device used in the traverse, i.e, a pitot-static tube and differential pressure gauge or a calibrated hot-wire anemometer.

7 Manufacturer: In the case of a pitot traverse, enter the manufacturer of the pressure gauge. In the case of a hot-wire anemometer, enter the manufacturer of the anemometer.

8 Model Number: Enter the model number of the device.

9 Serial Number: Enter the serial number of the device.

10 Rectangular or Round: Note whether the duct is rectangular or round.

11 Duct Area: Enter the cross-sectional area of the duct at the point of the traverse. Designate the units, either $\mathrm{m}^{2}$ or $\mathrm{ft}^{2}$.

The traverse data is recorded on Form X1 for a rectangular duct and Form X2 for a round duct. The instructions for these forms are provided at the end of section $\mathrm{D}$.

12 Start of Traverse: Enter the time at which the collection of traverse data began.

13 End of Traverse: Enter the time at which the collection of traverse data was completed. 
14 Root Mean Square Velocity Pressure: In the case of a pitot traverse, calculate the root mean square velocity pressure using the formula contained on the form. In the case of a hot-wire traverse, leave this space blank.

Designate the correct units, either $(\mathbf{P a})^{1 / 2}$ or (in.w.g.) $)^{1 / 2}$.

15 Average Air Speed: In the case of a hot-wire traverse, calculate the average value of the air speed. In the case of a pitot traverse, calculate the average air speed from the root mean square velocity pressure using the appropriate formula contained on the form.

Designate the units, either $\mathrm{m} / \mathrm{s}$ or $\mathrm{fpm}$.

16 Airflow Rate: Calculate the supply airflow rate by multiplying the duct area at entry \#11 by the average air speed at entry \#15.

Designate the units, either $\mathrm{m}^{3 / \mathrm{s}}$ or $\mathrm{cfm}$.

\section{FORM D-5C AIR INFILTRATION RATE: PERCENT OUTDOOR AIR INTAKE}

This form is used to measure the percent outdoor air intake in each air handler serving the entire building. The percent outdoor air intake is determined using a mass balance of air and carbon dioxide based on carbon dioxide concentration measurements in the outdoor air, the return air and the supply air. One form is required for each air handler serving the building. The entries on the form are to be completed as follows:

1 Date of Test: Enter the date on which the measurement is conducted.

2 Time: Enter the time at which the measurement is conducted.

3 Air Handler Number: Enter the air handler number used in the building mechanical plans.

4 Air Handler Location: Enter the location of the air handler, using a room number from the building plans if available. If no room number is available, enter the floor and location on the floor.

5 Air Sample Location, Outdoor Air Intake: Describe the location at which the outdoor air intake carbon dioxide concentration is measured. Provide the distance from the outdoor air intake grille, designated as upstream or downstream.

6 Air Sample Location, Supply Air: Describe the location at which the supply air carbon dioxide concentration is measured. Provide the distance from the supply fan, designated as upstream or downstream.

7 Air Sample Location, Return Air: Describe the location at which the return air carbon dioxide concentration is measured. Provide the distance upstream from the point at which the return and outdoor airstreams mix.

8 Manufacturer: Enter the manufacturer of the carbon dioxide concentration measurement device. 
9 Model Number: Enter the model number of the device.

10 Serial Number: Enter the serial number of the device.

The span and zero of the carbon dioxide monitor will be checked immediately before each determination of the percent outdoor air intake.

11 Span Concentration: Enter the carbon dioxide concentration of the span gas used to check the monitor.

12 Reading: Enter the response of the carbon dioxide monitor to the span gas.

13 Reading: Enter the response of the carbon dioxide monitor to the zero gas.

The concentration measurements are to consist of five successive readings at each of the three locations. At each location, record the concentration reading every 10 seconds. After the five readings, move immediately to the next location in order to complete all the measurements in the minimum amount of time.

14 Start of Measurement: Enter the time at which the concentration measurements began.

15 Outdoor Air: Enter the five concentration readings from the outdoor airstream.

16 Return Air: Enter the five concentration readings from the return airstream.

17 Supply Air: Enter the five concentration readings from the supply airstream.

18 End of Measurement: Enter the time at which the concentration measurements were completed.

19 Enter the mean of the outdoor air concentration readings.

20 Enter the standard deviation of the outdoor air concentration readings.

21 Enter the mean of the return air concentration readings.

22 Enter the standard deviation of the return air concentration readings.

23 Enter the mean of the supply air concentration readings.

24 Enter the standard deviation of the supply air concentration readings.

25 Percent Outdoor Air: Calculate the percent outdoor air intake using the formula provided on the form.

26 Error Estimate: Calculate the estimated error in the percent outdoor air intake using the formula provided on the form. 


\section{FORM D-5D AIR INFILTRATION RATE: OUTDOOR AIR INTAKE}

This form is used to determine the outdoor air intake rate in each air handler serving the entire building. Two methods are available to make this determination, the first being a pitot-tube traverse of the outdoor air intake duct according to standard procedures contained in the ACGIH Industrial Ventilation Manual, AMCA Publication 203-90 and the ASHRAE Standard 111. A traverse with a calibrated hot-wire anemometer is acceptable, using the same procedures as recommended for a hot-wire traverse. The second method involves the multiplication of the supply airflow rate (Form D-5B) by the percent outdoor air intake (Form D-5C). Method \#1 can only be used if the outdoor air intake is configured such that a traverse is possible (see the referenced documents for the ductwork configurations required for conducting a traverse). One form is required for each air handler serving the building. The entries on the form are to be completed as follows:

1 Date of Test: Enter the date on which the measurement is conducted.

2 Time: Enter the time at which the measurement is conducted.

3 Air Handler Number: Enter the air handler number used in the building mechanical plans.

4 Air Handler Location: Enter the location of the air handler, using a room number from the building plans if available. If no room number is available, enter the floor and location on the floor.

5 Location of Duct Traverse: Describe the point within the outdoor air intake ductwork at which the traverse is conducted. Provide the distance downstream from the outdoor air intake grille.

6 Measurement Device Type: Describe the device used in the traverse, such as pitot-static tube and differential pressure gauge or calibrated hot-wire anemometer.

7 Manufacturer: In the case of a pitot traverse, enter the name of the manufacturer of the pressure gauge. In the case of a hot-wire anemometer, enter the manufacturer of the anemometer.

8 Model Number: Enter the model number of the device.

9 Serial Number: Enter the serial number of the device.

10 Rectangular or Round: Note whether the duct is rectangular or round.

11 Duct Area: Enter the cross-sectional area of the duct at the point of the traverse. Designate the units, either $\mathrm{m}^{2}$ or $\mathrm{ft}^{2}$.

The traverse data is recorded on Form X1 for a rectangular duct and Form X2 for a round duct. The instructions for these forms are provided at the end of section $\mathrm{D}$.

12 Start of Traverse: Enter the time at which the collection of traverse data began.

13 End of Traverse: Enter the time at which the collection of traverse data was completed. 
14 Root Mean Square Velocity Pressure: In the case of a pitot traverse, calculate the root mean square velocity pressure using the formula contained on the form. In the case of a hot-wire traverse, leave this space blank.

Designate the correct units, either $(\mathrm{Pa})^{1 / 2}$ or (in.w.g.) $)^{1 / 2}$.

15 Average Air Speed: In the case of a hot-wire traverse, calculate the average value of the air speed. In the case of a pitot traverse, calculate the average air speed from the root mean square velocity pressure using the appropriate formula contained on the form.

Designate the units, either $\mathrm{m} / \mathrm{s}$ or $\mathrm{fpm}$.

16 Airflow Rate: Calculate the outdoor air intake rate by multiplying the duct area at entry \#10 by the average air speed at entry \#14.

Designate the units, either $\mathrm{m}^{3 / \mathrm{s}}$ or $\mathrm{cfm}$.

17 Supply Airflow Rate: Enter the supply airflow rate for the air handler from Form D5B, entry \#16.

Designate the units, either $\mathrm{m}^{3} / \mathrm{s}$ or $\mathrm{cfm}$.

18 Percent Outdoor Air Intake: Enter the percent outdoor air intake for the air handler from Form D-5C, entry \#26.

19 Outdoor Air Intake Rate: Calculate the outdoor air intake rate by multiplying the supply airflow rate in entry \#17 by the percent outdoor air intake in entry \#18 and dividing the result by 100 .

Designate the units, either $\mathrm{m}^{3} / \mathrm{s}$ or $\mathrm{cfm}$.

\section{FORM D-5E AIR INFILTRATION RATE: TRACER GAS DECAY}

This form is used to record the results of a tracer gas decay test in the building conducted to estimate the whole building air change rate. This test is to be conducted in accordance with ASTM E741. Based on the requirements contained in ASTM E741, this test must be conducted to determine the whole building air change rate. Tracer gas must be released into the entire building such that the concentration is uniform throughout the building. This test can not be performed by releasing tracer gas into the test space alone. Only a single tracer gas decay test is required, and therefore only one form is needed. However, one can repeat the test if the initial attempt does not provide satisfactory results. This measurement can be conducted using occupant generated carbon dioxide as the tracer gas after the occupants have left the building. The entries on the form are to be completed as follows:

1 Date of Test: Enter the date on which the measurement is conducted.

2 Manufacturer: Enter the manufacturer of the tracer gas concentration measurement device.

3 Model Number: Enter the model number of the device.

4 Serial Number: Enter the serial number of the device.

5 Concentration Units: Enter the tracer gas concentration units provided by the tracer gas concentration monitor. 
The tracer gas concentration must be monitored during the decay test at one outdoor location, ten locations within the occupied space, and locations within the air handlers. The concentration at each location should be measured once every 30 minutes, though the exact time interval is not critical as long as the sample times are recorded accurately. These sampling locations are described in Form D-5A. If one employs occupant generated carbon dioxide as the tracer gas, then the concentrations at these locations must be monitored after the occupants have left the building, while the interior carbon dioxide concentration is still significantly above the outdoor concentration. The concentration monitoring should begin very soon after the occupants have left the building, before the interior concentrations decay significantly. The tracer gas decay test requires that the interior concentration is significantly above the outdoor concentration and the interior concentration is uniform (within 10\%) throughout the building. If either of these conditions is not satisfied, the test will not provide acceptable estimates of the building air change rate.

6 Initial Reading

Outdoor, Time: Enter the time at which the outdoor conditions are measured.

Outdoor, Concentration: Enter the outdoor tracer gas concentration.

Outdoor, Temperature: Enter the outdoor air temperature.

Designate the units, either ${ }^{\circ} \mathrm{C}$ or ${ }^{\circ} \mathrm{F}$.

Outdoor, Wind Speed: Enter the wind speed.

Designate the units, either $\mathrm{m} / \mathrm{s}$ or $\mathrm{mph}$.

Location \#1, Time: Enter the time at which the tracer gas concentration at location \#1 is recorded.

Location \#1, Concentration: Enter the tracer gas concentration at location \#1.

For occupied space locations \#2 through \#10 and air handlers \#1 through \#10, enter the time and concentration as described for location \#1.

7 Second Reading: Record the information as described above for the initial reading.

8 Third Reading: Record the information as described above for the initial reading.

9 Fourth Reading: Record the information as described above for the initial reading.

10 Fifth Reading: Record the information as described above for the initial reading. 
The data analysis involves determining the tracer gas decay rate in air changes per hour at each of the 10 occupied space locations and the air handler locations. This is done by performing a least squares linear regression of the natural logarithm of concentration against time. Based on the assumption of a uniform tracer gas concentration within the building, the tracer gas concentration at each location decays according to the following expression:

$$
C(t)=C_{0} \exp (-I t)
$$

where

$C(t)=$ the tracer gas concentration at a location at time $t$ minus the outdoor concentration recorded at the same time

$\mathrm{C}_{0}=$ the tracer gas concentration at a location time $\mathrm{t}=0$ minus the outdoor concentration recorded at the same time

$I=$ the tracer gas decay rate at that location

In order to determine I, one rewrites the above equation in log form:

$$
\ln C=\ln C_{0}-I t
$$

This equation can be used to solve for I at each location by regressing the log of the difference between the tracer gas concentration at the location and the outdoor concentration against time. Linear regression techniques are described in many handbooks and are contained in many computer spreadsheet programs, as are procedures for determining the error associated with the estimate of the slope I.

11 Decay Rates: Enter the calculated decay rate in air changes per hour for each of the locations and the standard error of this decay rate.

12 Building Average Decay Rate: Enter the average of the decay rates at all of the sampling locations.

13 Standard Deviation: Enter the standard deviation of the decay rates at all of the sampling locations.

14 Average Exterior Temperature: Enter the average of the exterior temperatures measured during the decay.

Designate the units, either ${ }^{\circ} \mathrm{C}$ or ${ }^{\circ} \mathrm{F}$.

15 Average Wind Speed: Enter the average of the wind speeds measured during the decay.

Designate the units, either $\mathrm{m} / \mathrm{s}$ or $\mathrm{mph}$. 


\section{EORMD-5F AIRINFILTRATIONRATE: DATA ANALYSIS}

This form is used to conduct the data analysis necessary to determine the building air infiltration rate. Only one form is required for the building. If there are more than ten air handlers in the building, then additional copies of Form D-5F will be required. The entries on the form are to be completed as follows:

1 Date of Test: Enter the date on which the measurement is conducted.

2 Outdoor Air Intake Method: Enter the method used to determine the outdoor air intake rate using Form 5-5D.

3 Outdoor Air Intake Rate, Air Handler \#1: Enter the outdoor air intake rate determined for air handler \#1 from the Form D-5D corresponding to that air handler.

Designate the units, either $\mathrm{m}^{3} / \mathrm{s}$ or $\mathrm{cfm}$.

For entries \#4 through \#12, enter the outdoor air intake rate for air handlers \#2 through \#10 from the Form D-5D corresponding to each air handler. If there are more than ten air handlers in the building, then the outdoor air intake rate for the additional air handlers are entered on additional copies of Form D-5F.

Designate the correct units, either $\mathrm{m}^{3} / \mathrm{s}$ or $\mathrm{cm}$.

13 Total Outdoor Air Intake Rate: Enter the sum of the outdoor air intake rates for all of the air handlers in the building, contained in entries \#3 through \#12. If there are more than ten air handlers in the building, then the outdoor air intake rates for the additional air handlers must be included in this sum.

Designate the units, either $\mathrm{m}^{3} / \mathrm{s}$ or $\mathrm{cfm}$.

14 Outdoor Air Intake Rate in ACH: Enter the whole building outdoor air intake rate in units of air changes per hour by dividing entry \#13 by the building volume and converting the result to units of air changes per hour.

15 Total Building Air Change Rate: Enter the whole building air change rate in units of air changes per hour from entry \#12 on Form D-5E.

16 Building Infiltration Rate: Enter the building infiltration rate, equal to entry \#15 minus entry \#14. 


\section{D-X FORMS DUCT TRAVERSES}

Forms D-X1 and D-X2 are used to collect data when conducting duct traverses to measure airflow rates. Form D-X1 is used when the duct has a rectangular cross section and Form D-X2 is used for round ducts. One form is required for each traverse measurement.

\section{FORM D-X1 TRAVERSE OF A RECTANGULAR DUCT}

This form is used to collect data when conducting a pitot-tube or hot-wire traverse of a rectangular duct according to standard handbook procedures contained in the ACGIH Industrial Ventilation Manual, AMCA Publication 203-90 and the ASHRAE Standard 111. One form is required for each airflow rate measurement in a duct. The entries on the form are to be completed as follows:

Air Handler Number: Enter the air handler number used in the building mechanical plans.

Date of Test: Enter the date on which the measurement is conducted.

Time: Enter the time at which the traverse is started.

Duct Width: Enter the width of the duct.

Designate the units, either $\mathrm{m}$ or $\mathrm{ft}$.

Duct Height: Enter the height of the duct.

Designate the units, either $\mathrm{m}$ or $\mathrm{ft}$.

Duct Type: Note whether the duct is a supply, outdoor air intake or exhaust.

Air Speed or Velocity Pressure: Note whether the traverse data is in velocity pressure (pitottube) or air speed (hot-wire anemometer).

Velocity Pressure Units: Note the units of the velocity pressure measurements, $\mathrm{Pa}$ or in. w.g.

Air Speed Units: Note the units of the air speed measurements, $\mathrm{m} / \mathrm{s}$ or $\mathrm{fpm}$.

\section{Traverse Data Grid}

The form allows for an 8 by 8 grid of traverse points within the duct. Less points can be used for smaller ducts as described in the referenced handbooks. Along the top and left hand side of the data grid, enter the horizontal and vertical position of the traverse points within the duct. Each box in the data grid provides space for six measurements of velocity pressure or air speed at each traverse point. The measurement probe should be deployed at each traverse point, and the probe output recorded every 10 seconds. 


\section{FORM D-X2 TRAVERSE OF A ROUND DUCT}

This form is used to collect data when conducting a pitot-tube or hot-wire traverse of a round duct according to standard handbook procedures contained in the ACGIH Industrial Ventilation Manual, AMCA Publication 203-90 and the ASHRAE Standard 111. One form is required for each airflow rate measurement in a duct. The entries on the form are to be completed as follows:

Air Handler Number: Enter the air handler number used in the building mechanical plans.

Date of Test: Enter the date on which the measurement is conducted.

Time: Enter the time at which the traverse is started.

Duct Diameter: Enter the duct diameter.

Designate the correct units, either $m$ or $\mathbf{f t}$.

Duct Type: Note whether the duct is a supply, outdoor air intake or exhaust.

Air Speed or Velocity Pressure: Note whether the traverse data is in velocity pressure (pitottube) or air speed (hot-wire anemometer).

Velocity Pressure Units: Note the units of the velocity pressure measurements, $\mathrm{Pa}$ or in. w.g. Air Speed Units: Note the units of the air speed measurements, $\mathrm{m} / \mathrm{s}$ or $\mathrm{fpm}$.

\section{Traverse Data Grid}

The form calls for the traverse of 10 points along horizontal diameter of the duct and 10 points along a vertical. The positions of these points within the duct, in terms of the duct diameter, are provided on the form. Each box in the data grid provides space for six measurements of velocity pressure or air speed at each traverse point. The measurement probe should be deployed at each traverse point, and the probe output recorded every 10 seconds. 



\section{FORM D-1A: SUPPLY AIRFLOW RATE}

Four forms are required for each air handler serving the test space, with one form for each measurement of the supply airflow rate.

1 Date of Test:

3 Air Handler Number:
2 Time:

4 Air Handler Location:

5 Location of Duct Traverse:

Measurement Device Information

6 Measurement Device Type:

7 Manufacturer:

8 Model Number:

9 Serial Number:

Duct Dimensions

10 Rectangular or Round:

11 Duct Area: $\mathrm{m}^{2}$ or $\mathrm{ft}^{2}$

Traverse Data, Traverse Grid and Data on Form D-X1 or D-X2

12 Start of Traverse, time:

13 End of Traverse, time:

Calculations

14 Root Mean Square Velocity Pressure

$\Sigma\left(\mathrm{p}_{\mathrm{v}}\right)^{1 / 2} /$ Number of readings: $(\mathrm{Pa})^{1 / 2}$ or (in. w.g.) $)^{1 / 2}$

15 Average Air Speed

Air speed measurements, $\Sigma \mathbf{v}_{\mathrm{s}} /$ Number of readings: $\mathrm{m} / \mathrm{s}$ or fpm

Velocity pressure measurements $(\mathrm{Pa}), 1.29 \mathrm{x} \# 14$ : $\mathrm{m} / \mathrm{s}$

Velocity pressure measurements (in. w.g.), 4002 x \#14: fpm

16 Airflow Rate, \#11 x \#15: $\mathrm{m}^{3} / \mathrm{s}$ or $\mathrm{cfm}$ 


\section{FORM D-1B: PERCENT OUTDOOR AIR INTAKE}

Four forms are required for each air handler serving the test space, with one form for each measurement of the percent outdoor air intake.

1 Date of Test:

3 Air Handler Number:
2 Time:

4 Air Handler Location:

\section{Air Sample Locations}

5 Outdoor Air Intake:

6 Supply Air:

7 Return Air.

Measurement Device Information

8 Manufacturer:

10 Serial Number:
9 Model Number:

Zero check

13 Reading:

11 Span Concentration:

12 Reading:

Concentration Data

14 Start of Measurement, time:

15 Outdoor Air

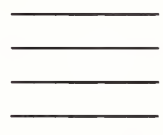

16 Return Air

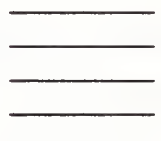

17 Supply Air

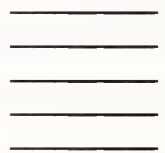

18 End of Measurement, time:

Calculations

Mean Concentrations

\begin{tabular}{|c|c|c|c|c|c|c|}
\hline 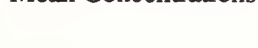 & & Outdoor air & & Return air & & Supply air \\
\hline Mean & 19 & $\ldots$ & 21 & $\ldots$ ppm & 23 & _ppm \\
\hline Standard Deviation & 20 & ppm & 22 & $\mathrm{ppm}$ & 24 & _ppm \\
\hline
\end{tabular}

Percent Outdoor Air Intake

25 Value, $100 \times(\# 21$ - \#23) / (\#21 - \#19): $\%$ OA

26 Error Estimate, $100 \times \# 25\left[\left(\# 22^{2}+\# 20^{2}\right) /(\# 21-\# 19)^{2}+\left(\# 22^{2}+\# 24^{2}\right) /(\# 21-\# 23)^{2}\right]^{1 / 2}$ $\% \mathrm{OA}$ 


\section{FORM D-1C: OUTDOOR AIR INTAKE RATE}

Four forms are required for each air handler serving the test space, with one form for each measurement of the outdoor air intake rate.

1 Date of Test:

3 Air Handler Number:

\section{METHOD \#1: TRAVERSE}

5 Location of Duct Traverse:

Measurement Device Information

6 Measurement Device Type:

7 Manufacturer:

9 Serial Number:

Duct Dimensions

10 Rectangular or Round:

11 Duct Area: $\mathrm{m}^{2}$ or $\mathrm{ft}^{2}$
Traverse Data, Traverse Grid and Data on Form D-X1 or D-X2

12 Start of Traverse, time:

Calculations

14 Root Mean Square Velocity Pressure

$\Sigma\left(\mathrm{p}_{\mathrm{v}}\right)^{1 / 2} /$ Number of readings:

13 End of Traverse, time:

15 Average Air Speed

Air speed measurements, $\Sigma v_{s} /$ Number of readings: $\mathrm{m} / \mathrm{s}$ or $\mathrm{fpm}$

Velocity pressure measurements $(\mathrm{Pa}), 1.29 \mathrm{x} \# 14$ : $\mathrm{m} / \mathrm{s}$

Velocity pressure measurements (in. w.g.), 4002 x \#14: fpm

16 Airflow Rate, \#11 x \#15: $\mathrm{m}^{3} / \mathrm{s}$ or $\mathrm{cfm}$

\section{METHOD \#2: CALCULATION}

17 Supply Airflow Rate from Form D-1A \#16, same date and time of day $\mathrm{m}^{3} / \mathrm{s}$ or $\mathrm{cfm}$

18 Percent Outdoor Air Intake from Form D-1B \#25, same date and time of day $\%$

19 Outdoor Air Intake Rate, \#17 times \#18

$\mathrm{m}^{3} / \mathrm{s}$ or cfm 


\section{FORM D-1D: SUPPLY AIR TEMPERATURE AND RELATIVE HUMIDITY}

Four forms are required for each air handler serving the test space, with one form for each measurement of the supply air conditions.

1 Date of Test:

3 Air Handler Number:

5 Location of Measurements:

Measurement Device Information

Temperature sensor

6 Measurement Device Type:

7 Manufacturer:

9 Serial Number:

Relative humidity sensor

10 Measurement Device Type:

11 Manufacturer:

13 Serial Number:

$\underline{\text { Data }}$

14 Start of Measurement, time:

15 Air Temperature

${ }^{\circ} \mathrm{C}$ or ${ }^{\circ} \mathrm{F}$

17 End of Measurement, time:

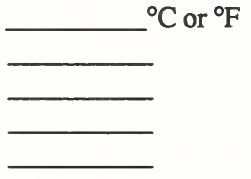

Calculations

Mean

Standard Deviation
Air Temperature

18

19

${ }^{\circ} \mathrm{C}$ or ${ }^{\circ} \mathrm{F}$

${ }^{\circ} \mathrm{C}$ or ${ }^{\circ} \mathrm{F}$
8 Model Number:

12 Model Number:

16 Relative Humidity

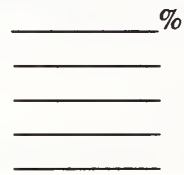

Air Handler Location: 


\section{FORM D-2A: EXHAUST FAN OPERATION}

One form is required for each exhaust fan serving the test space

1 Exhaust Fan Number:

2 Exhaust Fan Location:

Day\#1

AM

3 Time Operation Checked:

4 Operating: yes or no:

PM

5 Time Operation Checked:

6 Operating: yes or no:

Day \#2

$\mathrm{AM}$

7 Time Operation Checked:

8 Operating: yes or no:

PM

9 Time Operation Checked:

10 Operating: yes or no:

Day \#3

AM

11 Time Operation Checked:

12 Operating: yes or no:

13 Time Operation Checked:

14 Operating: yes or no:

Day \#4

AM

15 Time Operation Checked:

16 Operating: yes or no:

PM

17 Time Operation Checked:

18 Operating: yes or no:

Day \#5

AM

19 Time Operation Checked:

20 Operating: yes or no:

PM

21 Time Operation Checked:

22 Operating: yes or no: 


\section{FORM D-2B： EXHAUST FAN AIRFLOW RATE}

One form is required for each exhaust fan serving the test space

1 Date of Test:

2 Time:

3 Exhaust Fan Number:

4 Exhaust Fan Location:

5 Location of duct traverse:

Measurement Device Information

6 Measurement Device Type:

7 Manufacturer:

8 Model Number:

9 Serial Number:

Duct Dimensions

10 Rectangular or Round:

11 Duct Area: $\mathrm{m}^{2}$ or $\mathrm{ft}^{2}$

Traverse Data, Traverse Grid and Data on Form D-X1 or D-X2

12 Start of Traverse, time:

13 End of Traverse, time:

Calculations

14 Root Mean Square Velocity Pressure $\Sigma\left(\mathrm{p}_{\mathrm{v}}\right)^{1 / 2} /$ Number of readings: $(\mathrm{Pa})^{1 / 2}$ or (in. w.g.) $)^{1 / 2}$

15 Average Air Speed

Air speed measurements, $\Sigma \mathbf{v}_{\mathbf{s}} /$ Number of readings: $\mathrm{m} / \mathrm{s}$ or $\mathrm{fpm}$

Velocity pressure measurements $(\mathrm{Pa}), 1.29 \mathrm{x} \# 14$ : $\mathrm{m} / \mathrm{s}$

Velocity pressure measurements (in. w.g.), 4002 x \#14: fpm

16 Airflow Rate, \#11 x \#15: $\mathrm{m}^{3} / \mathrm{s}$ or cfm 


\section{FORM D-3A: LOCAL VENTILATION PERFORMANCE - AIRFLOW RATE}

One form is required

1 Date of Test:

\section{Measurement Device Information}

2 Measurement Device Type:

3 Manufacturer:

4 Model Number:

5 Serial Number:

6 Date of Last Calibration:

Data

7 Start of Measurement, time:

8 Units of Airflow Rate Measurement:

9 Airflow rate. For diffuser numbering, refer to test space floor plan.

\begin{tabular}{l}
$\# 1$ \\
$\# 4$ \\
$\# 7$ \\
$\# 10$ \\
$\# 13$ \\
$\# 16$ \\
$\# 19$ \\
$\# 22$ \\
$\# 25$ \\
$\# 28$ \\
$\# 31$ \\
$\# 34$ \\
$\# 37$ \\
$\# 40$ \\
$\# 43$ \\
$\# 46$ \\
$\# 49$ \\
$\# 52$ \\
$\# 55$ \\
$\# 58$ \\
$\# 61$ \\
$\# 64$ \\
$\# 67$ \\
$\# 70$ \\
$\# 73$ \\
\hline
\end{tabular}

\begin{tabular}{l}
$\# 2$ \\
$\# 5$ \\
$\# 8$ \\
$\# 11$ \\
$\# 14$ \\
$\# 17$ \\
$\# 20$ \\
$\# 23$ \\
$\# 26$ \\
$\# 29$ \\
$\# 32$ \\
$\# 35$ \\
$\# 38$ \\
$\# 41$ \\
$\# 44$ \\
$\# 47$ \\
$\# 50$ \\
$\# 53$ \\
$\# 56$ \\
$\# 59$ \\
$\# 62$ \\
$\# 65$ \\
$\# 68$ \\
$\# 71$ \\
$\# 74$ \\
\hline
\end{tabular}

\#3

\#6

$\# 9$

$\# 12$

$\# 15$

$\# 18$

$\# 21$

\#24

$\# 27$

$\# 30$

\#33

\#36

\#39

$\# 42$

$\# 45$

\#48

\#51

\#54

$\# 57$

$\# 60$

$\# 63$

\#66

$\# 69$

$\# 72$

\#75

10 End of Measurement, time: 


\section{FORM D-3B： LOCAL VENTILATION PERFORMANCE - SUPPLY AIR TEMPERATURE}

One form is required

1 Date of Test:

Measurement Device Information

2 Measurement Device Type:

3 Manufacturer:

4 Model Number:

5 Serial Number:

Data

6 Start of Measurement, time:

7 Units of Temperature Measurement:

8 Supply Air Temperature. For diffuser numbering, refer to test space floor plan.

\begin{tabular}{l}
$\# 1$ \\
$\# 4$ \\
$\# 7$ \\
$\# 10$ \\
$\# 13$ \\
$\# 16$ \\
$\# 19$ \\
$\# 22$ \\
$\# 25$ \\
$\# 28$ \\
$\# 31$ \\
$\# 34$ \\
$\# 37$ \\
$\# 40$ \\
$\# 43$ \\
$\# 46$ \\
$\# 49$ \\
$\# 52$ \\
$\# 55$ \\
$\# 58$ \\
$\# 61$ \\
$\# 64$ \\
$\# 67$ \\
$\# 70$ \\
$\# 73$ \\
\hline
\end{tabular}

\begin{tabular}{l}
$\# 2$ \\
$\# 5$ \\
$\# 8$ \\
$\# 11$ \\
$\# 14$ \\
$\# 17$ \\
$\# 20$ \\
$\# 23$ \\
$\# 26$ \\
$\# 29$ \\
$\# 32$ \\
$\# 35$ \\
$\# 38$ \\
$\# 41$ \\
$\# 44$ \\
$\# 47$ \\
$\# 50$ \\
$\# 53$ \\
$\# 56$ \\
$\# 59$ \\
$\# 62$ \\
$\# 65$ \\
$\# 68$ \\
$\# 71$ \\
$\# 74$ \\
\hline
\end{tabular}

\#3

\#6

\#9

$\# 12$

$\# 15$

$\# 18$

\#21

\#24

\#27

\#30

\#33

\#36

\#39

$\# 42$

$\# 45$

\#48

\#51

\#54

\#57

$\# 60$

\#63

\#66

\#69

\#72

\#75

9 End of measurement, time: 


\section{FORM D-4A: NATURAL VENTILATION - CONTINUOUS CARBON DIOXIDE}

Two forms are required, one for each of two days

1 Date of Test:

Measurement Device Information

2 Manufacturer:

4 Serial Number:

3 Model Number:

Measurement Locations

5 Outdoor Air:

6 Occupied Space \#1:

7 Occupied Space \#2:

8 Occupied Space \#3:

Data Analysis

Outdoor reading

96 am:

ppm

112 pm:

ppm

126 pm:

ppm

$1010 \mathrm{am}:$

Occupied space \#1

136 am:

Morning maximum

ppm

14 Concentration:

ppm

15 Time:

(

16 Outdoor Concentration:

ppm

Afternoon maximum

17 Concentration:

18 Time:

19 Outdoor Concentration:

ppm

Occupied space \#2

206 am: ppm

Morning maximum

Afternoon maximum

21 Concentration:

ppm

22 Time:

24 Concentration:

25 Time:

23 Outdoor Concentration:

ppm

26 Outdoor Concentration: ppm

Occupied space \#3

276 am: ppm Morning maximum

Afternoon maximum

28 Concentration: ppm

29 Time:

31 Concentration: ppm

30 Outdoor Concentration: ppm

32 Time:

33 Outdoor Concentration: ppm 


\section{FORM D-4B: NATURAL VENTILATION - TRACER GAS DECAY}

One form is required

1 Date of Test:

2 Tracer Gas:

Measurement Device Information

3 Manufacturer:

5 Serial Number:

4 Model Number:

6 Concentration Units:

Measurement Locations

7 Outdoor Air:

8 Occupied Space \#1:

9 Occupied Space \#2:

10 Occupied Space \#3:

11 Occupied Space \#4:

12 Occupied Space \#5:

13 Occupied Space \#6:

14 Occupied Space \#7:

15 Occupied Space \#8:

16 Occupied Space \#9:

17 Occupied Space \#10:

Data

18 Initial reading

Outdoor

Time:

Temperature: ${ }^{\circ} \mathrm{C}$ or ${ }^{\circ} \mathrm{F}$

Time Concentration

Location \#1

Location \#2

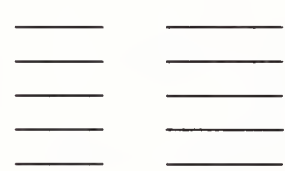

Concentration:

Location \#3

Location \#4

Location \#5

Wind speed: Time Concentration

Location \#6

Location \#7

Location \#8

Location \#9

Location \#10

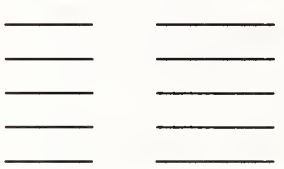

19 Second reading

Outdoor

Time:

Temperature: ${ }^{\circ} \mathrm{C}$ or ${ }^{\circ} \mathrm{F}$

Time Concentration

Location \#1

Location \#2

Location \#3

Location \#4

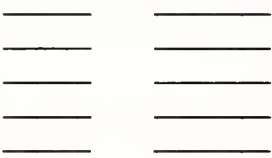

Location \#5

Concentration:

Wind speed:

Time Concentration

Location \#6

Location \#7

Location \#8

Location \#9

Location \#10 
20 Third reading

Outdoor

Time:

Temperature: ${ }^{\circ} \mathrm{C}$ or ${ }^{\circ} \mathrm{F}$ Time Concentration

Location \#1

Location \#2

Location \#3

Location \#4

Location \#5

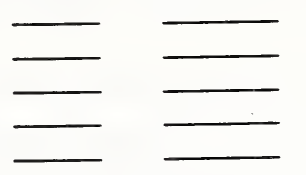

Concentration:

Wind speed:

Time Concentration

Location \#6

Location \#7

Location \#8

Location \#9

Location \#10

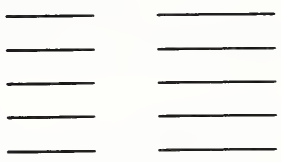

21 Fourth reading

Outdoor

Time:

Temperature: ${ }^{\circ} \mathrm{C}$ or ${ }^{\circ} \mathrm{F}$

Time Concentration

Location \#1

Location \#2

Location \#3

Location \#4

Location \#5

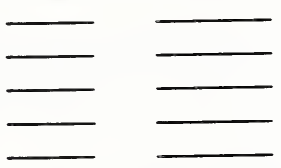

22 Fifth reading

Outdoor

Time:

Temperature:

Time Concentration

Location \#1

Location \#2

Location \#3

Location \#4

Location \#5

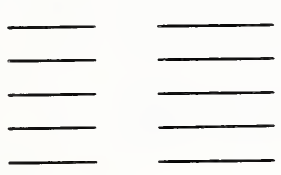

Concentration:

Wind speed:

Location \#6

Location \#7

Location \#8

Location \#9

Location \#10 $\mathrm{m} / \mathrm{s}$ or $\mathrm{mph}$

Time Concentration

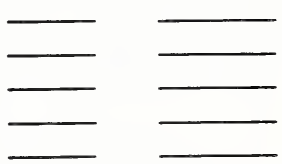

\section{Data Analysis}

23 Decay rates, air changes per hour

Location \#1

Location \#2

Value Standard Error

Location \#3

Location \#4

Location \#5

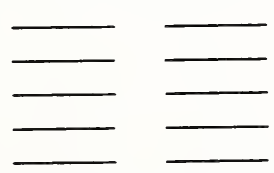

24 Building Average Decay Rate: ach

25 Standard Deviation: ach

Outdoor Conditions, Averages

26 Exterior temperature: ${ }^{\circ} \mathrm{C}$ or ${ }^{\circ} \mathrm{F} \quad 27$ Wind speed:

Time Concentration

Location \#6

Location \#7

Location \#8

Location \#9

Location \#10

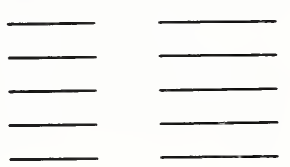

Location \#6

Location \#7

Location \#8

Location \#9

Location \#10
Value Standard Error

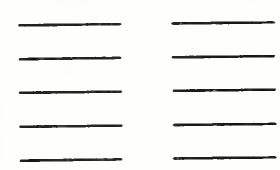




\section{FORM D-5A: AIR INFILTRATION RATE: TEST DESCRIPTION}

One form is required.

1 Date of Test:

2 Tracer Gas:

Tracer Gas Concentration Measurement Locations

3 Outdoor air:

4 Occupied Space \#1:

5 Occupied Space \#2:

6 Occupied Space \#3:

7 Occupied Space \#4:

8 Occupied Space \#5:

9 Occupied Space \#6:

10 Occupied Space \#7:

11 Occupied Space \#8:

12 Occupied Space \#9:

13 Occupied Space \#10:

14 \#1 Air Handler Number:

15 \#2 Air Handler Number:

16 \#3 Air Handler Number:

17 \#4 Air Handler Number:

18 \#5 Air Handler Number:

19 \#6 Air Handler Number:

20 \#7 Air Handler Number:

21 \#8 Air Handler Number:

22 \#9 Air Handler Number:

23 \#10 Air Handler Number:

Air Handler Location:

Air Handler Location:

Air Handler Location:

Air Handler Location:

Air Handler Location:

Air Handler Location:

Air Handler Location:

Air Handler Location:

Air Handler Location:

Air Handler Location: 


\section{FORM D-5B: AIR INFILTRATION RATE: SUPPLY AIRFLOW RATE}

One form is required for each air handler serving the building.

1 Date of Test:

3 Air Handler Number:
Time:

Air Handler Location:

5 Location of Duct Traverse:

Measurement Device Information

6 Measurement Device Type:

7 Manufacturer:

8 Model Number:

9 Serial Number:

Duct Dimensions

10 Rectangular or Round:

11 Duct Area: $\mathrm{m}^{2}$ or $\mathrm{ft}^{2}$

Traverse Data, Traverse Grid and Data on Form D-X1 or D-X2

12 Start of Traverse, time:

13 End of Traverse, time:

Calculations

14 Root Mean Square Velocity Pressure

$\Sigma\left(\mathrm{p}_{\mathrm{v}}\right)^{1 / 2} /$ Number of readings: $(\mathrm{Pa})^{1 / 2}$ or (in. w.g.) $)^{1 / 2}$

15 Average Air Speed

Air speed measurements, $\Sigma \mathbf{v}_{\mathbf{s}} /$ Number of readings: $\mathrm{m} / \mathrm{s}$ or fpm

Velocity pressure measurements $(\mathrm{Pa}), 1.29 \mathrm{x} \# 14$ : $\mathrm{m} / \mathrm{s}$

Velocity pressure measurements (in. w.g.), $4002 \mathrm{x} \# 14$ : fpm

16 Airflow Rate, \#11 x \#15: $\mathrm{m}^{3} / \mathrm{s}$ or cfm 


\section{FORM D-5C: AIR INFILTRATION RATE: PERCENT OUTDOOR AIR INTAKE}

One form is required for each air handler serving the building.

1 Date of Test:

3 Air Handler Number:

2 Time:

4 Air Handler Location:

Air Sample Locations

5 Outdoor Air Intake:

6 Supply Air:

7 Return Air:

Measurement Device Information

8 Manufacturer:

9 Model Number:

10 Serial Number:

Calibration Check

Span check

11 Span Concentration:

12 Reading:

Zero check

13 Reading:

Concentration Data

14 Start of Measurement, time:

15 Outdoor Air

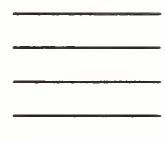

16 Return Air

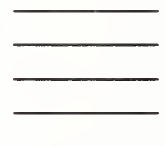

17 Supply Air

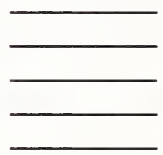

18 End of Measurement, time:

Calculations

Mean Concentrations

\begin{tabular}{|c|c|c|c|c|c|c|}
\hline & & Outdoor air & & Return air & & Supply air \\
\hline Mean & 19 & ppm & 21 & ppm & 23 & - $\mathrm{ppm}$ \\
\hline Standard Deviation & 20 & $\ldots$ ppm & 22 & _ppm & 24 & _ppm \\
\hline
\end{tabular}

Percent Outdoor Air Intake

25 Value, $100 \times(\# 21$ - \#23) / (\#21 - \#19): $\%$ OA

26 Error Estimate, $100 x \# 25\left[\left(\# 22^{2}+\# 20^{2}\right) /(\# 21-\# 19)^{2}+\left(\# 22^{2}+\# 24^{2}\right) /(\# 21-\# 23)^{2}\right]^{1 / 2}$ $\% \mathrm{OA}$ 


\section{FORM D-5D: AIR INFILTRATION RATE: OUTDOOR AIR INTAKE RATE}

One form is required for each air handler serving the building.

1 Date of Test:

3 Air Handler Number:

2 Time:

4 Air Handler Location:

\section{METHOD \#1: TRAVERSE}

5 Location of Duct Traverse:

Measurement Device Information

6 Measurement Device Type:

7 Manufacturer:

9 Serial Number:

8 Model Number:

Duct Dimensions

10 Rectangular or Round:

11 Duct Area: $\mathrm{m}^{2}$ or $\mathrm{ft}^{2}$

Traverse Data, Traverse Grid and Data on Form D-X1 or D-X2

12 Start of Traverse, time:

13 End of Traverse, time:

Calculations

14 Root Mean Square Velocity Pressure

$\Sigma\left(\mathrm{p}_{\mathrm{v}}\right)^{1 / 2} /$ Number of readings: $(\mathrm{Pa})^{1 / 2}$ or (in. wg. $)^{1 / 2}$

15 Average Air Speed

Air speed measurements, $\Sigma v_{s} /$ Number of readings: $\mathrm{m} / \mathrm{s}$ or fpm

Velocity pressure measurements $(\mathrm{Pa}), 1.29 \mathrm{x} \# 14$ : $\mathrm{m} / \mathrm{s}$

Velocity pressure measurements (in. wg), 4002 x \#14: fpm

16 Airflow rate, \#11 x \#15: $\mathrm{m}^{3 / \mathrm{s}}$ or $\mathrm{cfm}$

\section{METHOD\#2: CALCULATION}

17 Supply Airflow Rate from Form D-5B \#16, same air handler $\mathrm{m}^{3} / \mathrm{s}$ or $\mathrm{cfm}$

18 Percent Outdoor Air Intake from Form D-5C \#25, same air handler $\%$

19 Outdoor Air Intake Rate, \#17 times \#18

$\mathrm{m}^{3} / \mathrm{s}$ or $\mathrm{cfm}$ 


\section{FORM D-5E: AIR INFILTRATION RATE: TRACER GAS DECAY}

One form is required

1 Date of Test:

Measurement Device Information

2 Manufacturer:

4 Serial Number:

\section{$\underline{\text { Data }}$}

6 Initial Reading

Outdoor

Time:

Temperature: ${ }^{\circ} \mathrm{C}$ or ${ }^{\circ} \mathrm{F}$

Time Concentration

Occupied Space

Location \#1

Location \#2

Location \#3

Location \#4

Location \#5

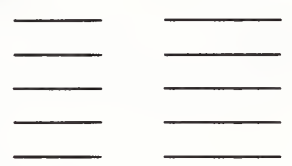

Air Handlers

Location \#1

Location \#2

Location \#3

Location \#4

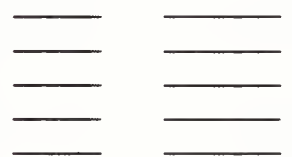

Location \#5

$7 \quad$ Second Reading

Outdoor

Time:

Temperature: ${ }^{\circ} \mathrm{C}$ or ${ }^{\circ} \mathrm{F}$

Occupied Space

Location \#1

Location \#2

Location \#3

Location \#4

Location \#5

Air Handlers

Location \#1

Location \#2

Location \#3

Location \#4

Location \#5
3 Model Number:

5 Concentration Units:
Concentration:

Wind Speed:

Time Concentration

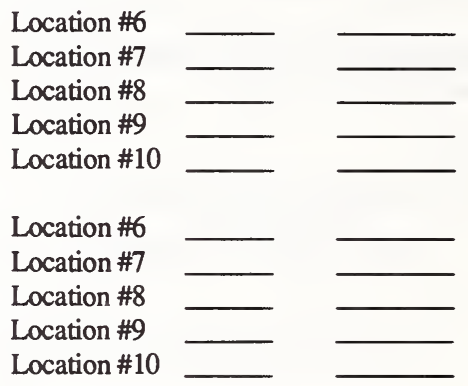

Concentration:

Wind Speed:

Time Concentration

Location \#6

Location \#7

Location \#8

Location \#9

Location \#10

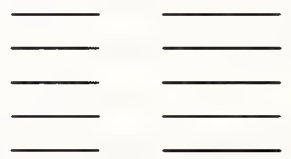

Location \#6

Location \#7

Location \#8

Location \#9

Location \#10 $\mathrm{m} / \mathrm{s}$ or $\mathrm{mph}$ 
8 Third Reading

Outdoor

Time:

Temperature: ${ }^{\circ} \mathrm{C}$ or ${ }^{\circ} \mathrm{F}$

Time Concentration

Occupied Space

Location \#1

Location \#2

Location \#3

Location \#4

Location \#5

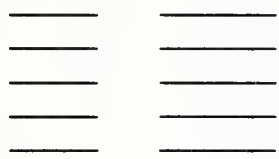

Air Handlers

Location \#1

Location \#2

Location \#3

Location \#4

Location \#5

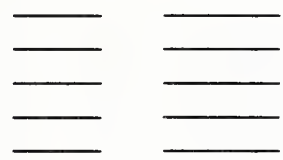

9 Fourth Reading

Outdoor

Time:

Temperature: ${ }^{\circ} \mathrm{C}$ or ${ }^{\circ} \mathrm{F}$

Occupied Space
Time Concentration

Location \#1

Location \#2

Location \#3

Location \#4

Location \#5

Air Handlers

Location \#1

Location \#2

Location \#3

Location \#4

Location \#5
Concentration:

Wind Speed:

Time $\mathrm{m} / \mathrm{s}$ or $\mathrm{mph}$

Concentration

Location \#6

Location \#7

Location \#8

Location \#9

Location \#10

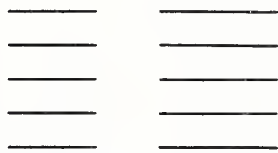

Location \#6

Location \#7

Location \#8

Location \#9

Location \#10

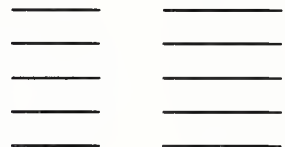

Concentration:

Wind Speed:

Time Concentration

Location \#6

Location \#7

Location \#8

Location \#9

Location \#10

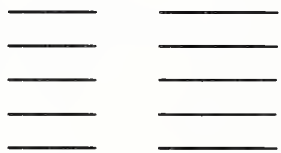

Location \#6

Location \#7

Location \#8

Location \#9

Location \#10

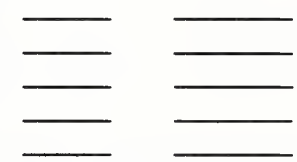


10 Fifth Reading

Outdoor

Time:

Temperature:

Occupied Space

Location \#1

Location \#2

Location \#3

Location \#4

Location \#5

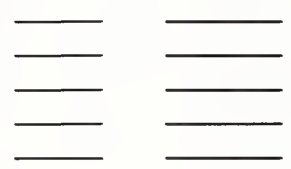

Air Handlers

Location \#1

Location \#2

Location \#3

Location \#4

Location \#5

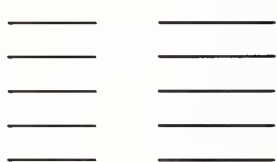

Data Analysis

11 Decay Rates, air changes per hour

Value Standard Error

Occupied Space

Location \#1

Location \#2

Location \#3

Location \#4

Location \#5

Air Handlers

Location \#1

Location \#2

Location \#3

Location \#4

Location \#5

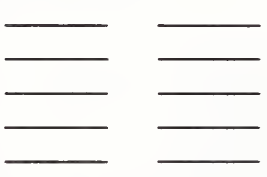

12 Building Average Decay Rate: ach

13 Standard Deviation: ach
Concentration:

Wind Speed:

Time Concentration

Location \#6

Location \#7

Location \#8

Location \#9

Location \#10

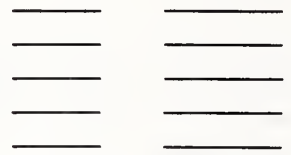

Location \#6

Location \#7

Location \#8

Location \#9

Location \#10

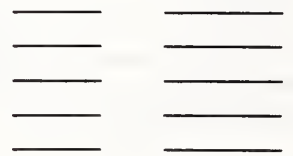

Value Standard Error

Location \#6

Location \#7

Location \#8

Location \#9

Location \#10

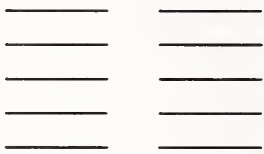

Location \#6

Location \#7

Location \#8

Location \#9

Location \#10

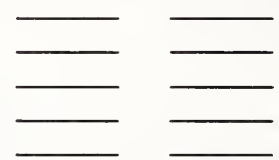

Outdoor Conditions, Averages

14 Exterior Temperature: ${ }^{\circ} \mathrm{C}$ or ${ }^{\circ} \mathrm{F} \quad 15$ Wind Speed:

$\mathrm{m} / \mathrm{s}$ or $\mathrm{mph}$ 


\section{FORM D-5F： AIR INFILTRATION RATE: DATA ANAL YSIS}

One form is required

1 Date of Test:

Outdoor Air Intake Rate, From Forms D-5D

2 Determined by Method \#1 Traverse or Method \#2 Calculation:

3 \#1 Air Handler: $\mathrm{m}^{3} / \mathrm{s}$ or $\mathrm{cfm}$

4 \#2 Air Handler: $\mathrm{m}^{3} / \mathrm{s}$ or $\mathrm{cfm}$

5 \#3 Air Handler:

6 \#4 Air Handler: $\mathrm{m}^{3 / \mathrm{s}}$ or $\mathrm{cfm}$

7 \#5 Air Handler:

8 \#6 Air Handler:

9 \#7 Air Handler:

10 \#8 Air Handler:

11 \#9 Air Handler: $\mathrm{m}^{3} / \mathrm{s}$ or $\mathrm{cfm}$

12 \#10 Air Handler: $\mathrm{m}^{3} / \mathrm{s}$ or $\mathrm{cfm}$ $\mathrm{m}^{3} / \mathrm{s}$ or $\mathrm{cfm}$ $\mathrm{m}^{3} / \mathrm{s}$ or $\mathrm{cfm}$ $\mathrm{m}^{3} / \mathrm{s}$ or $\mathrm{cfm}$ $\mathrm{m}^{3 / \mathrm{s}}$ or $\mathrm{cfm}$

13 Total Outdoor Air Intake Rate, Add \#3 through \#12 $\mathrm{m}^{3} / \mathrm{s}$ or $\mathrm{cfm}$

14 Outdoor Air Intake Rate in air changes per hour, \#13 divided by building volume air changes per hour

15 Total Building Air Change Rate, From Form D-5E, \#13 air changes per hour

16 Building Infiltration Rate, \#15 minus \#14 air changes per hour 
Air Handler Number:

Date of Test:

Time:

Duct width:

Duct height:
Supply, Intake or Exhaust Duct:

Velocity Pressure or Air Speed:

Velocity Pressure - Pascals or in. w.g.:

Air Speed - m/s or fpm:

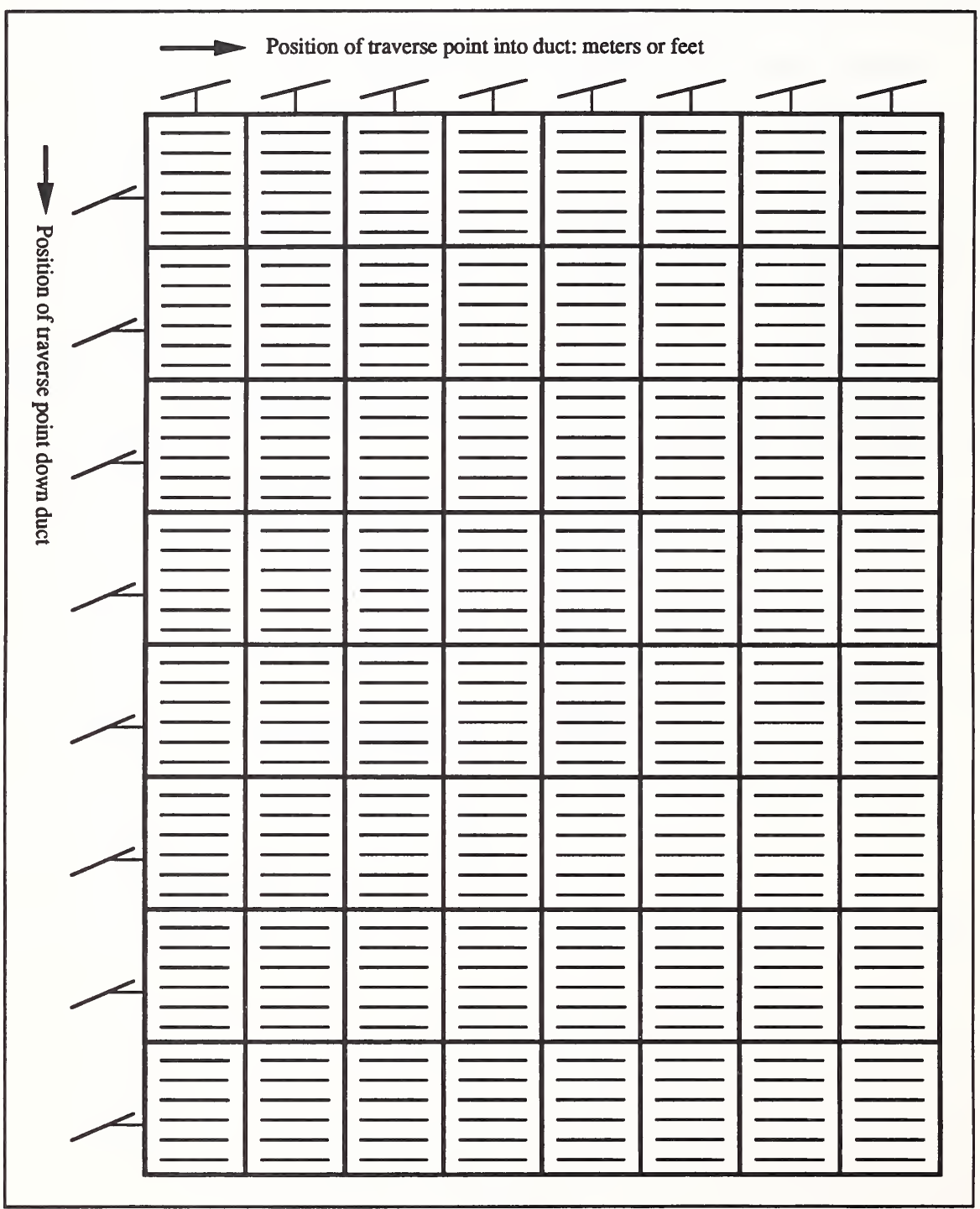


Air Handler Number:

Date of Test:

Time:

Duct diameter:
Supply, Intake or Exhaust Duct:

Velocity Pressure or Air Speed:

Velocity Pressure - Pascals or in. w.g.:

Air Speed - $\mathrm{m} / \mathrm{s}$ or fpm:

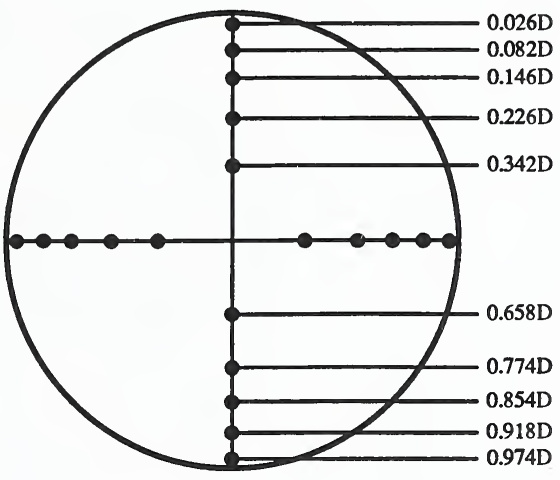

Horizontal Traverse

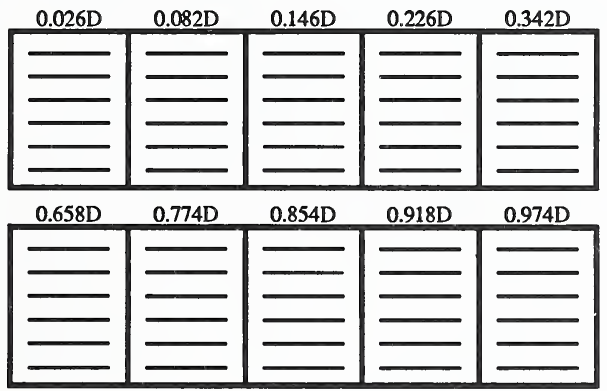

Vertical Traverse

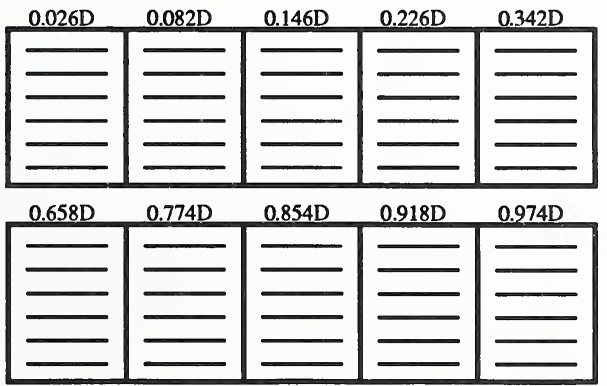




